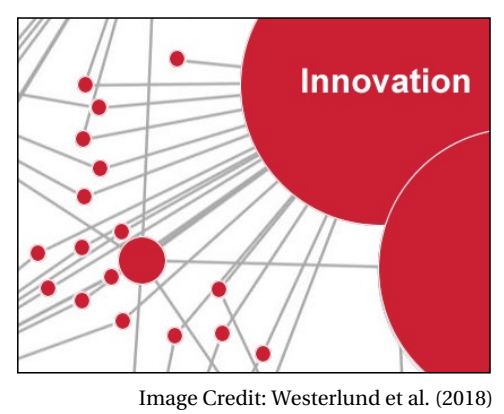

\title{
Innovation Management
}

Welcome to the July issue of the Technology Innovation Management Review. We welcome your comments on the articles in this issue as well as suggestions for future article topics and issue themes.

Editorial: Innovation Management Chris McPhee

The Prime Mover Matrix: A Conversation Piece for Building Strategic

Innovative Capacity Magnus Hoppe

How to Develop Innovation KPIs in an Execution-Oriented Company Victoria Lakiza and Isabelle Deschamps

The Role of Middle Managers in the Implementation of a Corporate

Incubator: A Case Study in the Automotive Sector Rebecca Hirte

A Topic Modelling Analysis of Living Labs Research Mika Westerlund, Seppo Leminen, and Mervi Rajahonka

Q\&A. Innovation and Entrepreneurial Ecosystem Research: Where Are

We Now and How Do We Move Forward? Paavo Ritala and Robin Gustafsson 


\section{Publisher}

The Technology Innovation Management Review is a monthly publication of the Talent First Network.

\section{ISSN}

1927-0321

\section{Editor-in-Chief}

Chris McPhee

\section{Advisory Board}

Tony Bailetti, Carleton University, Canada

Peter Carbone, Ottawa, Canada

Parm Gill, Gill Group, Canada

Leslie Hawthorn, Red Hat, United States

Michael Weiss, Carleton University, Canada

\section{Review Board}

Tony Bailetti, Carleton University, Canada

Peter Carbone, Ottawa, Canada

Parm Gill, Gill Group, Canada

G R Gangadharan, IBM, India

Mohammad Saud Khan, Victoria University of

Wellington, New Zealand

Seppo Leminen, Laurea University of Applied Sciences and Aalto University, Finland

Colin Mason, University of Glasgow, United Kingdom

Steven Muegge, Carleton University, Canada

Jennifer Percival, University of Massachusetts, United

States

Risto Rajala, Aalto University, Finland

Sandra Schillo, University of Ottawa, Canada

Marina Solesvik, Nord University, Norway

Stoyan Tanev, Carleton University, Canada

Michael Weiss, Carleton University, Canada

Mika Westerlund, Carleton University, Canada

Blair Winsor, Memorial University, Canada

(C) $2007-2018$

Talent First Network

www.timreview.ca

\section{Overview}

The Technology Innovation Management Review (TIM Review) provides insights about the issues and emerging trends relevant to launching and growing technology businesses. The TIM Review focuses on the theories, strategies, and tools that help small and large technology companies succeed.

Our readers are looking for practical ideas they can apply within their own organizations. The TIM Review brings together diverse viewpoints - from academics, entrepreneurs, companies of all sizes, the public sector, the community sector, and others - to bridge the gap between theory and practice. In particular, we focus on the topics of technology and global entrepreneurship in small and large companies.

We welcome input from readers into upcoming themes. Please visit timreview.ca to suggest themes and nominate authors and guest editors.

\section{Contribute}

Contribute to the TIM Review in the following ways:

- Read and comment on articles.

- Review the upcoming themes and tell us what topics you would like to see covered.

- Write an article for a future issue; see the author guidelines and editorial process for details.

- Recommend colleagues as authors or guest editors.

- Give feedback on the website or any other aspect of this publication.

- Sponsor or advertise in the TIM Review.

- Tell a friend or colleague about the TIM Review.

Please contact the Editor if you have any questions or comments: timreview.ca/contact

\section{About TIM}

The TIM Review has international contributors and readers, and it is published in association with the Technology Innovation Management program (TIM; timprogram.ca), an international graduate program at Carleton University in Ottawa, Canada. 


\section{Editorial: Innovation Management Chris McPhee, Editor-in-Chief}

Welcome to the July 2018 issue of the Technology Innovation Management Review. This month's editorial theme is Innovation Management in recognition of the ongoing partnership between this journal and the International Society for Professional Innovation Management (ISPIM; ispim-innovation.com). ISPIM is a network of researchers, industrialists, consultants, and public bodies who share an interest in innovation management.

Next year's event in North America - ISPIM Connects Ottawa (ispim-connects-ottawa.com) - will be held in Ottawa, Canada, from April 7-10, 2019. The TIM Review and its associated academic program at Carleton University, the TIM Program (timprogram.ca), are proud to be the local hosts of the event in collaboration with other partners. See Box 1 for further details about this event.

\section{About this issue}

In this issue, the authors share insights on a variety of innovation management topics, and all of the articles have links to ISPIM. The first three articles were developed from papers presented at the 2018 ISPIM Innovation Forum in Boston, USA; the last two articles feature authors who play key leadership roles in the ISPIM community and its Special Interest Groups.

In the first article, Magnus Hoppe from Mälardalen University in Sweden introduces the Prime Mover Matrix - a model to help management build strategic innovation capacity, which requires a company to deliberately build its technical innovative capacity and business innovative capacity in relation to the influence of other actors' actions and innovations. The Prime Mover Matrix is intended to act as a "conversation piece" in the sense that it helps managers engage in strategic conversations about the technical and business aspects of a company's innovation capacity.

Next, Victoria Lakiza and Isabelle Deschamps from Polytechnique Montreal in Canada report on action research to help a company better manage innovation by first developing key performance indicators (KPIs) to measure it. Their research focuses on established, execution-oriented companies, which struggle to overcome a focus on executing everyday routines and to reverse an associated reduction in innovation capabilities. They describe key challenges the case company met during their KPI development project,
Box 1. ISPIM Connects Ottawa ispim-connects-ottawa.com

ISPIM Connects Ottawa is a three-day event that will bring together world-renowned innovation managers, researchers, and business and thought leaders to share insights on specific local and global innovation challenges. Hosted by local universities in partnership with industry and the public sector, ISPIM Connects Ottawa seeks participation, submissions and presentations from academia, industry, research organizations, consultants, intermediaries, and policy makers.

Ottawa is Canada's Capital City and it boasts a highly educated and skilled technology workforce, world-class research and higher-education institutions, strong startup ecosystems, and nearly 2,000 knowledge-based businesses. But, it takes more than that to stand out on the global stage. Invest Ottawa - the city's leading economic development agency - recently completed its new strategic plan, which focuses on the city's need to create local capability to be competitive in global markets, with the ultimate goal of cementing Ottawa's status as a global technology hub. With this goal in mind, ISPIM Connects Ottawa will highlight three local innovation challenges that are also of global importance:

- Scaling Startups: How can we design and sustain a startup ecosystem in a way that enables new ventures to grow early, rapidly, and securely? How can we help startups quickly reach a scale where they can make a real impact on the local economy and in global markets?

- Adopting AI and Analytics: How can we move from hype to real customer value and competitive advantage? How can we transform the use of AI and machine learning to enable SME innovation and growth? How do we encourage adoption while navigating ethical issues?

- Innovating with Government: How can we encourage collaboration between industry and government to drive innovation and provide benefit to citizens? How can we use this as an opportunity to develop advanced capacity and capability in startups, SMEs, and large companies?

ISPIM Connects Ottawa will also feature various other innovation management topics, as detailed in the call for submissions: bit.ly/2LzkUCS 


\section{Editorial: Innovation Management}

\section{Chris McPhee}

and they offer practical recommendations for others seeking to develop and then implement KPIs in execution-oriented firms.

Then, Rebecca Hirte from the Karlsruhe Institute of Technology in Germany examines the role of middle managers in the implementation of a corporate incubator by conducting an in-depth case study within a large German automotive company. Interviews with 13 middle managers revealed key challenges and success factors - at both the individual and organizational levels - in the implementation of a corporate incubator as an instrument of innovation and change. The findings from this study are particularly relevant for managers of large corporations who are considering incubation as a means of transforming their organization in response to digitalization and unpredictable markets.

Next, Mika Westerlund from Carleton University in Canada, Seppo Leminen from Aalto University in Finland, and Mervi Rajahonka from the South-Eastern Finland University of Applied Sciences XAMK use topic modelling to analyze 86 publications from this journal to understand how the phenomenon of living labs has been approached in the recent innovation management literature. They identify and interpret seven broad topics (Design, Ecosystem, City, University, Innovation, User, and Living lab) and highlight a trend in the research on living labs, which is moving away from an initial conceptual focus to a more practical focus on design and management.

Finally, Paavo Ritala from Lappeenranta University of Technology, Finland, and Robin Gustafsson from Aalto University, Finland, report on a recent real-time survey conducted with participants in a workshop on innovation and entrepreneurial ecosystem research. The overall aim of the survey was to take stock of the field by asking "Where are we now, and how do we move forward?" They present the survey's findings and interpret themes emerging from the participant's views on the value of the ecosystem concept, research challenges in the field, promising theoretical foundations, requirements for rigorous empirical studies on ecosystems, and future research priorities.

\section{Upcoming issues}

In August, the theme is Transdisciplinary Innovation, and our guest editors will be Martin Bliemel and Mieke van der Bijl-Brouwer, who are both from the Faculty of Transdisciplinary Innovation at the University of Technology Sydney, Australia.

Looking ahead to other future issues, I am pleased to announce a call for papers for an upcoming special issue on Action Research with guest editors Magnus Hoppe (the author of the first article in this issue) and Erik Lindhult from Mälardalen University in Sweden, which arose from discussions at past ISPIM events. The submission deadline for abstracts is October 1, 2018. Please see the call for papers (tinyurl.com/yd5gacsv) for details.

For our regular issues, we are also accepting general submissions of articles on technology entrepreneurship, innovation management, and other topics relevant to launching and growing technology companies and solving practical problems in emerging domains.

Please contact us (timreview.ca/contact) with potential article topics and submissions, and proposals for future special issues.

\section{Chris McPhee \\ Editor-in-Chief}

\section{About the Editor}

Chris McPhee is Editor-in-Chief of the Technology Innovation Management Review. Chris holds an MASc degree in Technology Innovation Management from Carleton University in Ottawa, Canada, and BScH and MSc degrees in Biology from Queen's University in Kingston, Canada. He has nearly 20 years of management, design, and content-development experience in Canada and Scotland, primarily in the science, health, and education sectors. As an advisor and editor, he helps entrepreneurs, executives, and researchers develop and express their ideas. 


\title{
The Prime Mover Matrix: A Conversation Piece for Building Strategic Innovative Capacity Magnus Hoppe
}

\author{
"Those people who develop the ability to continuously" \\ acquire new and better forms of knowledge that they can \\ apply to their work and to their lives will be the movers \\ and shakers in our society for the indefinite future.
}

\author{
Brian Tracy \\ Speaker and author
}

\begin{abstract}
The article introduces the Prime Mover Matrix as a conversation piece that will help management build strategic innovation capacity and gain desired influence on industrial standards and thus power. After all, just because a company calls itself innovative and invests in $R \& D$ does not mean it is actually innovative. To be strategically innovative means that a company deliberately builds its technical innovative capacity and business innovative capacity in relation to the influence of other actors' actions and innovations. By doing this, a company will be able to increase its influence on industrial standards and gain the necessary power to reach its objectives. It is a relative position towards a moving target, which is why companies must continuously change through learning. This means that management needs help to reflect on how their own company's innovative capacity compares to their competitors, and they must unceasingly steer their capacity towards the desired innovation position. Today, we lack intuitive and usable tools that will facilitate strategic conversations on how to best invest for desired innovation capacity. In order to fill this void, this article proposes the Prime Mover Matrix: a model that functions as a conversation piece for triggering an assessment of an industry's technical, business, and prime movers.
\end{abstract}

\section{Introduction}

The concept of innovation is gradually losing its strategic value as many organizations adapt it more or less as a synonym to product and service development, often emphasizing the technical aspects of innovation. Many, not to say most, companies today describe themselves as innovative. They might even be innovative in the common understanding of the term, utilizing their innovative capacity for developing new products and services. However, from a strategic perspective, this is not enough. The strategic value of a company's innovative capacity is instead how it deliberately tailors its capacity relative to other actors and, by doing so, creates a successful innovation strategy.

From this perspective, a successful innovation strategy is built around a profound understanding of what is driving the evolution of industry standards, by which I mean the established technical and business norms of a specific industry. From this insight, a choice is made on how to engage in this evolution. A central question thus arises: In what aspects should you strive to gain influence over existing standards, thereby adopting a leader strategy, and in what aspects should you opt for a follower strategy, thereby reaping the returns from the possibly costly pioneering activities of other actors?

This question lies at the core of building a successful innovation strategy. In such a strategy, resources are cunningly deployed for steering the company's innovative capacity over time. But, how do we support these types of strategic decisions and conversation regarding the company's innovative capacity? That is the question that I aim to answer through this article by proposing the Prime Mover Matrix, which highlights the connection between technical and business aspects of innovative capacity. First, though, I venture into a short background on the use of popular models for strategy development. 


\section{The Prime Mover Matrix: A Conversation Piece for Building Strategic Innovative Capacity Magnus Hoppe}

\section{Models for Strategic Conversations}

There are already several popular analytical tools and models that help managers engage in strategic conversations, although not primarily aimed for innovation. Some of the most popular ones are SWOT, STEEP, VRIO, and Porter's Five Forces. They force management to take an outside perspective on their business and relate their company to both the surrounding environment and the competition. Scenario planning adds a dynamic dimension to the other models, opening up different contingencies, complexities, and relationships in "the future to be". It can be argued that the point with all these models is not so much about being right or being satisfied by having finished them, but rather the point is to make people talk about the same things and muster a collective force for changing what they do and how they do it. That is, the objective is for people to work together towards a business design that appears adequate in relation to the goals of the company in the situation they interpret (Normann, 2001; Van der Heijden, 2011).

This strategic conversation also needs to be continuously fuelled, not finished, as the world keeps on changing even though we would like it to be stable. Continuous change is what companies need to strive for, and it is where models for upholding a continuous strategic conversation will help. This goes for all aspects of the business, including innovation, where most models are a bit dangerous as they invite us to be satisfied when the result is an answer and a plan rather than ever-changing insights on change. Using the categorizations by Ahlstrand, Lampel, and Mintzberg (2001), one might say that we need to move from the planning and design school perspectives towards the learning school perspective on strategy where an interest in the world help the company better understand its competitive situation and move correspondingly.

The models mentioned above are well known and are also part of the curriculum at most business schools. They have in recent years been complemented by an increasing interest in different canvas models that visualize the interconnectivity of different important business aspects that need to be addressed for achieving success (Joyce \& Paquin, 2016). These new models are also more geared towards understanding changing business conditions from a network perspective, which give us an indication of what conversations and insights are seen as important today. What is lacking, however, are models that are able to fuel a strategic conversation encompassing innovation, business mod- els, and futurizing: the "how" component of being innovative and competitively successful at the same time.

What I propagate is not a conversation about innovation and competitors in general, for instance, their strength and weaknesses. No, what is needed is an insightful strategic conversation about how a company's innovative capacity compares to their main competitors and other important actors - one that sets the standards of an industry, and thus ultimately defines it. One might object that the "innovation funnel" (the model where one starts with ideas and successively reduce them as they pass different stage gates) to some extent would do this (Wang, 2017). I would disagree though, as the innovation funnel mainly concerns product development priorities. The stage-gate process will successively limit the discussion to developmental issues of already existing ideas. The model will thus not help the company build its innovative capacity for future possibilities of steering its industrial influence.

Scrutinizing the other models mentioned, none of them builds on an innovation perspective. Instead, they usually are constructed from a market perspective. Despite its flaws, the SWOT analysis is used in all parts of society because it brings out important questions that trigger a general strategic conversation, but not specifically on innovation. The same goes for STEEP and VRIO, which aim to link societal and competitive development to a desired market or industry position. The same goes for more developed concepts such as Michael Porters Five Forces (2008), and you might also consider Kim and Mouborgnes' (2004) Blue Ocean Strategy, to name a few. However, when it comes to innovation, there is a lack of a model that stands out. There have been attempts, such as the conceptual framework for prime movers developed by Normann (2001) (focusing on a quite complex process for company reorganization) as well as networking ideas connected to Henry Chesbrough's open innovation (2006), but they are more concerned with how to become more innovative than deciding what should we be innovative about.

Open innovation is interesting, as it suggests how the innovative capacity of a company can increase by deliberately inviting other actors to participate in innovation processes, but it is more a strategy in itself than a model for creating strategy. Open innovation might be one of several answers, but what we need to do in order to develop an innovation strategy is to pursue the question: In what innovative aspects do we want to gain industrial influence and how should we go about doing it? What 


\section{The Prime Mover Matrix: A Conversation Piece for Building Strategic Innovative Capacity Magnus Hoppe}

we need is a usable model that both helps us pose that question and engages in a strategic conversation about how to achieve the evasive answers we agree upon and move with the flow.

\section{Usability of Models}

What are the requisites for a good, usable model? To start, there is no real need for it to be exact in depicting reality, as this is impossible to achieve when one can never summon up all aspects of reality nor make all those concerned agree on what aspects to cover. Instead, usability lies in a certain level of abstraction of reality in relation to the questions the model triggers. The questions are central in all models, as they will fuel a strategic conversation around what aspects are most important to consider for business success, as argued above. Working with the model, agreeing and disagreeing, rewriting, rethinking, and by that reflecting together to build insights and knowledge, is the point, just like Cummings argues that the drawing of strategy can be more important than the finished models (McPhee \& Cummings, 2015).

It does not stop there. In order to be used, any tool also needs to be quite intuitive and easy to understand. It is also what characterizes the models mentioned above. They are all inviting as you do not have to be well read in business to use them. Instead, their main advantage, I would argue, is that they do not provide answers but that they state important questions that need to be answered before any mutual decisions or actions can be taken. In between the questions and the answers is, however, a most important process where people come together in order to explore a mutual topic. And, they do this by using the same concepts and images inherent in the used model, aligning their thinking and ideas that in turn will make it possible for them to act as one. Using models thus create processes for mustering common efforts so that a company will be able to forcefully commit to an agreed strategy. That is what good usable models do.

The model itself is thus less important than the discussion it triggers, as one of my informants to my thesis (Hoppe, 2009) put it. Since then I have started to view models as conversation pieces that draw attention to something worth discussing. The more interesting discussion, the better the model; interesting in the sense of evoking a feeling that past understanding is inadequate (Weick, 1989). To Weick, finding something inadequate means that the person opens up for reflection and learning. New information and synthesis is needed in order to create new mental structures (understandings) that satisfy and can be interpreted as adequate in the situation the person encounters. In a business setting, learning means that you understand your own business in relation to others in novel ways that make more sense, where this new understanding will be a reference point for further thinking and action. Another way of viewing it is that using models is not so much about filling in blanks in a pre-ordered way, but raising questions that are important for those concerned (Van der Heijden, 2011), forcing them to reflect on the current state of their business in novel ways. But, how do we then best raise strategic questions about building innovative capacity in a deliberate way?

\section{The Prime Mover Matrix}

My suggestion for a model that fulfils the specifications above is the Prime Mover Matrix, which is used to assess a company's ability to absorb, develop, and deploy new technology and new business ideas and turn these into innovations, changing technologies deployed, and business models used. The matrix takes an industry perspective and differentiates between those companies that lead innovation and those who follow; and it is defined along two dimensions: technical innovative capacity and business innovative capacity, as described below. Put simply, in this context, innovation capacity means usable knowledge for interpreting and developing ideas into innovations along these two dimensions.

Describing it theoretically, innovative capacity depends on the company's ability to align its dynamic capabilities in order to meet the innovation challenges it faces (Birkinshaw et al., 2016; Teece et al., 1997). Specifically, of interest for innovation is the absorptive capacity, meaning a company's capacity for organizational learning in absorbing new innovation ideas. Using Weick (1989), a company that can stimulate interesting reflective processes in key issues will have a better absorptive capacity. My contribution with respect to innovation capacity is my call for a division between technical innovative capacity and business innovative capacity. They are related in that they both need to be addressed and attuned in order to make the best of any innovation attempt, but they rest on different knowledge bases - and that is why it is important to treat them differently. Technical innovation capacity rests on technical knowledge, whereas business innovative capacity rests on business knowledge. These knowledge bases are usually also found in different places within an organization. Taking a popular example, we might consider Apple, where Steve Wozniak was the main 


\section{The Prime Mover Matrix: A Conversation Piece for Building Strategic Innovative Capacity Magnus Hoppe}

technological mind, whereas Steve Jobs was the main business mind. Both products and business were developed through their ability to combine their specific strengths. The success of Apple's innovations came through the combination in certain products and services (although not all new ideas and products succeeded). Having the capacity means that you will be able to innovate better, but it does not mean that you will succeed in achieving your goals.

If we use this insight for creating a model with two axes we will arrive in an embryonic model just by recognizing that a company's technical innovation capacity and business innovation capacity can be both low and high. Adding that you might be a leader, a follower, or a lagger, invites us to find other dimensions in the model, where we can also add, with respect of innovation, "mover". As a mover, you do not just lead an industry in an aspect, you actually move it, changing how it functions. A mover is an actor that changes existing standards with respect to what technologies are used and how, as well as what business models are used and then how business is conducted (Normann, 2001). Some companies can do both at the same time, giving them a very advantageous position as they will be able to redefine the existing borders of an industry. And, through this mental exercise, we have arrived at the Prime Mover Matrix (Figure 1).
Being innovative, in the respect to the model, is relative to other actors, where an appropriate innovation strategy can be derived from the dependencies within industrial structures. A company scoring high in one dimension will be able to change the industry structure, move boundaries, set new standards, and thus adopt a leader strategy in a specific technology or business field. A company scoring low must instead adopt a follower strategy, where they structure themselves after other companies' innovations. A company scoring high in both dimensions, on the other hand, will be able to totally redefine an industry in both dimensions at the same time, giving it a position as prime mover.

Both a technical mover and a business mover will have a potentially large industrial impact, but not as much as a prime mover. In contrast, a company scoring low on both technical innovation capacity and business innovation capacity will be lagging behind others and have low industrial impact. Their positions are, and will be, a product of how they have invested in innovative capacity. Aiming for a more influential position means you have to invest now in order for a later potential harvest as a mover.

One might object that it is impossible to fill in the model, as there is no clear description of how to do the assessment. This objection is missing the point. The

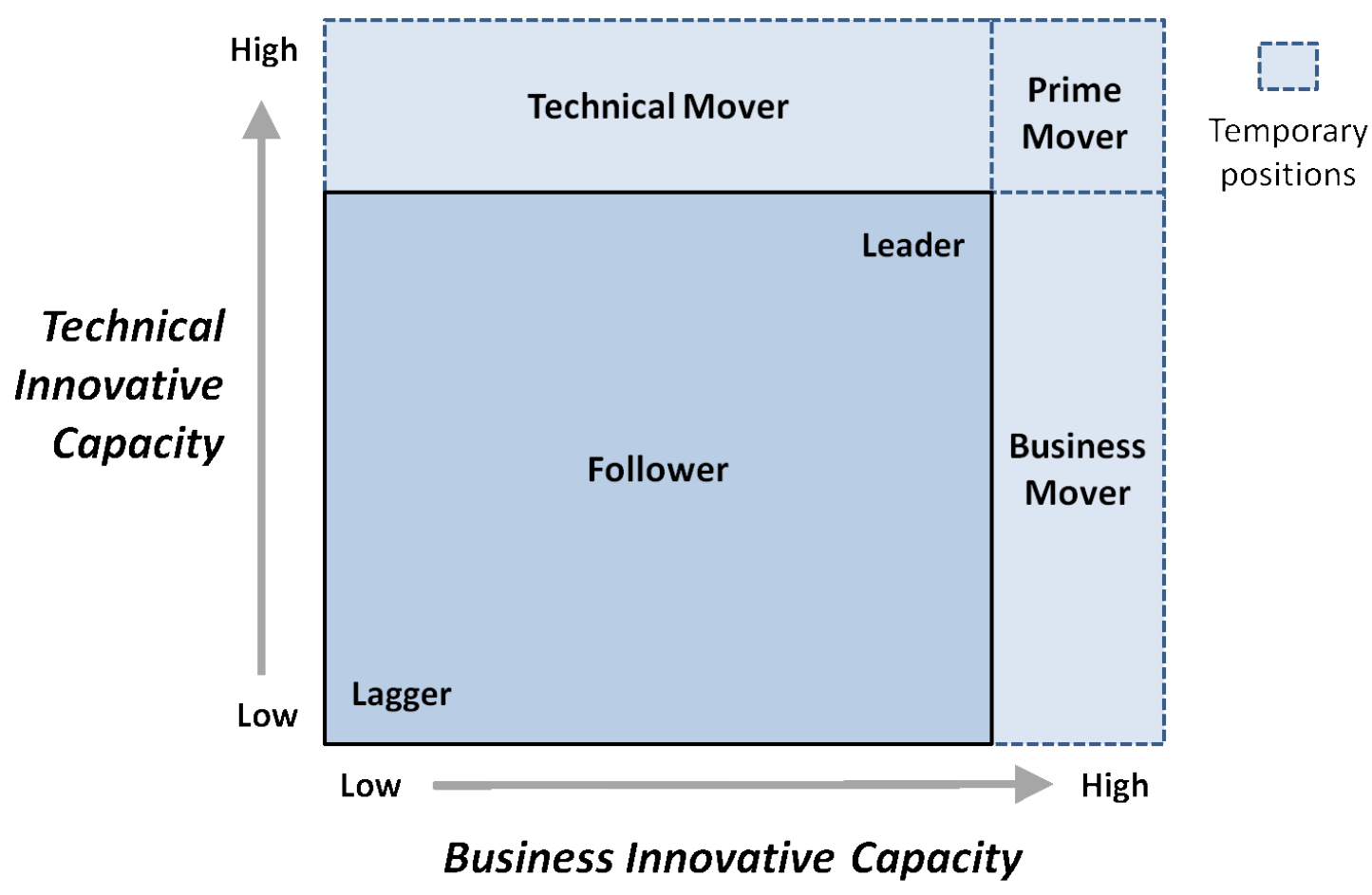

Figure 1. The Prime Mover Matrix 


\section{The Prime Mover Matrix: A Conversation Piece for Building Strategic Innovative Capacity Magnus Hoppe}

model is created in order to raise questions, not answers. What it will do is to provide you with a visual arena for conversation, where those who engage in the discussion can do their own personal assessments on the same page, draw lines and arrows and put forward their arguments (cf. McPhee \& Cummings, 2015). If the model provokes a lively discussion and helps those engage in building common understanding of how innovation is made, by whom, and in what patterns, then knowledge is created that will support a wellgrounded innovation strategy for a desired industrial impact.

\section{Industrial Impact}

Industrial impact, with the respect to the model, connects to Schumpeter's ideas of how society evolves through innovation, with the important understanding that all industrial and societal changes are temporary. Once the standards of technology and business have been moved, other changes will follow, continuously moving standards and industrial borders. When a company introduces new technology or business practices that are adopted by the market, industry, and society, it acts entrepreneurially by treading new ground. But, as Schumpeter (1934) points out, this is just a temporary state. When the novelty has been introduced and accepted (accordingly setting new standards), entrepreneurial action has to give way to more traditional management, in order to protect what has been gained.

On the one hand, the major challenge for a company that aims to stay as a leader in one or both dimensions is consequently to remain in change, building and attaining innovative capacity that will make that possible. On the other hand, they might also settle for a more defensive innovation strategy, protecting their gains, but then slowly moving away from a leading position opening up for others. Building innovative capacity that facilitates choices like this equals having an innovation strategy.

Hence, product and service development is not enough for a company that wants to label itself as innovative. Instead, it must uphold capacities for deliberate change where it continuously assesses how the industry is evolving and, from these insights, adapt their technical innovation capacity and business innovation capacity in accordance with the objectives of the firm. A discussion emanating from the model should support insightful decisions and actions on this topic.

\section{A Need for Knowledge}

In these discussions, centred around a conversation piece such as the Prime Mover Matrix, management will be in constant need of updated information about industry developments. Just trusting existing company knowledge, also with the risk of relying on existing preconceptions and dogmas, will not suffice. This need for structured knowledge building about an industry creates a close connection between innovative capacity and organized intelligence work, or competitive intelligence (Gilad \& Hoppe, 2016; Hoppe, 2009, 2013).

In order to interpret and gain from new knowledge, by absorbing it into the company's innovation processes, a company must have relevant prior knowledge (that is an absorptive capacity). It is the implementation of a long-term strategy for deliberately building the absorptive capacity, the company's knowledge base, that will define the technical innovation capacities and business innovation capacities of a company. For example, by adapting an open innovation strategy, a company will access a broader knowledge base and, by that, increase what kind of innovations it can embrace. An alternative move would be to hire specific competences, engage in partnerships, buy startups, etc. As the resources of a company are limited, it will need to choose where to increase the knowledge base and how, and those are the strategic decisions that ultimately will define a company's innovative capacity, both in technical innovation capacity and business innovation capacity.

Before we leave the more theoretical reasoning about models and innovative capacity and turn to a few general examples of what kind of conversations a model such as the Prime Mover Matrix can trigger, a few closing points are to be made. As with any model, the Prime Mover Matrix is simplifying reality without any aspiration of portraying something as complex as innovation in a correct way. Instead, I hope the matrix will be understood quite intuitively and will therefore do the job of raising important questions about industrial relations, rather than giving clear answers. It can possibly be used on different analytical levels, where I, for communicative reasons, limit myself to a quite general level. Still, on this level, it can provoke interesting reflections and insights on how industries evolve and what strategies to deploy. I would like to emphasize that the model has not been developed in order to rely on exact numbers or measurements. It is possible that both technical innovation capacity and business innovation capacity can be measured in some aspects, but the numbers are of lesser importance than the shared 


\section{The Prime Mover Matrix: A Conversation Piece for Building Strategic Innovative Capacity Magnus Hoppe}

understanding of relationships between different industrial actors as well as the relationship between technical innovation capacity and business innovation capacity for each studied actor. If the model and the strategic conversation can unravel how innovation develops inside an industry and within companies, important insights can be reached that will help the company move towards a desired innovative position within the industry.

\section{Prime Movers of Our Time}

Apple's 2007 introduction of the iPhone (showing high technical innovation capacity) with a new business model for capitalization on applications (showing high business innovation capacity) might be one of the most obvious examples of a prime mover. The impact of the iPhone/smartphone on society is massive, and it is hard to imagine how society would have looked like without it. The iPhone/smartphone case shows us that being a prime mover gives you a chance to not only influence industry structures but totally redefine them with a huge impact on society. Hence, we can also label this as a product and service innovation in comparison to more normal product and service development, where the important aspect in respect of the Prime Mover Matrix is that Apple acted as prime mover and other companies had to follow and adapt their innovation strategies in order to keep up with the industrial and societal change.

Interestingly, Google was quite quick on the uptake, deliberately building and utilizing technical innovation capacity. With the acquisition and development of the Android software, they did not just follow Apple but could also become a technical mover, setting a new technical standard for a part of the industry that Apple could not claim. With Android, a breach between hardware and software development for phones was also created, with large side effects on the business side of the industry, why it is possible to also call Google a prime mover at that time.

Both Apple and Google/Android still hold positions as industry leaders. Whether we should label them as prime movers or not today is not so much up to me but to other actors in the industry and, of course, it also depends on what part of the industry they are involved in. Depending on how they define their industry and its players, Apple and Google might be movers, but just as well, they might not. The label is less interesting than how we understand the relationships within the in- dustry and how different actors interact and influence each other through their technical and business innovations.

In retrospect, any analysis is quite simple, just like this one. We already know the answer. That Apple, since the introduction of the iPhone, has become the number one company in the world when it comes to market capitalization comes as no surprise. Apple still has great impact on many industries, but it has not been able to uphold the same position as unchallenged prime mover. As a company, it still has great impact, but maybe mostly due to its size and ability for continuous technical innovation. I am not sure though that their business innovative capacity is as high as their technical innovative capacity, which might be interesting to reflect upon.

\section{Prime Movers of the Past}

Occasionally, we might find prime movers in any industry, but we should always recognize that this position is temporary. A good example is Kodak. Once a very innovative company, Kodak went bankrupt in 2013 after not being able to align their innovation strategies for technical innovation capacity and business innovation capacity with how the industry was evolving due to the digitalization of photography. This is quite ironic given that it was Kodak who started it all.

By discussing how Kodak has moved through the Prime Mover Matrix, we can gain insights into how the company since the introduction of digital photography in 1975, scored high on technical innovation capacity but with no real business innovation capacity to accompany it. Even though we might label Kodak a technical mover, at that time, it did not do the company much good. The company mainly capitalized on analogue photography technology and was not able to create new sustainable business models that did not threaten their core businesses. Eventually, Kodak moved to an extreme position to the left: a position where they became vulnerable to other companies with a stronger business innovation capacity. In the end, Kodak's technical innovation capacity decreased and the company became a lagger, just waiting for liquidation.

It was not just one innovation or industrial actor that sealed Kodak's doom. Instead, it was the continuous change in an industry that earlier tended to follow a well-established structure. Then, standards started to change. Previous industrial borders and logics were 


\section{The Prime Mover Matrix: A Conversation Piece for Building Strategic Innovative Capacity Magnus Hoppe}

destabilized through innovation, and Kodak could not adapt quickly enough. Digitalization paved the way for a merger between cameras and phones, where the movers of the camera industry increasingly came from other industries such as computers and phones. Through the change of standards, an industrial border seized to exist, opening up societal changes where photography was used in new communicative ways, and money was made through new business models.

Upholding a leader position at one time does not mean that you will stay there, especially in today's complex and rapidly changing business environment. Industrial boundaries are becoming less stable, where innovations in adjacent industries always constitute potential threats, especially for more narrow-minded managers who think their business is protected due to what used to be true. This innovation threat does not come as substitutes though, as described in Michel Porter's (2008) Five Forces model, for example, but as the change of standards and by that the reconfiguration of industrial boundaries.

\section{Prime Movers of the Future}

Turning to the future, it is impossible to state which companies will be successful and which will not. An innovation strategy does not guarantee success, but it will increase the company's ability to move with the development of an industry, sometimes becoming a mover and having influence on the standards of industries. True innovation means that industries and society will change with effects that go beyond what can be foreseen. In order to emphasize this, I have come to use a more philosophical definition of innovation as follows:

\section{"Innovation is a value-enforcing change that goes beyond adaptation; it is a self-reinforcing move- ment that continuously gains wider effects on its context."}

With this definition, I would like to enforce the need for a continuous change perspective as well as the need for increasing a company's learning ability. If these perspectives are enforced within the structures of a company, the likelihood that it will be able to prosper increases as it will be able to make the best of the opportunities that arise in the wake of new innovations in technology and business.

Nonetheless, there are several interesting innovative companies that set new standards today, moving industrial borders and driving change. Although my lack of expert knowledge of any industry prevents me from making any predictions, I can at least mention that I am intrigued by the group of companies now forming around Elon Musk. What makes them especially interesting is Elon Musk's visions about electricity and transport and that he has stated that his main goal is to be a prime mover in society. By that, he has stated that his vision predominantly is about innovation, which contrasts with more limited visions of a specific industry position, maximum profitability, or shareholder yield. Of course, companies guided by visions like Musk's will have an innovation advantage relative other companies with more limited ideas of what they want to achieve. If they will be more profitable though, we do not know and should not even expect that. The vision is about change, not money, where innovation has another purpose.

If you are looking for someone who is setting new standards and moving industrial boundaries you need to look no further than Musk. A glimpse at the Prime Mover Matrix also tells us that, for most companies affected, it is appropriate to at least in some aspects adopt a follower strategy in order to move with the industry. Obviously, there are other options such as building niche strategies through high capacity in either technical innovation capacity or business innovation capacity, but to ignore the present and possible future impact of this particular actor would be hazardous for many companies related to electricity and transport. Many car manufacturers are now following the Tesla lead but are also challenging the leading position. They do that for good reasons, since the position as lagger at the bottom-left corner of the matrix (Figure 1) is not so compelling. Nobody wants to be the next Kodak.

No wonder, then, that we see many different conceptual electric cars from a variety of makers. By building them, the development teams encounter new problems that need to be solved, and in this process their technical innovation capacity increases, moving up the matrix. This is a common innovation strategy in the car industry. Problem solving not only solves problems; more importantly, it builds knowledge and thus absorptive capacity, and by that, it increases the possibility of attaining a more influential position. When it comes to business innovation capacity, we do not see the same obvious investments in knowledge through structured problem solving. Instead, as outside observers, we sometimes read about preproduction models that are tested in different environments and towards different customer groups. Whether this will be able to increase the business innovation capacity of the companies, I do 


\section{The Prime Mover Matrix: A Conversation Piece for Building Strategic Innovative Capacity Magnus Hoppe}

not know, but I find it interesting to reflect upon if we, through different models and processes, could increase a company's business innovation capacity in similar ways as we use tools like conceptual cars to increase their technical innovation capacity. What the Prime Mover Matrix does is to at least pose the question if this might be a good move to increase a company's business innovation capacity. How it is to be done is then a question for the strategic conversation the matrix triggers.

\section{Conclusion}

The article has introduced the Prime Mover Matrix as a conversation piece that will help management build strategic innovation capacity and gain desired influence on industrial standards and thus power.

There are several other models and tools for supporting strategic conversations, but these do not particularly focus on innovation as a strategic choice to guide how a company should build their innovative capacity in relation to industrial standards. Of course, you do not need the Prime Mover Matrix (or any other model) to have this conversation. It is, however, my firm belief that a common terminology along with a common visual model will help focus any conversation. Those who use the Prime Mover Matrix have to discuss and plot their company's movement in comparison to other influential industrial actors and from this understanding develop strategies for how to best develop their technical innovation capacity or business innovation capacity. Building these capacities deliberately means you have a plan for navigating the power structures that will determine your future, but also a chance for increasing your own power and leverage.

It should also be stressed that becoming a technical, business, or prime mover has no value in itself and no company will automatically prosper from it. Instead, what these positions offer is influence over industries and society, where it is not the position but how you deal with it that will decide what you gain.

The Prime Mover Matrix is based on the insight that continuous change is something natural in society, and companies need to find ways to continuously redesign themselves for best fit. All positions are temporary, and we should pay more attention to movements than ideas that bind us to view industrial standards, borders, or anything else as fixed. True innovations change industries and society, and we need to reclaim the profound impact of this understanding. Hence, having a good innovation strategy actually means that you have the desire to not just follow the stream as a dead fish, but to be part of the complex that drive change.

Even if you invest in product and service development, it does not automatically mean you will change anything in industry or society. Neither does hollow proclamations that a company is innovative. What will change industries and society is innovation, which in turn is dependent on the innovation capacity of your company. Low capacity then means low innovation potential and low influence, whereas high capacity means that you will have the potential of being able to change the world; just like the high technical innovation capacity or business innovation capacity of Tesla (and related companies) now is changing the billion-dollar industry of car manufacturing. In this way, the Prime Mover Matrix is also a contribution in differentiating innovation as something extraordinary and as something very important for companies and the world. A good innovation strategy is dependent on good reflections, which in turn are dependent on good questions. What the Prime Mover Matrix does is to offer visual help towards posing interesting questions, driving reflections, and reaching insights into how to build innovative capacities that will help you reach the influence you desire.

\section{Acknowledgements}

This article was developed from a paper presented at the ISPIM Innovation Forum in Boston, USA, March 25-28, 2018. ISPIM (ispim-innovation.com) - the International Society for Professional Innovation Management - is a network of researchers, industrialists, consultants, and public bodies who share an interest in innovation management. 


\section{The Prime Mover Matrix: A Conversation Piece for Building Strategic Innovative Capacity Magnus Hoppe}

\section{About the Author}

Magnus Hoppe is an Associate Professor at the School of Economics, Society and Engineering at Mälardalen University, Sweden. At the university, he is member of the Faculty Board and leads processes for collaborative research in sustainable development. Magnus holds a PhD in Business Administration from Åbo Akademi University in Finland, where he presented his thesis on organized intelligence work in modern organizations. His current research concerns both private and public organizations and spans intelligence, entrepreneurship, and innovation. A special research interest lies in questioning dominating perspectives that bind our understanding of specific topics, and he now works to establish new ways of talking and thinking about innovation. His aim is to help organizations build new insights that will enhance their ideation processes and strategy building and, thereby, improve their innovative capabilities.

Citation: Hoppe, M. 2018. The Prime Mover Matrix: A Conversation Piece for Building Strategic Innovation Capacity. Technology Innovation Management Review, 8(7): 5-13. http://doi.org/10.22215/timreview/1167

Keywords: Prime Mover Matrix, technical innovative capacity, business innovative capacity, industrial standards, innovation strategy, analytical models, conversation pieces

\section{References}

Ahlstrand, B., Lampel, J., \& Mintzberg, H. 2001. Strategy Safari: A Guided Tour Through the Wilds of Strategic Mangament. New York: Simon and Schuster.

Birkinshaw, J., Zimmermann, A., \& Raisch, S. 2016. How Do Firms Adapt to Discontinuous Change? Bridging the Dynamic Capabilities and Ambidexterity Perspectives. California Management Review, 58(4): 36-58. https://doi.org/10.1525/cmr.2016.58.4.36

Chesbrough, H. W. 2006. Open Innovation: The New Imperative for Creating and Profiting from Technology. Boston, MA: Harvard Business Press.

Gilad, B., \& Hoppe, M. 2016. The Right Way to Use Competitive Intelligence. HBR.org, June 16, 2016. Accessed July 6, 2018: https://hbr.org/2016/06/the-right-way-to-use-analytics-isnt-forplanning

Hoppe, M. 2009. Myten om det rationella flödet [The Myth of the Rational Flow]. Dissertation. Turku, Finland: Åbo Akademi University.

Hoppe, M. 2013. The Intelligence Worker as a Knowledge Activist-An Alternative View on Intelligence by the Use of Burke's Pentad. Journal of Intelligence Studies in Business, 3(1): 59-68.

Joyce, A., \& Paquin, R. L. 2016. The Triple Layered Business Model Canvas: A Tool to Design More Sustainable Business Models. Journal of Cleaner Production, 135(1): 1474-1486. https://doi.org/10.1016/j.jclepro.2016.06.067

Kim, W. C., \& Mauborgne, R. 2004. Blue Ocean Strategy. Harvard Business Review, 82(10): 76-84.

McPhee, C., \& Cummings, S. 2015. Communicating Strategy: How Drawing Can Create Better Engagement. Technology Innovation Management Review, 5(8): 44-48. https://timreview.ca/article/922

Normann, R. 2001. Reframing Business: When the Map Changes the Landscape. West Sussex, UK: John Wiley.

Porter, M. E. 2008. Competitive Strategy: Techniques for Analyzing Industries and Competitors. New York: Simon and Schuster.

Schumpeter, J. A. 1934. The Theory of Economic Development: An Inquiry into Profits, Capital, Credit, Interest, and the Business Cycle. London: Transaction Publishers.

Teece, D. J., Pisano, G., \& Shuen, A. 1997. Dynamic Capabilities and Strategic Management. Strategic Management Journal, 18(7): 509-533.

https://www.jstor.org/stable/3088148

Van der Heijden, K. 2011. Scenarios: The Art of Strategic Conversation. Hoboken, NJ: John Wiley \& Sons.

Wang, J. 2017. Structuring Innovation Funnels for R\&D Projects under Uncertainty. R\&D Management, 47(1): 127-140.

https://doi.org/10.1111/radm.12183

Weick, K. E. 1989. Theory Construction as Disciplined Imagination. Academy of Management Review, 14(4): 516-531. https://doi.org/10.5465/amr.1989.4308376 


\title{
How to Develop Innovation KPIs in an Execution-Oriented Company \\ Victoria Lakiza and Isabelle Deschamps
}

\author{
(6) Noverything that can be counted counts, and not everything that counts can be counted. ") \\ William Bruce Cameron \\ In Informal Sociology: A Casual Introduction to Sociological Thinking (1963) \\ (This quotation was used frequently during the workshops in this study.)
}

\begin{abstract}
Numerous established companies look for ways to rejuvenate their innovation capabilities, as it is essential for their long-term survival. One way is through the development of key performance indicators (KPIs) to measure innovation success. However, the wrong performance measurement approach can hinder innovation efforts. This case study explores the steps and challenges associated with the development of innovation KPIs in an established execution-oriented manufacturing company. Three prerequisites are proposed for such a project in a similar context: 1) a minimal maturity level of innovation processes, 2) strategic alignment, and 3) commitment to innovation. It is also proposed that, in such an executionoriented company, it might be more effective to start with KPIs that would encourage behaviours more favourable to innovation. Then, with stronger innovation capabilities, it will be easier to develop appropriate KPIs to measure the success of innovation endeavours.
\end{abstract}

\section{Introduction}

When they grow and become more established, companies tend to lose their innovation capabilities while focusing on the execution of everyday routines. In this article, we refer to such companies as execution-oriented, where "execution" refers mainly to short-term actions as opposed to long-term, systemic, and strategic thinking" (Lakiza, 2018). Such a company is risk averse and focuses on delivering tangible outputs without ensuring that the resources spent are contributing to the company's high-level objectives. This approach is not compatible with strong innovation capabilities, which are defined by Olsson and colleagues (2010) as the "ability to continuously develop innovations as a response to a changing environment".

In the context of increasingly shorter company lifespans (Morris, 2009), the loss of innovation capabilities becomes a significant problem for established firms, which lose market share to more innovative players. This was one of the challenges faced by a 60 -year-old family-owned Canadian manufacturer (hereafter "the company") when our research group began its longitudinal research on innovation management practices based out of their head offices.
The starting assumption of this longitudinal research was that the performance measurement systems in place have an influence on the company's innovation capabilities (Christensen, 1997; Perez-Freije \& Enkel, 2007; Pinchot III, 1985; Ries, 2011). Hence, a development project focused on innovation key performance indicators (KPIs) was seen by the Company as one way to support the development of their innovation capabilities. It was led by the first author of this paper as one of seven projects within a portfolio of longitudinal action research supervised by the second author.

Two key questions driving this research are:

\section{What kind of indicators are more appropriate for innovation? \\ 2. How they can be used to support and improve a company's innovation capabilities?}

Indeed, according to Saunila (2016), there is a lack of literature on the role of performance measurement in developing innovation capabilities. Although some companies do not measure their innovation performance, many of those who measure it do not know how to choose the appropriate metrics and systems. Ill-suited 


\section{How to Develop Innovation KPIs in an Execution-Oriented Company}

Victoria Lakiza and Isabelle Deschamps

indicators can result in inhibiting a company's innovation capabilities instead of supporting them (Christensen, 1997). Thus, the core interest behind this case study is to better understand how an established company can rejuvenate its innovation capabilities through the development of innovation KPIs.

This article is structured as follows. First, we present the case study context. Next, we share an overview of relevant innovation measurement theories. Then, we detail the research methodology and the case study steps, along with the proposed innovation KPIs. We then describe the biggest challenges met throughout the KPI development project. Finally, we conclude the article with recommendations regarding some prerequisites of innovation KPI implementation for similar contexts.

\section{Case Study Context}

In this section, the research context is presented, followed by a quick overview of the company and its existing performance measurement systems before our intervention.

\section{Research context}

Our longitudinal action research involved a total of 7 field researchers over three years. Each of them was present for 8 to 12 months at the case company and had a dual mandate:

1. Exploration of a specific research theme related to innovation management and analysis of the company's status with regards to this theme.

2. Execution of a specific mandate for the company by transferring and implementing best practices from literature to improve their innovation capabilities with regards to the research theme.

The present case study is based mainly on the work of the first author on innovation performance measurement systems. The company asked the researcher to help develop KPIs to measure the overall performance of all types of their technical innovation projects.

For the purposes of this action research, the researcher worked as an integral part of the recently formed Innovation, Research \& Development and Technology (IRDT) group within the company's engineering department. The technical innovation performance under study included new product development projects, innovation on customer orders, and new technology development. These covered anything from minor incremental improvements on existing products to "new to the world" products. The management of the IRDT group saw the development of innovation KPIs as a way to legitimize and improve the visibility of the innovation management practices being implemented.

\section{Case company}

The company is a Canadian specialized manufacturer that counts almost 2000 employees in North America and Europe. It was founded in the 1950s by an inventor and entrepreneur. As it is often the case in companies founded on a single technological innovation (McAdam \& Keogh, 2004), the founder was an engineer with multiple patents to his credit but lacking some of the specific knowledge and skills necessary to develop within his company what Wolpert (2002) describes as "exploration competencies". With the high power concentration in the founding family's hands for decades, the company did not build solid management capacity nor key elements of an innovative company culture such as decision making and accountability (Rao \& Weintraub, 2013).

The founder remained at the head of the company until the early 2000s and continued to be its main driving force of innovation for several more years. As in a typical family business generational model (Hiebl, 2015), the second generation focused more on operations optimization and acquisitions; the third generation, which recently began to access upper management positions, is trying to rejuvenate the company's innovation capabilities (Brodeur et al., 2017).

During the presence of our research group on site, the company hired its first non-family member President and CEO. He joined the Company after major operational issues started to affect its overall performance and high-quality reputation due to significant delivery delays. The new CEO took on the challenge of fixing these operational issues.

\section{Existing performance measurement systems}

During the second year of our longitudinal research, each department (engineering, marketing, sales, and operations) had its own data management system. However, there were few links and little transversal communication between the systems and the departments. Few employees had access to any system from other departments. Moreover, the main data management systems (engineering and sales) had been built 


\section{How to Develop Innovation KPIs in an Execution-Oriented Company}

Victoria Lakiza and Isabelle Deschamps

mostly in-house throughout the years, and their usage was far from intuitive for someone new or from a different department.

The new CEO developed a new scorecard to measure the company's performance. Most of the high-level KPIs chosen were short-term financial metrics, with none regarding innovation, as illustrated in Table 1. The VPs received the mandate to cascade down the new company goals and KPIs. Few, however, seemed to know how to approach this task.

Moreover, an effort to develop and implement indicators to measure the success of new product development projects only, was undertaken by the company's innovation management team during the first year of our research (i.e., before the case study presented here) and therefore was done without the participation of our research team. As part of that effort, a brainstorming session with innovation stakeholders on what is possible to measure resulted in a list of 38 indicators, presented in Table 2. This initial step was followed by an assessment of which indicators were measurable with the existing data management systems, which eliminated 14 indicators that were too difficult to collect (in bold in Table 2). The innovation management team found that different stakeholders were interested in different indicators. The company began to collect the remaining 24 metrics monthly and to share them with the relevant stakeholders. However, no specific goals were attached to most of these indicators, and they were not strategically related to the executive scorecard presented in Table 1. The chosen indicators were associated with one of three phases: 1) Front-End of Innovation (FEI), 2) Product Development Process (PDP), or 3) Post PDP. They were a mix of financial, operational, process, and portfolio indicators as categorized in Table 2. The 14 indicators that were not implemented seemed like the most important ones to the IRDT group. However, there were no resources available to work with the relevant departments in order to implement these indicators.

\section{Innovation Measurement Theories and Their Applicability}

Performance measurement is necessary to be able to detect poor performance and take appropriate actions towards improvement (Godener \& Soderquist, 2004). While some authors believe that control systems and performance measurement systems can hinder employee creativity and intrapreneurial efforts (Christensen, 1997; Morris \& Kuratko, 2002; Pinchot III, 1985; Shih \& Yong, 2001), others think that they can contribute to higher innovation effectiveness by providing guidance and highlighting where improvement is possible

Table 1. The case company's executive scorecard

\begin{tabular}{lll} 
Category & KPI & Description \\
\hline Financial Performance & Past Due & Value of orders past due $[\$]$ \\
\cline { 2 - 3 } & Turns & \# of annual inventory turns \\
\cline { 2 - 3 } & Material Savings & Procurement savings relative to average price in previous year [\$] \\
\cline { 2 - 3 } & Anchor Bookings & Bookings for anchor products [\$] \\
\cline { 2 - 3 } Delivery & Spares Billings & Billings for spare parts [\$] \\
\cline { 2 - 3 } & Supplier on-time-delivery (OTD) & Supplier OTD by receiving line with 0 days grace \\
\hline Puality & Project OTD & Project OTD by order line with 0 days grace \\
\hline Rework Cost & Rework Cost as a fraction of value-added labour [\$] \\
\hline First Test Fail & \# of failures related to \# of products tested \\
\hline & Total Recordable Cases & \# of Total Global Recordable Cases per 200,000 hours
\end{tabular}




\section{How to Develop Innovation KPIs in an Execution-Oriented Company}

Victoria Lakiza and Isabelle Deschamps

Table 2. New product development performance indicators developed prior to our innovation KPI mandate

\begin{tabular}{|c|c|c|c|}
\hline Category & FEI & PDP & Post-PDP \\
\hline Financial & $\begin{array}{l}\text { - Engineering budget allocated to } \\
\text { product innovation } \\
\text { - Operations budget allocated to } \\
\text { product innovation }\end{array}$ & $\begin{array}{l}\text { - Project payback period at gate } 2 \\
\text { - Operations budget spent per } \\
\text { project } \\
\text { - Engineering budget spent per } \\
\text { project } \\
\text { - Earned value project } \\
\text { management }\end{array}$ & $\begin{array}{l}\text { - Gross margin of product } \\
\text { innovation compared to } \\
\text { standard portfolio } \\
\text { - \% of sales generated by product } \\
\text { innovation } \\
\text { - Product innovation payback } \\
\text { period } \\
\text { - } \text { Operation resources spent } \\
\text { during the last cycle } \\
\text { - Engineering resources spent } \\
\text { during the last cycle }\end{array}$ \\
\hline Operational & $\begin{array}{l}\text { - } \begin{array}{l}\text { Engineering hours allocated to } \\
\text { product innovation }\end{array} \\
\text { - Operations hours allocated to } \\
\text { product innovation }\end{array}$ & $\begin{array}{l}\text { - Engineering budget spent per } \\
\text { project } \\
\text { - Operations hours spent per } \\
\text { project }\end{array}$ & $\begin{array}{l}\text { - Final Engineering budget } \\
\text { - Final Operations budget }\end{array}$ \\
\hline Process & $\begin{array}{l}\text { - Most frequent requests for } \\
\text { quotation (RFQs) which end in } \\
\text { "no bid" } \\
\text { - Most costly manufacturing } \\
\text { processes/operations } \\
\text { - One-pager score cut-off } \\
\text { - Ratio \# new ideas/opportunity } \\
\text { one-pagers vs. Total\# of } \\
\text { collected one-pagers } \\
\text { - \# of one-pagers received per } \\
\text { plant } \\
\text { - \# of one-pagers received per } \\
\text { department }\end{array}$ & $\begin{array}{l}\text { - \# of active projects at each gate } \\
\text { within allocated resources } \\
\text { - \# of active projects per PDP stage } \\
\text { - \# of active projects at each gate } \\
\text { that are on time } \\
\text { - \# of cancelled gates }\end{array}$ & $\begin{array}{l}\text { - Hit rate of RFQs related to } \\
\text { product innovation } \\
\text { - } \quad \text { \# of failure and service reports } \\
\text { related to product innovation } \\
\text { - \# of design requests related to } \\
\text { product innovation }\end{array}$ \\
\hline Portfolio & $\begin{array}{l}\text { - Potential sales value of the } \\
\text { portfolio } \\
\text { - \# of strategic arenas to focus } \\
\text { innovation efforts } \\
\text { - } \# \text { of projects in portfolio } \\
\text { - \% of projects aligned with the } \\
\text { innovation strategy } \\
\text { - Annual portfolio review killing } \\
\text { rate }\end{array}$ & $\begin{array}{l}\text { - \% accepted/ rejected/ recycled/ } \\
\text { on-hold during gate } \\
\text { - Quality rating cards of gates and } \\
\text { projects }\end{array}$ & $\begin{array}{l}\text { - } \% \text { of projects closed by post- } \\
\text { mortem }\end{array}$ \\
\hline
\end{tabular}




\title{
How to Develop Innovation KPIs in an Execution-Oriented Company
}

\author{
Victoria Lakiza and Isabelle Deschamps
}

(Cooper \& Edgett, 1996; Griffin, 1997; Hart et al., 2003; Jiménez-Zarco et al., 2006; Marginson, 2002; Neely et al., 2000; Neely et al., 1997). This section provides a quick overview of the history of performance measurement systems, as well as a short literature review on such systems specifically related to measuring innovation. The main functions and usages of performance measurement systems are also discussed and followed by a few guiding principles for their effectiveness.

\section{History of performance measurement systems}

Historically, performance measurement systems used to be under the finance function, had mostly financial metrics, and used data from accounting and finance (Bremser \& Barsky, 2004; Neely et al., 2000; Neely et al., 1997). However, this approach provided limited diagnostic power and forced a short-term orientation, eventually resulting in a demand for more balanced performance indicators with measures of customer satisfaction and human capital (Jiménez-Zarco et al., 2006).

More balanced performance measurement systems covering different performance perspectives were developed to address this need. These included the Balanced Scorecard (Kaplan \& Norton, 1992) and the Performance Pyramid Prism (Lynch \& Cross, 1991). Such models focus on strategic alignment and facilitate translating strategy into action (Garengo et al., 2005). While a number of authors believe that the Balanced Scorecard can be used for innovation performance measurement (Bremser \& Barsky, 2004; Kerssens-van Drongelen \& Bilderbeek, 1999; Kerssens-van Drongelen et al., 2000), others think it is too complex to implement and not appropriate for this context (Garengo et al., 2005; McAdam, 2000; Oriot \& Misiaszek, 2012).

Garengo and colleagues (2005) found that a focus on stakeholders has become one of the key dimensions of models for contemporary performance measurement systems. According to Kaplan and Norton (1996), customers' concerns generally fall under time, quality, performance, and cost. Knowledge of stakeholders' expectations and attention to their needs is essential for a company to thrive (Atkinson et al., 1997; Neely et al., 2002), especially in highly uncertain contexts characteristic of innovation (Dewangan \& Godse, 2014). In their study on the effectiveness of $R \& D$ performance measurement in the Netherlands, Kerssens-van Drongelen and Bilderbeek (1999) found that customer focus might be the most important characteristic that distinguishes effective performance measurement systems. Storey and Kelly (2001) claim that, from a customer point of view, a successful new product satisfies new needs or desires and outperforms other products. According to a survey of practitioners by Griffin and Page (1993), while many would like to measure customer satisfaction $(44 \%)$, very few do $(10 \%)$ as it usually incurs additional costs.

\section{Innovation performance measurement systems}

Innovation performance measurement brings additional challenges given its dynamic and evolving nature (Kirchhoff et al., 2013). While the financial metrics are the most popular, there is no consensus among researchers (Jiménez-Zarco et al., 2006) or practitioners (Griffin \& Page, 1993) on the most useful innovation KPIs. According to Werner and Souder (1997), who reviewed 40 years of literature, the most complex metrics are often the most useful. They are also the most costly to develop and use.

Following a survey of practitioners, Griffin and Page (1993) found a gap between the measures used and those that the managers would like to use. They also found that the most innovative firms focus on measures of recent and future company growth while the least innovative ones prefer more efficiency-oriented metrics (Griffin \& Page, 1996). According to Hitt and colleagues (1996), the most innovative companies focus more on strategic controls than on the financial ones. Storey and Kelly (2001) also found that the truly innovative firms favour soft indicators while the least innovative ones focus on financial metrics.

Through decades of research, it has been difficult to achieve a common understanding and provide clear recommendations to managers on innovation management and decision making because of the inherent variance of innovation and its context specificity (Brophey et al., 2013; Vorbach \& Perl, 2007). The appropriate success metrics depend on the type and context of the project (Petersen et al., 2010). Indeed, some case study research highlights the fact that the uniqueness of each innovation context makes comparisons and generic best practices impracticable (Bremser \& Barsky, 2004; Brophey et al., 2013; Brophey \& Brown, 2009; Godener \& Soderquist, 2004; Griffin \& Page, 1996; Jiménez-Zarco et al., 2006). Consequently, the perfect KPIs probably do not exist. It is more worthwhile to look for guidelines on how to choose appropriate metrics and systems based on various contextual factors. 


\section{How to Develop Innovation KPIs in an Execution-Oriented Company}

\section{Victoria Lakiza and Isabelle Deschamps}

Functions and usage of performance measurement systems Innovation performance measurement is idiosyncratic for each company at a given point in time and for each type of innovation project (Bremser \& Barsky, 2004; Brophey et al., 2013; Brophey \& Brown, 2009; Godener \& Soderquist, 2004; Griffin \& Page, 1996; Jiménez-Zarco et al., 2006). It is important to understand the reasons why there is a need to measure performance and what is the intended use of the data, before looking into what to measure (Ojanen \& Vuola, 2005; Perez-Freije \& Enkel, 2007).

Kerssens-van Drongelen (1999) identified the seven following functions of a performance measurement system:

1. Provide insight into deviations of performance from objectives to allow management to decide if steering measures are necessary

2. Provide insight into deviations of performance from objectives to allow staff to decide if steering measures are necessary

3. Fuel learning on the system that is being controlled to enable better planning and control in the future

4. Facilitate alignment and control of objectives

5. Support decision making with regards to performance-based rewards

6. Provide input to support and justify decision making

7.Motivate employees through feedback

Godener and Soderquist (2004) examined the literature and regrouped the possible uses of performance measurement for $\mathrm{R} \& \mathrm{D}$ and new product development into five categories:

\section{Communication of objectives, agreements and rules}

2. Definition of corrective actions based on diagnosis and control

3. Resource allocation

4. Decision making on individual rewards and incentives

5. Learning and continuous improvement
From a different perspective, Cirka (1997) groups control strategies into three categories based on what they do: 1) regulate the organization's inputs, 2) govern employees' behaviours, or 3) measure achievement and outputs.

Guiding principles for an effective performance measurement system

Based on a study of the literature of performance measurement systems for innovation, Dewangan and Godse (2014) propose five guiding principles for an effective performance measurement scheme, arguing that it must:

1. Be multi-dimensional

2. Measure performance of various stages within the innovation cycle

\section{Address organizational stakeholder goals}

\section{Support a cause-and-effect relationship}

5. Be easy to implement and use (aligned with existing performance measurement systems and cascaded through various hierarchical levels)

According to Bremser and Barsky (2004), properly selected metrics should be drivers of sustained profitability. To do so, the firm should develop a set of hypothesized cause-and-effect relationships that show the expected long-term results from specific current actions (Bremser \& Barsky, 2004). Over time, the hypotheses can be verified and adjusted if proven wrong. Finally, Collins and Smith (1999) believe that there has to be a balance between leading, lagging, real-time, and learning indicators.

\section{Summary of insights from literature with regards to our} case study

There is no consensus in either the literature or practice on the appropriate KPIs to use for innovation performance measurement (Griffin \& Page, 1993; Jiménez-Zarco et al., 2006). Nevertheless, the literature review allowed for the identification of several common characteristics of performance measurement systems that are more conducive to innovation, as presented in Table 3. Based on our analysis of the company's context, these characteristics did not apply to the company's performance measurement systems at the time of study and were used to guide our propositions. 


\section{How to Develop Innovation KPIs in an Execution-Oriented Company}

Victoria Lakiza and Isabelle Deschamps

Indeed, the case company's performance measurement systems are not balanced as they are mostly financial and have a significant lack of customer-based metrics. Success from a customer point of view is difficult to define as there are no efficient feedback loops between the company and its customers. In addition, there is little alignment between their executive scorecard and the one for new product development, notably because innovation is not part of the executive scorecard.

Moreover, the case company favours easy and accessible efficiency-oriented metrics. However, when asked about what really needs to be measured, the stakeholders are interested in intangible indicators that are difficult to measure, but they do not invest the resources necessary to develop the appropriate measurement systems. This is typical of the least innovative firms according to both Griffin and Page (1996) and Storey and Kelly (2001).

Several authors agree that innovation performance measurement is idiosyncratic to each company's specific context (Brophey et al., 2013). Consequently, some authors propose guidelines on how to choose the appropriate metrics for each case (Dewangan \& Godse, 2014). Finally, it is important to determine the intended use of performance measurement in order to choose suitable indicators (Ojanen \& Vuola, 2005; Perez-Freije \& Enkel, 2007).

\section{Innovation KPI Development at the Case Company}

The objective of the researcher's mandate was to develop a set of three to five simple but comprehensive KPIs to assess the performance of technological innovation and to evaluate the contribution of the IRDT team to the company's overall performance. The KPIs were meant to cover new product development, innovation on customer orders, and technology development. Below, we present a brief overview of the researcher's general methodology before diving into the key steps taken in the development of the innovation KPIs.

\section{Research methodology}

The central interest of this study was to better understand how organizational change unfolds in practice. Research design choices, as presented in Figure 1 were made to achieve this goal. Although some general research steps were planned, the multiple data collection methods presented in Figure 1 were used mostly iteratively, adapting to new questions and opportunities arising as the research unfolded.

Table 3. Characteristics of performance measurement systems favourable to innovation (reproduced from Lakiza, 2018)

\begin{tabular}{ll}
\hline Characteristics & References \\
\hline Encouragement of initiative taking & Jiménez-Zarco et al. (2006) \\
\hline Focus on intangible aspects & $\begin{array}{l}\text { Dewangan \& Godse (2014); Gama et al. (2007); Kaplan \& Norton (2001); Rao \& } \\
\text { Weintraub (2013) }\end{array}$ \\
\hline Focus on objectives as opposed to results & Kaplan \& Norton (1992) \\
\hline $\begin{array}{l}\text { Measurement of employee learning and } \\
\text { continuous development }\end{array}$ & $\begin{array}{l}\text { Dewangan \& Godse (2014); Jiménez-Zarco et al. (2006); Kaplan \& Norton (1992); Ries } \\
\text { (2011) }\end{array}$ \\
\hline $\begin{array}{l}\text { Focus on forecasting future processes as } \\
\text { opposed to controlling past activities }\end{array}$ & $\begin{array}{l}\text { Bremser \& Barsky (2004); Garengo et al. (2005); Jiménez-Zarco et al. (2006); Kaplan \& } \\
\text { Norton (1992) }\end{array}$ \\
\hline $\begin{array}{l}\text { Dynamic and flexible } \\
\text { Marginson (2002); McAdam \& Keogh (2004); Morris \& Kuratko (2002); Neely et al. }\end{array}$
\end{tabular}

Informal and loose

Covin \& Slevin (1991); Morris et al. (2006); Morris \& Kuratko (2002); Pinchot III (1985)

Focus on strategy and vision as opposed to finance and controls

Garengo et al. (2005); Hitt et al. (1996); Kaplan \& Norton (1992) 


\section{How to Develop Innovation KPIs in an Execution-Oriented Company}

Victoria Lakiza and Isabelle Deschamps
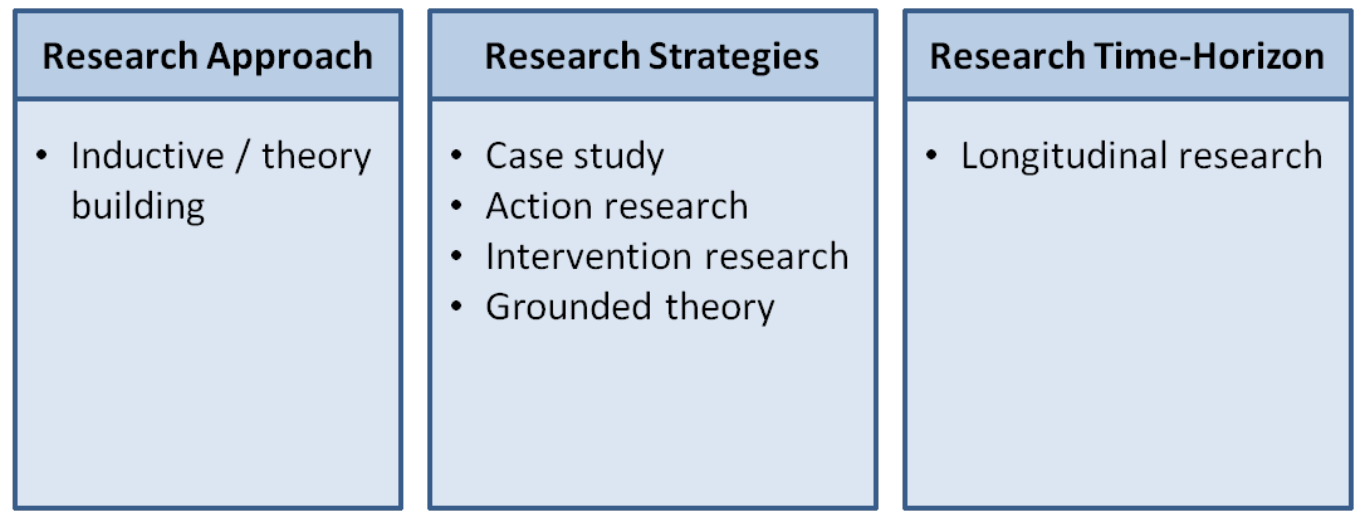

\begin{tabular}{|l|}
\hline Data-Collection Methods \\
\hline - Prior data \\
- Document review \\
- Interviews \\
- Workshops \\
- Questionnaire \\
- Observations \\
- Meetings \\
\hline
\end{tabular}

Figure 1. Research design choices

Although not all the research data collection methods were directly associated with the KPI development mandate, the resulting observations also contributed to the thinking on the most appropriate innovation KPIs.

\section{KPI development steps}

Figure 2 presents the general process flow of the innovation KPI development mandate within the case company. Some of the key high-level steps are described in greater detail below.

\section{Stakeholder input}

At the beginning of our mandate, we met the internal innovation stakeholders in order to outline the project's scope, describe the researcher's role, understand their expectations, and build trust (Patton, 1987). A total of 16 interviews were carried out with stakeholders from the Engineering, Marketing, Sales, and IT \& Strategy departments. External company stakeholders were not involved in this mandate, primarily because of the general lack of external input in the company's activities, as explained later. The project-scope interviews identified a clear need to bridge the gap between different stakeholders' views on innovation and their measurement needs. Therefore, a participatory workshop was developed to build shared understanding through discussions among key stakeholders on their main expectations and needs for measurement. The aim was to achieve a common view on the most important aspects to be measured.

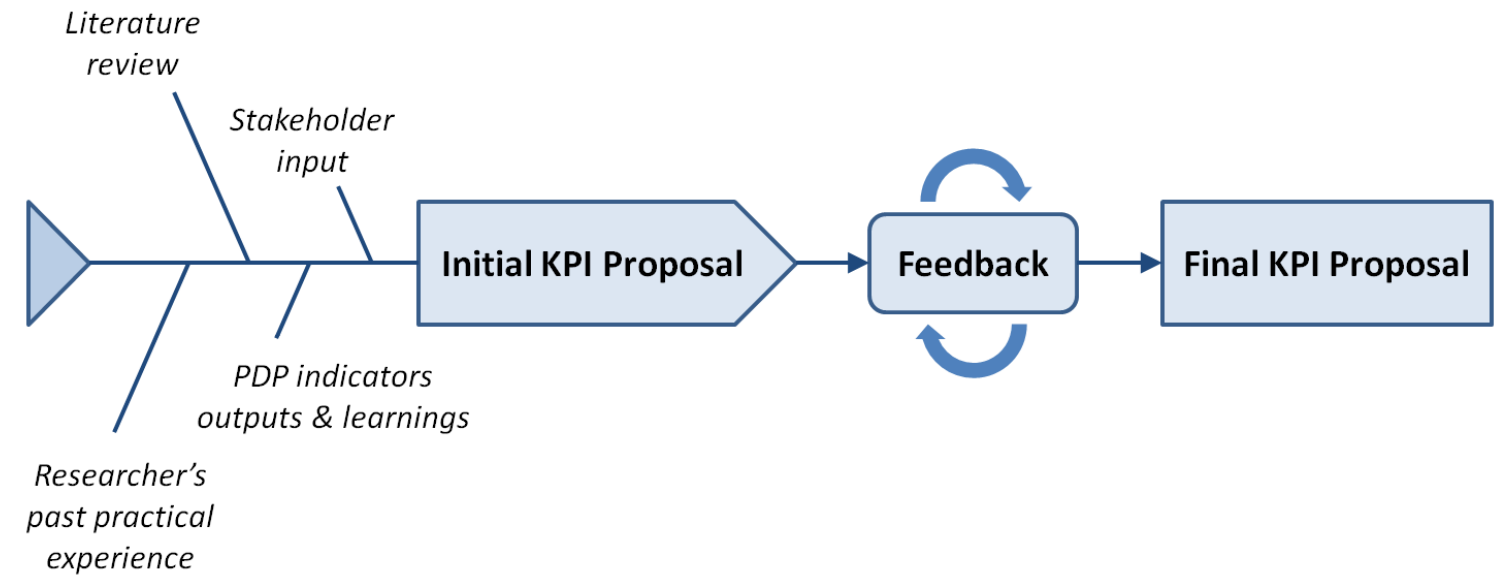

Figure 2. Process flow for developing innovation KPIs 


\section{How to Develop Innovation KPIs in an Execution-Oriented Company}

\section{Victoria Lakiza and Isabelle Deschamps}

First, the participants were asked to share what functions of performance measurement systems (Kerssensvan Drongelen, 1999) they were looking for and how they would like to use the future innovation KPIs (Godener \& Soderquist, 2004). This input helped the stakeholders focus on what matters to them, instead of choosing some existing popular metrics without ensuring their usefulness.

Further questions helped explore what successful innovation meant to the participants. This step contributed to the sharing of different views on the subject so as to start building a common understanding on how they want success to look for the company's projects.

The alignment of innovation activities with corporate strategy is judged by many as essential (Bremser \& Barsky, 2004; Jiménez-Zarco et al., 2006; Kuratko et al., 2014). Moreover, senior management involvement is crucial in order to ensure successful implementation and overall alignment of key measures within a scorecard (Kaplan \& Norton, 1992). However, it was not possible to work fully in alignment with the upper management and strategy as innovation management efforts were not well integrated with high-level priorities. However, efforts were made to obtain key input from the stakeholders in order to apply some of the Balanced Scorecard philosophy. As part of the workshop, key questions addressing each of the four Balanced Scorecard perspectives (Kaplan \& Norton, 1992) were used and are presented in Table 4.

Table 4. Balanced Scorecard perspectives questions used at the KPI requirements workshop

\begin{tabular}{ll} 
Perspective & Question \\
\hline Customer & $\begin{array}{l}\text { To achieve our vision, how } \\
\text { should we appear to our } \\
\text { customers? }\end{array}$ \\
\hline $\begin{array}{l}\text { Internal business } \\
\text { processes }\end{array}$ & $\begin{array}{l}\text { To satisfy our shareholders and } \\
\text { customers, what business } \\
\text { processes must we excel at? }\end{array}$ \\
\hline Learning and growth & $\begin{array}{l}\text { To achieve our vision, how will } \\
\text { we sustain our ability to change } \\
\text { and improve? }\end{array}$ \\
\hline Financial & $\begin{array}{l}\text { To succeed financially, how } \\
\text { should we appear to our } \\
\text { shareholders? }\end{array}$ \\
\hline
\end{tabular}

Finally, of all the topics discussed during the workshop, each participant was asked to identify the single most important one that they believe will demonstrate innovation success. The responses were then clustered in categories and voted on. The "Customer Wow Factor" was determined as the main aspect to measure.

\section{Feedback discussions and KPI decision making}

Following the KPI requirements workshop, input from the participants was analyzed and discussed with fellow researchers as well as with the lead academic researcher. During the development of the first KPI proposal, several discussions were held with some of the key stakeholders including the IRDT director, some managers from the IRDT group, and from the Marketing department. The first set of KPIs was then presented to 11 stakeholders for feedback during individual interviews. This led to modifications to the proposed KPIs before the final proposal.

As functional integration has a positive impact on project lead-time and cost (Clark \& Fujimoto, 1991; Gomes \& Pearson, 2001), Godener and Soderquist (2004) believe that inter-functional processes and measurement can improve the performance of innovation endeavours. However, Engineering and Marketing decision makers were unable to agree on common measures to implement; each group focused on its own interests and avoided getting involved in the other's KPIs. Unfortunately, this resulted in working separately with Engineering and Marketing stakeholders on different metrics.

\section{Proposed KPIs}

The five guiding principles proposed by Dewangan and Godse (2014) and presented above were used for the development of proposed KPIs, as presented in Table 5.

The introduction of innovation performance metrics can contribute to higher performance by providing guidance and direction to the innovation efforts (Marginson, 2002). However, it might sometimes be too early to effectively introduce KPIs. According to a review of 10 business process management (BPM) models by Röglinger, Pöppelbuß, and Becker (2012), in most models, the development of KPIs is at maturity level 3 (out of 5). In this case, the company's innovation processes were assessed as being mostly between BPM maturity level 1 and 2 (Houllier, 2017) by a member of our research team. 


\section{How to Develop Innovation KPIs in an Execution-Oriented Company}

Victoria Lakiza and Isabelle Deschamps

Table 5. Guiding principles for KPI development, based on Dewangan and Godse (2014)

\begin{tabular}{ll} 
GuidingPrinciple & $\begin{array}{l}\text { Use for Innovation KPI } \\
\text { Development Mandate }\end{array}$ \\
\hline Multi-dimensional & $\begin{array}{l}\text { A mix of financial/non-financial, } \\
\text { hard/soft, and leading/lagging } \\
\text { indicators was proposed. }\end{array}$
\end{tabular}

Measuring performance at different stages of the innovation cycle

Measure several indicators at three stages of the innovation process:

1. Generation and selection of ideas

2. Incubation and realization

3. Realization of innovation

Addressing organizational Use of input collected through stakeholdergoals interviews and the KPI requirements workshop
Supporting a cause-andeffect relationship

Some of the proposed KPIs were hypothesized to help drive behaviours that would address some of the key innovation challenges that the company had (such as proximity to customers and inter-functional integration).

Easy to implement and use (aligned and cascaded through the hierarchy)
Great care was taken in applying this principle as much as possible despite concerns that the easy metrics are rarely the useful ones (Werner \& Souder, 1997). In addition, full alignment with the existing performance measurement systems was not possible in the context of this study.
In such circumstances, instead of developing KPIs to measure the success of innovation activities, it was decided to focus on KPIs that could help drive the right behaviours to help the company mature its innovation processes and improve its innovation capabilities. Several characteristics of the case company that hindered its ability to continuously develop innovations were identified (Brodeur et al., 2017; Lakiza et al., 2017) and further confirmed by results of an Innovation Quotient (IQ) questionnaire that was used to assess how favourable the company's culture was to innovation (Rao \& Weintraub, 2013).
It was possible to propose a set of KPIs suited for a company with an immature innovation management system working towards rejuvenating its innovation capabilities. Table 6 presents a summary of the KPIs proposed as well as the practices they encourage and the behaviours they are meant to change in order to improve the company's innovation capabilities over time.

\section{Summary of KPI Development Challenges}

In summary, there was a significant gap between what came out as the appropriate measures from the stakeholder input activities, the type of measures they were using, and the specific indicators they had in mind for innovation. This is not surprising, as Griffin and Page (1993) found little overlap between the measures used by practitioners and those that they would like to use. When asked why they would not use what they believe would be more useful, the reasons from the survey by Griffin and Page (1993) were:

1. Lack of appropriate systems in place $(37 \%$ of respondents)

2. Company culture does not support measuring (17\%)

3. No one is held accountable for the results (12\%)

\section{Short-term orientation (10\%)}

5. Lack of understanding of the development process $(10 \%)$

6. No time to measure $(8 \%)$

7. Measuring is unimportant (6\%)

These reasons align well with some of the challenges met when trying to develop innovation KPIs at the case company. As mentioned in the previous section, the level of maturity of the company's innovation processes was too low for an efficient introduction of innovation KPIs. Therefore, it was decided to focus on KPIs that would help improve innovation capabilities and mature the company's overall innovation management processes. In addition, four other KPI development challenges were met: the lack of strategic alignment both internally and externally, as well as risk aversion and execution mindset. Table 7 summarizes how the five challenges inhibited the successful development of innovation KPIs. 


\section{How to Develop Innovation KPIs in an Execution-Oriented Company}

Victoria Lakiza and Isabelle Deschamps

Table 6. Proposed innovation KPIs with encouraged practices and desired behaviour change

\begin{tabular}{|c|c|c|}
\hline KPI & Encouraged Practices & $\begin{array}{l}\text { Desired Behaviour Change and Improvements to } \\
\text { Innovation Capabilities }\end{array}$ \\
\hline Economic Value for Customers (EVC) & $\begin{array}{l}\text { - Customer-driven analysis } \\
\text { starting at the concept stage } \\
\text { - Efficient feedback loops } \\
\text { with customers }\end{array}$ & $\begin{array}{l}\text { - More focus on product value-add and uniqueness } \\
\text { - Better inter-functional communication regarding } \\
\text { innovation: to obtain an EVC score, stakeholders } \\
\text { from different departments will have to understand } \\
\text { how the potential new product would respond to } \\
\text { customers' needs or desires, and assess together } \\
\text { the value a given product could bring (Nagle \& } \\
\text { Hogan, 2006). }\end{array}$ \\
\hline
\end{tabular}

Innovation Quotient (IQ) score

Innovation Quotient(1Q) score

(2)

- Assess and improve internal capacity to innovate
- Take time to step back and assess where they stand in order to choose appropriate actions to improve

- Identify gaps and encourage behaviours more conducive to innovation
Time-to-market

- Increase innovation speed
- More agile and focused work: encourage faster development projects requiring more focus and more dedicated resources. Prioritize work on fewer projects instead of spreading resources thin.

\begin{abstract}
Sales and number of "launch worthy" products
\end{abstract}

Time spent on innovation work
- More focus on market launch and marketingoriented activities

- Dedicated time for innovation
- Prioritize development with distinct value for customers. This requires taking the time to understand what it means.
- Better balance between day-to-day execution and future development by setting targets to ensure that at least some time and resources are spent on future activities.

\section{Recommendations}

The results of the IQ questionnaire confirmed that the company's culture was not favourable to innovation at the time of study. During the development of the innovation KPIs, numerous challenges resulting from the company's culture were met, such as risk aversion, silos, and an execution-oriented mentality. Based on these challenges, three conditions were identified as prerequisites to implementing successful innovation KPIs: a minimal BPM maturity level of innovation processes, the strategic alignment of the innovation efforts with the company's goals as well as commitment to innovation. Each of these conditions is addressed in greater detail in the following paragraphs.

First, when most innovation processes are in the early stages of being developed and tested, it is difficult to develop robust and useful KPIs, as the processes that are being measured are themselves in development and constantly change. In a context of limited resources, developing KPIs to measure the performance of immature processes might not be the best investment. KPIs to encourage desired behaviours that are hypothesized to improve future performance might be a more efficient approach than KPIs to measure the performance of innovation processes.

Second, the lack of strategic alignment made this mandate less efficient. It was not possible to fully align the proposed KPIs with the company strategy. In addition, alignment among the innovation stakeholders revealed itself to be a significant challenge in a context of strong silos. Discussions on the KPI development were dragging as both sides were focused on their own ideas, biased by their functional background, and with little common innovation language. A holistic approach is necessary to ensure that the different parts of the company 


\section{How to Develop Innovation KPIs in an Execution-Oriented Company}

Victoria Lakiza and Isabelle Deschamps

Table 7. Key challenges and their impact as inhibitors on innovation KPI development

\begin{tabular}{|c|c|c|c|}
\hline KeyChallenge & Desired State & $\begin{array}{l}\text { Overview of the Challenge at } \\
\text { the Case Company }\end{array}$ & $\begin{array}{l}\text { How It Inhibits Development } \\
\text { of Innovation KPIs }\end{array}$ \\
\hline RiskAversion & $\begin{array}{l}\text { Innovation requires testing, } \\
\text { risk, and some failure before } \\
\text { breakthrough (Christensen, } \\
\text { 1997; Rao \& Weintraub, 2013; } \\
\text { Ries, 2011). }\end{array}$ & $\begin{array}{l}\text { The employees exhibit risk- } \\
\text { averse behaviour, prioritizing } \\
\text { projects with incremental } \\
\text { improvement and a guarantee } \\
\text { to sell today (Garengo et al., } \\
\text { 2005). }\end{array}$ & $\begin{array}{l}\text { Input and hard KPIs are } \\
\text { prioritized even though they } \\
\text { do not measure the actual } \\
\text { success of innovation } \\
\text { endeavours, while there is } \\
\text { resistance to output KPIs that } \\
\text { could show ultimate } \\
\text { innovation results a few years } \\
\text { later, as well as to soft KPIs } \\
\text { that could be drivers of } \\
\text { innovation. }\end{array}$ \\
\hline
\end{tabular}

Execution Mindset Innovation requires stepping out of the day-to-day execution and making time and space to think and test ideas.
There are few dedicated resources for innovation. These resources mostly get pulled back in response to day-to-day emergencies.
The execution mindset asks for innovation KPIs that showcase execution of innovation, such as the number of ideas and development projects. These do not encourage activities essential to the development of innovative capabilities.
Internal Alignment

Information systems allowing quick access to the details when something goes wrong are important (Kaplan \& Norton, 1992).
Lack of alignment does not allow for synergy with existing systems nor for efficient ways to develop and manage crossfunctional metrics.

With data management systems separated by functions, manual work is required to compile interfunctional metrics and to track back and understand how the data was pulled together. There is also a lack of agreement on the kinds of KPIs the key stakeholders want.

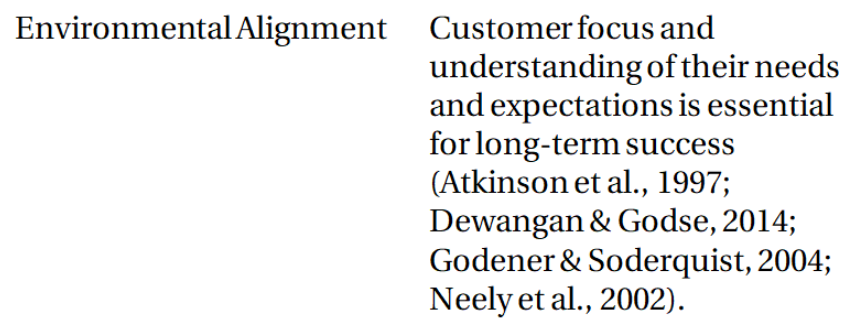

Process Maturity
Typically, KPIs are introduced at level 3 of BPM maturity (Houllier, 2017; Röglinger et al., 2012).
The company is not set up to meet future needs as there is a lack of feedback loops with customers and most development efforts focus on catching up to the competition and to standards requirements.

Lowlevel of BPM maturity of the innovation management processes. The average maturity level of innovation processes at the time of study was between 1 and 2 (Houllier, 2017).
The disconnect with the other stakeholders in the industry makes it difficult to have a good understanding of what success would mean and what should be measured and how.

KPIs are generally developed at BPM maturity level 3. Other work needs to be done on the development of processes and teams before innovation KPIs can be effectively developed and implemented. 


\title{
How to Develop Innovation KPIs in an Execution-Oriented Company
}

\author{
Victoria Lakiza and Isabelle Deschamps
}

are working together towards higher performance (Kaplan \& Norton, 1992). When development work is done without alignment and is not prioritized by upper management, it ends up being half completed or used incorrectly, and is sometimes dropped (Garengo et al., 2005). Experience with these outcomes makes the stakeholders lose faith in such projects and makes similar efforts even more difficult in the future.

Third, there was no commitment, particularly from upper management, towards innovation. The longitudinal research was taking place in the midst of numerous organizational changes, most of which were focused on fixing the company's operational issues. While many believed that innovation is important, there was no formal commitment to innovation and it was rarely an employee's priority. Important resources were granted to develop new teams, tools, and processes towards operational excellence, while the IRDT group was struggling to justify a dedicated budget and resources for new product development. While IRDT employees were encouraged to innovate, they were constantly pulled into day-to-day incremental improvements and firefighting. Without commitment, no risk will be sufficiently encouraged as it will never be prioritized over the day-to-day operations.

These three prerequisites also influence one another. When there is real commitment to innovation, it will be part of the company's strategy and it will be easier to align the innovation management development efforts with the company's goals. When there is alignment, more resources will be available and focused on developing more solid and mature processes.

These prerequisites are by no means meant to be exhaustive, especially in a general context. They represent the biggest barriers met during the innovation KPI mandate at the case company and are indicative of what can make a similar project challenging in a comparable context.

\section{Discussion and Conclusion}

The purpose of this article was to share learnings from the development of innovation KPIs in an executionoriented Canadian manufacturing company. It brings to light the current state of the literature on innovation performance measurement and proposes steps and guidelines that could be followed to develop appropriate innovation KPIs in an execution-oriented company. The lessons learned and challenges met could benefit managers embarking on a journey to rejuvenate their company's innovation capabilities, as well as researchers in the field of innovation performance measurement systems and management. However, the specific KPIs proposed in this study may not necessarily be transposable to a different situation, even with a similar context.

Performance measurement systems are idiosyncratic to the context (Bremser \& Barsky, 2004; Brophey et al., 2013; Brophey \& Brown, 2009; Godener \& Soderquist, 2004; Griffin \& Page, 1996; Jiménez-Zarco et al., 2006). Thus, our approach was to use guiding principles for an effective performance measurement system by Dewangan and Godse (2014) in order to propose appropriate KPIs for the company at its specific state of innovation management capacity, rather than searching for the "perfect" KPIs.

The mandate at the case company was originally to propose KPIs to measure the success of innovation efforts. The low BPM maturity level of its innovation processes, the lack of strategic alignment, as well as the lack of commitment to innovation made this task very challenging. However, "the measures are not an end point but a dynamic phenomena that must be continually reviewed and developed during the transitional period when creativity and innovation is [sic] developed" (McAdam \& Keogh, 2004). Given that a bigger goal was the rejuvenation of innovation capabilities, it made sense to focus on KPIs that would help drive behaviours favourable to innovation and the development of better innovation capabilities rather than KPIs that measure innovation success. If we are right in believing that better innovation processes are the foundation of better innovation performance, this will ultimately have the desired results.

The introduction of KPIs with a goal to encourage behaviours more conducive to innovation is believed to eventually contribute to changing the company's culture, opening it up to opportunities. With a more intrapreneurial culture, an introduction of KPIs with a goal to measure the success of innovation activities might be easier, as some of the challenges and inhibitors met in this case study will normally be less prominent. For more on this aspect and a conceptual framework on the triple dynamic relationship between intrapreneurial culture, performance measurement systems, and innovation capabilities, see Lakiza (2018).

This case study lays the groundwork for several research opportunities. First, the proposed framework mentioned above, as well as the findings shared in this 


\section{How to Develop Innovation KPIs in an Execution-Oriented Company}

Victoria Lakiza and Isabelle Deschamps

article, could be further tested in other companies of similar and different types to understand what company aspects have an influence on similar projects. More comprehensive research regarding the barriers to the implementation of innovation KPIs in an executionoriented company could follow. Additional longitudinal research focusing on innovation KPI implementation and its impacts on the case company's culture and innovation capabilities a few years later could help verify the propositions raised by our longitudinal action-research study.

\section{Acknowledgements}

This work was supported by Mitacs Canada through the Mitacs Accelerate Program, which is sponsored by the Government of Canada and the Government of Quebec. This research would not be possible without the support of the case company and its employees and managers, as well as the academic support of Polytechnique Montreal. The authors also wish to thank other researchers involved in this longitudinal research Jonathan Brodeur, Amélie Beaulieu, and Guillaume Houllier - for their ongoing contributions and feedback on the mandate described in this article. The authors are also grateful to Dana Giacobbi for his valuable feedback and insights on the concepts and content of this article.

This article was developed from a paper presented at the ISPIM Innovation Forum in Boston, USA, March 25-28, 2018. ISPIM (ispim-innovation.com) - the International Society for Professional Innovation Management - is a network of researchers, industrialists, consultants, and public bodies who share an interest in innovation management.

\section{About the Authors}

Victoria Lakiza is a consultant, facilitator and coach committed to unlocking the potential of people and organizations. She is passionate about change management and organizational transformation. Victoria's Master's degree in Industrial Engineering from Polytechnique Montreal allowed her to deepen her knowledge and understanding of organizational change dynamics and of the role of performance measurement in promoting culture change. Her professional experience includes supporting a culture shift towards intrapreneurship, developing a complete performance measurement system and managing an organizational restructuring and re-branding in an innovative engineering consulting company. Concurrently she was co-leading a volunteer initiative aiming to accelerate sustainable innovations in organizations through the development of intrapreneurial leaders.

Isabelle Deschamps is a Professional Engineer, Business Manager, Coach and Entrepreneur active in Tech Incubation, Venture Capital, Intellectual Property Strategy and Hi-Tech Financing. In her 35-year career, she has been involved with 100 start-ups, SMEs and R\&D groups in Information Technologies, new materials, 3D print, CleanTech and Medical devices. Isabelle is a recognized professor and researcher (HEC Montreal, ÉTS and Polytechnique Montreal). She is a speaker and expert in technology entrepreneurship, innovation \& product management, science and technology policy \& ecosystems, and SME financing. Isabelle advises Canadian industrial clusters, $R \& D$ consortia, governmental agencies and ecosystem members, such as National Research Council Canada, Prima Quebec, Aero Montreal and TechnoMontreal. She specialized in longitudinal and action research field studies and has published on technology implementation, crisis management, open and collaborative innovation, and start-up incubation. Isabelle is a metallurgist (Polytechnique Montreal) and holds an MBA (HEC Montreal) and a DBA (Harvard Business School). 


\section{How to Develop Innovation KPIs in an Execution-Oriented Company}

\section{Victoria Lakiza and Isabelle Deschamps}

\section{References}

Atkinson, A. A., Waterhouse, J. H., \& Wells, R. B. 1997. A Stakeholder Approach To Strategic Performance Measurement. Sloan Management Review, 38(3): 25.

Bremser, W. G., \& Barsky, N. P. 2004. Utilizing the Balanced Scorecard for $R \& D$ Performance Measurement. R\&D Management, 34(3): 229-238.

https://doi.org/10.1111/j.1467-9310.2004.00335.x

Brodeur, J., Deschamps, I., \& Lakiza, V. 2017. NPD Implementation: Beyond Best Practices. Paper presented at the ISPIM Innovation Forum, Toronto, Canada, March 19-22.

Brophey, G., Baregheh, A., \& Hemsworth, D. 2013. Innovation Process, Decision-Making, Perceived Risks and Metrics: A Dynamics Test. International Journal of Innovation Management, 17(3): 1340014.

https://doi.org/10.1142/S1363919613400148

Brophey, G., \& Brown, S. 2009. Innovation Practices within Small to Medium-Sized Mechanically-Based Manufacturers. Innovation, 11(3): 327-340. https://doi.org/10.5172/impp.11.3.327

Cameron, W. B. 1963. Informal Sociology: A Casual Introduction to Sociological Thinking. New York: Random House.

Christensen, C. M. 1997. The Innovator's Dilemma: When New Technologies Cause Great Firms to Fail. Boston, MA: Harvard Business School Press.

Cirka, C. 1997. A Piece of the Puzzle: Employee Responses to Control Practices and Effects on Firm Control Strategy. Philadelphia, PA: Temple University Press.

Clark, K. B., \& Fujimoto, T. 1991. Product Development Performance: Strategy, Organization, and Management in the World Auto Industry. Boston, MA: Harvard Business School Press.

Collins, J., \& Smith, D. 1999. Innovation Metrics: A Framework to Accelerate Growth. Prism, 2: 33-48.

Cooper, R. G., \& Edgett, S. J. 1996. Critical Success Factors for New Financial Services. Marketing Management, 5(3): 26

Covin, J. G., \& Slevin, D. P. 1991. A Conceptual Model of Entrepreneurship as Firm Behavior. Entrepreneurship Theory and Practice, 16(1): 7-25.

https://doi.org/10.1177/104225879101600102

Dewangan, V., \& Godse, M. 2014. Towards a Holistic Enterprise Innovation Performance Measurement System. Technovation, 34(9): 536-545.

https://doi.org/10.1016/j.technovation.2014.04.002

Gama, N., Da Silva, M. M., \& Ataíde, J. 2007. Innovation Scorecard: A Balanced Scorecard for Measuring the Value Added by Innovation. In P. F. Cunha, \& P. G. Maropoulos (Eds.), Digital Enterprise Technology: Perspectives and Future Challenges: 417-424. Boston, MA: Springer US

Garengo, P., Biazzo, S., \& Bititci, U. S. 2005. Performance Measurement Systems in SMEs: A Review for a Research Agenda. International Journal of Management Reviews, 7(1): 25-47. https://doi.org/10.1111/j.1468-2370.2005.00105.x
Godener, A., \& Soderquist, K. E. 2004. Use and Impact of Performance Measurement Results in R\&D and NPD: An Exploratory Study. R\&D Management, 34(2): 191-219. https://doi.org/10.1111/j.1467-9310.2004.00333.x

Gomes, J., \& Pearson, A. 2001. Effect of NPD Stages and Product Innovativeness on the Relationship Between Functional Integration and Performance. In Proceedings of the 8th EIASM International Product Development Management Conference: 361-372. Enschede, Netherlands: University of Twente.

Griffin, A. 1997. PDMA Research on New Product Development Practices: Updating Trends and Benchmarking Best Practices. Journal of Product Innovation Management, 14(6): 429-458. https://doi.org/10.1111/1540-5885.1460429

Griffin, A., \& Page, A. L. 1993. An Interim Report on Measuring Product Development Success and Failure. Journal of Product Innovation Management, 10: 291-308. https://doi.org/10.1111/1540-5885.1040291

Griffin, A., \& Page, A. L. 1996. PDMA Success Measurement Project: Recommended Measures for Product Development Success and Failure. Journal of Product Innovation Management, 13(6): 478-496. https://doi.org/10.1111/1540-5885.1360478

Hart, S., Hultink, E. J., Tzokas, N., \& Commandeur, H. R. 2003. Industrial Companies' Evaluation Criteria in New Product Development Gates. Journal of Product Innovation Management, 20(1): 22-36. https://doi.org/10.1111/1540-5885.201003

Hiebl, M. R. W. 2015. Family Involvement and Organizational Ambidexterity in Later-Generation Family Businesses. Management Decision, 53(5): 1061-1082. https://doi.org/10.1108/MD-04-2014-0191

Hitt, M. A., Hoskisson, R. E., Johnson, R. A., \& Moesel, D. D. 1996. The Market for Corporate Control and Firm Innovation. Academy of Management Journal, 39(5): 1084-1119. https://doi.org/10.5465/256993

Houllier, G. 2017. Implantation d'un processus de gestion agile des opportunités d'innovation contractuelles dans une entreprise manufacturière. Montreal: Polytechnique Montreal.

Jiménez-Zarco, A. I., Martínez-Ruiz, M. P., \& González-Benito, Ó. 2006. Performance Measurement Systems (PMS) Integration into New Product Innovation: A Literature Review and Conceptual Framework. Academy of Marketing Science Review, 9(10): 1-16.

Kaplan, R. S., \& Norton, D. P. 1992. The Balanced Scorecard: Measures that Drive Performance. Harvard Business Review, 70(1): $71-79$

Kaplan, R. S., \& Norton, D. P. 1996. Using the Balanced Scorecard as a Strategic Management System. Harvard Business Review, 74(1): 75-85.

Kaplan, R. S., \& Norton, D. P. 2001. Transforming the Balanced Scorecard from Performance Measurement to Strategic Management: Part I. Accounting Horizons, 15(1): 87-104 https://doi.org/10.2308/acch.2001.15.1.87

Kerssens-van Drongelen, I. C. 1999. Systematic Design of $R \& D$ Performance Measurement Systems. Enschede, Netherlands: Universiteit Twente. 


\section{How to Develop Innovation KPIs in an Execution-Oriented Company}

\section{Victoria Lakiza and Isabelle Deschamps}

Kerssens-van Drongelen, I. C., \& Bilderbeek, J. 1999. R\&D Performance Measurement: More than Choosing a Set of Metrics. R\&D Management, 29(1): 35-46.

https://doi.org/10.1111/1467-9310.00115

Kerssens-van Drongelen, I. C., Nixon, B., \& Pearson, A. 2000. Performance Measurement in Industrial $\mathrm{R} \& \mathrm{D}$. International Journal of Management Reviews, 2(2): 111-143. https://doi.org/10.1111/1468-2370.00034

Kirchhoff, B. A., Linton, J. D., \& Walsh, S. T. 2013. Neo-Marshellian Equilibrium versus Schumpeterian Creative Destruction: Its Impact on Business Research and Economic Policy. Journal of Small Business Management, 51(2): 159-166. https://doi.org/10.1111/jsbm.12018

Kuratko, D. F., Covin, J. G., \& Hornsby, J. S. 2014. Why Implementing Corporate Innovation Is So Difficult. Business Horizons, 57(5): 647-655.

https://doi.org/10.1016/j.bushor.2014.05.007

Lakiza, V. 2018. Relationships Between Performance Measurement Systems, Intrapreneurial Culture and Innovation Capabilities: A Longitudinal Field Case Study. Montreal: Polytechnique.

Lakiza, V., Deschamps, I., \& Brodeur, J. 2017. Propelling Innovation: The Role of Intrapreneurial Culture and Performance Measurement. Paper presented at the ISPIM Innovation Forum, Toronto, Canada, March 19-22.

Lynch, R. L., \& Cross, K. F. 1991. Measure Up! Yardsticks for Continuous Improvement. Oxford: Blackwell Business.

Marginson, D. E. W. 2002. Management Control Systems and Their Effects on Strategy Formation at Middle-Management Levels: Evidence from a U.K. Organization. Strategic Management Journal, 23(11): 1019-1031.

https://doi.org/10.1002/smj.271

McAdam, R. 2000. Quality Models in an SME Context. International Journal of Quality \& Reliability Management, 17(3): 305-323. https://doi.org/10.1108/02656710010306166

McAdam, R., \& Keogh, W. 2004. Transitioning Towards Creativity and Innovation Measurement in SMEs. Creativity and Innovation Management, 13(2): 126-139.

https://doi.org/10.1111/j.0963-1690.2004.00300.x

Morris, L. 2009. Business Model Innovation The Strategy of Business Breakthroughs. International Journal of Innovation Science, 1(4): 191-204.

https://doi.org/10.1260/1757-2223.1.4.191

Morris, M. H., Allen, J., Schindehutte, M., \& Avila, R. 2006. Balanced Management Control Systems as a Mechanism for Achieving Corporate Entrepreneurship. Journal of Managerial Issues: 468-493.

https://www.jstor.org/stable/40604554

Morris, M. H., \& Kuratko, D. F. 2002. Corporate Entrepreneurship: Entrepreneurial Development Within Organizations. Nashville, TN: South-Western Publishing Group.

Neely, A. D., Adams, C., \& Kennerley, M. 2002. The Performance Prism: The Scorecard for Measuring and Managing Business Success. London: Financial Times/Prentice Hall.
Neely, A. D., Mills, J., Platts, K., Richards, H., Gregory, M., Bourne, M., \& Kennerley, M. 2000. Performance Measurement System Design: Developing and Testing a Process-Based Approach. International Journal of Operations \& Production Management, 20(10): $1119-1145$. https://doi.org/10.1108/01443570010343708

Neely, A. D., Richards, H., Mills, J., Platts, K., \& Bourne, M. 1997. Designing Performance Measures: A Structured Approach. International Journal of Operations \& Production Management, 17(11): 1131-1152. https://doi.org/10.1108/01443579710177888

Ojanen, V., \& Vuola, O. 2005. Coping with the Multiple Dimensions of $\mathrm{R} \& \mathrm{D}$ Performance Analysis. International Journal of Technology Management, 33(2-3): 279-290. https://doi.org/10.1504/IJTM.2006.008315

Olsson, A., Wadell, C., Odenrick, P., \& Bergendahl, M. N. 2010. An Action Learning Method for Increased Innovation Capability in Organisations. Action Learning: Research and Practice, 7(2): 167-179. https://doi.org/10.1080/14767333.2010.488328

Oriot, F., \& Misiaszek, E. 2012. Le Balanced Scorecard au filtre d'une PME française. Ou pourquoi les PME préferent le "sur-mesure". Revue française de gestion, 38(225): 27-43. http://doi.org/10.3166/rfg.225.27-43

Patton, M. Q. 1987. How to Use Qualitative Methods in Evaluation. Thousand Oaks, CA: Sage.

Perez-Freije, J., \& Enkel, E. 2007. Creative Tension in the Innovation Process: How to Support the Right Capabilities. European Management Journal, 25(1): 11-24. https://doi.org/10.1016/j.emj.2006.11.005

Petersen, A. M., Jung, W. S., Yang, J.-S., \& Stanley, H. E. 2010. Quantitative and Empirical Demonstration of the Matthew Effect in a Study of Career Longevity. Proceedings of the National Academy of Sciences, 108(1): 18-23.

https://doi.org/10.1073/pnas.1016733108

Pinchot III, G. 1985. Intrapreneuring: Why You Don't Have to Leave the Corporation to Become an Entrepreneur. New York: Harper and Row.

Rao, J., \& Weintraub, J. 2013. How Innovative Is Your Company's Culture? MIT Sloan Management Review, 54(3): 9.

Ries, E. 2011. The Lean Startup: How Today's Entrepreneurs Use Continuous Innovation to Create Radically Successful Businesses. Washington, DC: Crown Books.

Röglinger, M., Pöppelbuß, J., \& Becker, J. 2012. Maturity Models in Business Process Management. Business Process Management Journal, 18(2): 328-346. https://doi.org/10.1108/14637151211225225

Saunila, M. 2016. Performance Measurement Approach for Innovation Capability in SMEs. International Journal of Productivity and Performance Management, 65(2): 162-176. https://doi.org/10.1108/IJPPM-08-2014-0123

Shih, M. S. H., \& Yong, L.-C. 2001. Relationship of Planning and Control Systems with Strategic Choices: A Closer Look. Asia Pacific Journal of Management, 18(4): 481-501. https://doi.org/10.1023/A:1012875326074 


\section{How to Develop Innovation KPIs in an Execution-Oriented Company \\ Victoria Lakiza and Isabelle Deschamps}

Storey, C., \& Kelly, D. 2001. Measuring the Performance of New Service Development Activities. Service Industries Journal, 21(2): 71-90.

https://doi.org/10.1080/714005018

Vorbach, S., \& Perl, E. 2007. Decision Making in Innovation Processes: A Concept to Support Small and Medium Sized Enterprises. Journal of Automation Mobile Robotics and Intelligent Systems, 1(4): 3-15.

Werner, B. M., \& Souder, W. E. 1997. Measuring R\&D Performance State of the Art. Research Technology Management, 40(2): 34-42. https://doi.org/10.1080/08956308.1997.11671115

Wolpert, J. D. 2002. Breaking Out of the Innovation Box. Harvard Business Review, 80(8): 76-83.

Citation: Lakiza, V., \& Deschamps, I. 2018. How to

Develop Innovation KPIs in an Execution-Oriented

(cc) BY

Company. Technology Innovation Management Review

8(7): 14-30. http://doi.org/10.22215/timreview/1168

Keywords: KPI, organizational culture, innovation, PMS, case study, action research, performance measurement, execution orientation, innovation capabilities 


\title{
The Role of Middle Managers in the Implementation of a Corporate Incubator: A Case Study in the Automotive Sector
}

\author{
Rebecca Hirte
}

\author{
"(Ideas are a commodity. Execution of them is not. ") \\ Michael Dell \\ Dell Chairman and CEO
}

\begin{abstract}
Lately, there has been a growing tendency of corporations to establish corporate incubators as a strategic tool of transformation. However, the managers of those incubators are often lacking the appropriate knowledge and experience when it comes to setting the right framework for implementing such novel innovation units. In this context, the role of middle managers needs to be re-evaluated in order to support them with the right toolset for such an endeavour to become successful. This article analyzes the role of middle managers in the implementation of a corporate incubator by conducting an in-depth single case study within a large German automotive company. In addition to insights from a comprehensive literature review, the study's interviews with 13 experts reveal challenges as well as key success factors from the perspective of middle managers on the stated research problem. In particular, the ability of middle managers to influence employees and top management has been considered with the aim of avoiding resistance and failure. The findings from this study contribute to the research streams of corporate incubation and middle management. In addition, the findings are particularly relevant for managers of large corporations who are facing the challenge of transforming their organization due to digitalization and unpredictable developments in the market.
\end{abstract}

\section{Introduction}

Currently, established corporations are facing significant challenges due to digital transformation, which is blurring borders between traditional sectors and new market entrants, which in turn, affect the corporations' innovation endeavours (Gao et al., 2016). Thus, in order to advance their innovation activities, many large corporations implement new centres of innovation, for example, corporate incubators, where employees have the opportunity to work on new business models within a protected environment (Klandt \& Brüning, 2002).

According to Weiblen and Chesbrough (2015), corporate incubators aim to provide an atmosphere in which "innovation can grow better than in the slow and bureaucratic parent organization". In connection with this, corporate incubators represent a strategic tool for re-defining established processes and structures, which creates a non-bureaucratic environment (Ford et al., 2010).
Existing incubation literature mainly focuses on the classification of different types of incubators (e.g., Barbero et al., 2012) and the impact on their environment (e.g., Colombo \& Delmastro, 2002). The latter research stream particularly incorporates studies on incubator tenants as well as economic spill-over effects (Becker \& Gassmann, 2006). However, the challenge of successfully implementing such a novel innovation unit within an established corporation from the perspective of middle managers has been neglected by researchers so far.

In general, corporate incubators are classified at the intersection between corporate venturing and business incubation (Ford et al., 2010) and therefore refer to the corporate entrepreneurship literature. Hereby, a decentralized innovation approach as well as a high degree of management support are considered essential (e.g., Scheepers, 2011). Thus, the role of middle managers as an interface between employees and top management (Balogun, 2007) should be included in this context. 


\section{The Role of Middle Managers in the Implementation of a Corporate Incubator: A Case Study in the Automotive Sector Rebecca Hirte}

Research on middle management highlights two major streams: the strategic contribution of middle managers within organizations and their role in connection with organizational change (Rezvani, 2017). To date, no explicit research on middle management in the field of corporate incubation has been conducted, which indicates a significant gap.

Given that middle managers often struggle with applying the right measures for a successful implementation of new entities (Floyd \& Woolridge, 1994; Kuyvenhoven \& Buss, 2011), and especially due to the role of a lack of specific knowledge about their specific function and expertise in connection with the case of corporate incubation (e.g., Hornsby et al., 2002), avoiding a high risk of failure requires a deeper analysis of this issue. This research aims to combine the research fields of corporate incubation and middle management in order to contribute to closing the mentioned research gaps. Furthermore, practical recommendations for the successful implementation of a corporate incubator would be relevant to middle and upper management of such incubators. Therefore, the following research question has been analyzed:

\section{What challenges occur during the implementation of a corporate incubator and how can middle managers successfully guide this process?}

In order to provide a more detailed understanding of the research topic, the following section depicts the theoretical framework of the outlined problem statement. In addition, the presented research question is analyzed by the aid of 13 qualitative expert interviews that highlight practical lessons learned, critical success factors, and challenges within the studied context. Finally, the conclusion of this article incorporates relevant implications for research and practice, as well as limitations of this study.

\section{Theoretical Framework}

\section{Corporate incubators as a catalyst for innovation}

The concept of incubation dates back to 1959 when a large factory building was provided to several founders and small firms for a favourable fee (Adkins, 2002). Throughout the years, incubators developed from offering infrastructure in form of affordable office space and shared resources in the first generation (Lalkaka, 2000) to the current approach of supporting various facets of novel ventures by financial support, shared resources, office space, business support, and access to networks (Hansen et al., 2000).
Corporate incubators represent an instrument of typically large corporations to enhance their R\&D-based innovation activities with the aim of developing novel business opportunities (Gassmann \& Becker, 2006b). According to Smilor (1987), corporate incubators are "managed as professional service firms, acting in the larger interest of their parent corporation while leveraging their knowledge networks". Furthermore, several studies describe them as "specialized corporate units that hatch new businesses by providing physical resources and support" (Colombo \& Delmastro, 2002; Hansen et al., 2000; Seidel, 2001). Based on their analysis of 25 case studies, Becker and Gassmann (2006) proposed four different archetypes of corporate incubators: the fast profit incubator, the leveraging incubator, the in-sourcing incubator, and the market incubator.

Such new incubation entities are applied by firms in order to enable small and agile teams to operate within a flexible and non-bureaucratic environment. Thereby, involved employees are encouraged to adopt new perspectives and apart from their usual way of thinking, which at the same time has the potential to speed up their operations (Ford et al., 2010; Von Zedtwitz, 2003). In connection with this, existing research shed light on the incubation process, which basically incorporates three phases: pre-incubation, incubation, and post-incubation (e.g., Bergek \& Norrman, 2008; Hackett \& Dilts, 2004). During the pre-incubation phase, the screening and selection of incubator tenants take place, as well as the preparation of the program with respect to (financial) resources (Gassmann \& Becker, 2006a). The main incubation phase refers to the incubator's support services for business development (Gerlach \& Brem, 2015) and the post-incubation phase addresses the ventures' exit and consolidation (Ratinho, 2011).

Furthermore, a significant number of studies focuses on a corporate incubator's impact on its environment, which for instance depends on the selection criteria of tenants (e.g., Bergek \& Norrman, 2008; Hackett \& Dilts, 2004; Soetanto, 2004). Several studies attempt to define success factors for the outcome of corporate incubation and thereby, for instance, refer to client-specific metrics (Bøllingtoft \& Ulhøi, 2005; Lee \& Osteryoung, 2004). According to Allen and McCluskey (1991), the value proposition of incubators strongly depends on the provided infrastructure and other service offers, which is supported by several authors (De Cleyn et al., 2013; Hansen et al., 2000; Lewis, 2002;). While existing studies provide valuable insights for the corporate incubation approach itself, the last phase after the incubation as 


\section{The Role of Middle Managers in the Implementation of a Corporate Incubator: A Case Study in the Automotive Sector Rebecca Hirte}

well as the implementation of such an entity beforehand have been rather neglected so far. However, as both aspects also seem to be significant for the outcome of incubation, this study has the aim to provide a contribution to this gap in the research.

Given that corporate incubators represent a strategic tool for organizations, which entails change and transformation, the capabilities of managers - especially on an intermediate level - to steer such an endeavour becomes highly relevant with respect to a diligent implementation and employees' perception of such a new unit.

\section{The middle manager's role within an organization}

The importance of middle managers in contemporary organizations was first addressed by the study of Bower in 1970. In this context, Uyterhoeven (1989) defined a middle manager as "a general manager who is responsible for a particular business unit at the intermediate level of the corporate history". Existing studies incorporate intensive research on the role of middle managers within firms (e.g., Fenton-O'Creevy, 2000; Raghu Raman, 2009), their impact on employee involvement (Fenton-O'Creevy, 1998), or human resources and middle managers (Currie \& Procter, 2001). In addition, several key studies need to be mentioned in the context of middle management, such as Floyd and Wooldridge's (1992) analysis of the strategic role of middle managers or Wang and Schneider's (2003) longitudinal study on the dynamics of multicultural leadership team development.

Further research has analyzed the role of middle managers and their contributions in connection with entrepreneurship and strategy (e.g., Drucker, 1985; Pinchott, 1985; Zahra, 1991). In particular, middle managers take on the following roles for effective corporate entrepreneurship: innovator, risk taker, and facilitator of organizational learning (Burgess, 2013). Quinn (1985) highlighted the value and importance of middle managers in connection with the innovation process of established corporations. Furthermore, a middle manager's expertise (Raghu Raman, 2009) with regards to the firm's internal environment has the potential to positively influence systems, processes, and the management of resources (Geisler, 1993), and therefore their contribution to corporate entrepreneurship (Burgess, 2013). As most senior managers do not actively participate in any day-to-day operations, middle managers represent a crucial vehicle for communicating the firm's mission, goals, and priorities to employees. Thereby, they apply formal as well as informal ap- proaches to support idea generation and innovations within the firm's strategic framework (Burgelman, 1983). Furthermore, middle managers encourage corporate entrepreneurial activities by providing rewards and allowing their staff to take risks (Kanter, 1985). According to Schiersmann and Thiel (2008), particularly within large organizations, middle management is often responsible for the promotion of agility and transformation. Therefore, the attitude and initiative of middle managers decisively impact the success of any organizational transformation initiative (e.g., Osterman, 2009).

Besides an extensive body of research on middle management within several fields, the role of middle managers has not been analyzed in connection with corporate incubators, which depicts a rather new scenario for firms in transition. Therefore, the following analysis aims to tackle this research gap using an in-depth single case study approach.

\section{Methodological Approach}

In order to analyze the depicted problem statement, this research relies on the methodological approach of an in-depth single case study based on qualitative data. According to Yin (2011), this research design is especially suitable for studies in underexplored research areas. Furthermore, single case studies are recommended if researchers seek deeper understanding of the subject and want to study a group of people.

The presented case study has been conducted in collaboration with a large multinational German corporation from the automotive sector. This type of organization is often characterized by practitioners and scholars as reluctant to change (e.g., Brunninge et al., 2007). This research object was also chosen because its innovation endeavours, corporate structure, and culture are considered comparable to many established global players of the manufacturing sector and, thus, the findings may be applicable beyond the automotive industry. Furthermore, the selected organization had been in the process of implementing an organization-wide cultural change program during the time of data collection. This endeavour included several corporate initiatives, such as building up a corporate incubator in order to foster intrapreneurship and business model innovations among all employees.

Qualitative data in form of 13 expert interviews with middle managers was collected between March and April in 2017 using the approach of Gläser and Laudel 


\section{The Role of Middle Managers in the Implementation of a Corporate Incubator: A Case Study in the Automotive Sector Rebecca Hirte}

(2010). Thereby, the interview subjects were selected such that the diversity of sex, age (between 33 to 57 years), working area, and seniority (5.5 years on average) covered a broad perspective. However, all experts were required to be team leaders or department heads. Three experts were familiar with the concept of a corporate incubator; the others were not. Furthermore, all experts were German and have been working in German locations within the organization. The preparation of a semi-structured interview guideline incorporated a prior analysis of internal documents, preliminary talks with middle managers, as well as academic conclusions of existing studies in business psychology and related fields (e.g., Faulbaum et al., 2009).

In order to avoid biased responses, the selected experts were asked about their assessment of peer behaviour among other middle managers in connection with the introduction of the corporate incubator. Altogether, the experts referred to concrete issues and solution approaches derived from their day-to-day experience within their field of operation. In addition to the collected qualitative data, further internal and external data as well as presentations and studies have been taken into account in order to enhance the validity of the material. The collected data was analyzed by qualitative content analysis according to Mayring (2015). In order to create a system of categories, the transcribed data material has been coded by the aid of several theoretical change models, as described earlier.

\section{Findings}

The presented case study has identified challenges as well as key measures middle managers can undertake in order to successfully implement a corporate incubator and the accompanied transformation. Therefore, depicted statements of interviewed experts have been aligned with existing theoretical approaches and models. The following section describes conducted findings with the aid of anchor citations that represent essential lessons learned from practice. In addition, the mentioned challenges and success factors are divided according to individual and organizational perspectives.

Based on the role of middle managers as change agents in the existing literature, this study particularly considered their change orientation, which refers to their efforts to foster change. Even though prior internal analyses indicated a negative correlation between age and change orientation, the analyzed qualitative data has not validated this assumption. Demographic data, in- cluding age or period of employment, could not have been connected to the experts' willingness to change. However, longer employment with the company led to a subtle feeling of security. Furthermore, all interviewed experts indicated that they have experienced several transformation initiatives before the analyzed implementation of a corporate incubator. However, none of them expressed the feeling of urgency at the beginning of such challenges:

"No, not really. So far, my work life has been shaped by the concern of competitors outperforming us. But I've never experienced any fear of working in an industry that might soon not exist anymore." (Expert 6)

In this case, middle managers seem to underestimate the sense of urgency, which is addressed by the initiated implementation of a novel innovation unit. As also highlighted by Kotter (2012), this attitude is often found in large corporations, where employees and managers rely on past successes and high availability of resources. Consequently, middle managers will eventually transfer this attitude to their teams.

Referring to Lewin's (2012) field theory, involved experts clearly validated the required balance between accelerating and retarding forces, which is expressed by the need for resting periods within a change process:

\section{"And you also need some periods for recovery from change. Your employees need phases in which they can establish continuity and operational excel- lence." (Expert 6)}

Accordingly, in connection with the implementation of a corporate incubator, middle managers highlight the importance of time for employees to get used to such a new entity in order to adopt novel working conditions.

The collected qualitative data reveals that middle managers' understanding of their own role during the implementation of a corporate incubator incorporates the following descriptions: driver, expert, enabler, innovator, pacemaker, motivator, and project lead. Accordingly, the self-perception of their role mainly refers to their supporting function and to enabling their employees to become innovators from the bottom-up. However, several statements indicated that the responsibility of middle managers still needs to be adapted to advanced requirements of a more agile innovation environment: 


\section{The Role of Middle Managers in the Implementation of a Corporate Incubator: A Case Study in the Automotive Sector Rebecca Hirte}

\begin{abstract}
"I believe that there certainly is a need for action. I clearly see the responsibility of a modern manager in terms of supporting this change process, and I think we need to do more and become broader in this context." (Expert 5)
\end{abstract}

With respect to middle managers' ability to influence employees' perception of a novel incubation unit, their impact on employees has been described as the following:

\begin{abstract}
"I can either motivate them by saying that I'm convinced of this initiative and highlighting the advantages or I could also cause the opposite - if I was a bad manager." (Expert 10)
\end{abstract}

Moreover, most experts stated the important aspect that their own ambition towards transformation needs to be integrated within their team in order to be successful:

\section{"I believe the most important aspect refers to the team's ability to have an impact on such initiatives. So the team has to say which processes are necessary and important from their point of view. And I need to listen to them and include their opinions and feedback. I need to define the right methods and processes together with my team." (Expert 3)}

In this context, opportunities for middle managers to receive individual training have been addressed. In general, the analyzed corporation offered plenty of workshops in the field of change management, which certainly supports their efforts in implementing a new work environment. However, middle managers complained about missing capacity for participating in these measures. With respect to their superiors, all middle managers explained that their power of influence on top-managers seems to be high as well, even though this type of relationship requires "more effort" (Expert 7). In this context, included experts especially mentioned that top-managers mostly accept their proposals and support their ideas:

"Yes, in principle they depend on my input. Obviously, it only works like this." (Expert 4)

In addition to providing a better understanding of the role of middle managers in the implementation of a corporate incubator, the following section highlights challenges that might lead to resistance and failure of such transformation initiatives. Furthermore, success factors in the studied context on an individual and organizational level have been suggested in order to prevent fail- ure. On an individual level, middle managers refer to challenges being based on the following aspects: willingness to adapt to new work environment by established employees (Expert 1), need for security (Expert 2 ), feeling of too rapid change (Expert 7), strong micromanagement (Expert 9), and need for different and novel skills of employees (Expert 5). In addition, on an organizational level, middle managers feel like their decision making is negatively affected by their area of responsibility that is too extensive (Expert 1, Expert 2, and Expert 9). Furthermore, missing transparency and communication (Expert 2, Expert 4, Expert 7, and Expert 9) were named, as well as a mismatch between agile project management for radical innovation projects and existing corporate structures and processes (Expert 2). Another statement refers to barriers to collaboration between small businesses or new ventures and corporates in the field of innovation (Expert 6). Last but not least, little cooperation between internal business units is considered as a challenge (Expert 6). With respect to the implementation of a corporate incubator in particular, Expert 1 suggested the compensation of temporary capacity loss during the time of incubation as an essential challenge that needs to be addressed by appropriate measures in advance. Furthermore, Expert 4 highlighted additional personnel requirements in case of a spin-off after a successful incubation.

In contrast, several key measures for a successful implementation of a corporate incubator have been named by the interviewed middle managers. These include the following dimensions on an individual level: decisionmaking by operative teams (Expert 1), open feedback culture (Expert 2), team goals instead of individual goals (Expert 3), feeling of responsibility (Expert 3), as well as exemplifying culture of change by middle and top management (Expert 4). Furthermore, on an organizational level, the appointment of an additional board member who is responsible for digital transformation and the accompanied change, in particular, is considered crucial (Expert 3). The reduction of hierarchy levels and increased responsibility of employees (Expert 4), as well as target-group-specific communication about required changes (Expert 6 and Expert 7), reinforced job-rotation of middle managers for an increased portfolio of experience (Expert 6), and an early detection and elimination of less promising projects (Expert 3) were named as well. Regarding the implementation of a corporate incubator, the interviewed experts mentioned the following success factors: ensuring sufficient and skilled workforce as temporary replacement (all experts), flexible working hours for increased innovation activities and training (Expert 2), systematic 


\section{The Role of Middle Managers in the Implementation of a Corporate Incubator: A Case Study in the Automotive Sector Rebecca Hirte}

enhancement of employee motivation for intrapreneurship activities (Expert 1), and stronger exchange with the external startup world in order to learn and adopt new processes (Expert 3).

In summary, the findings represent helpful insights for the successful implementation of a corporate incubator, which requires a new and agile working environment (see Table 1). Thereby, middle managers have the opportunity to make use of their decisive role within their organization and positively impact employees during times of transformation. Presented challenges and success factors will help corporations to initiate the management of such new innovation entities.

\section{Conclusion}

This research has combined existing perceptions of middle management with the case of implementing a corporate incubator, which has not been addressed by existing studies so far. As middle managers have been depicted as decisive actors within change projects and organizational transformation in general, the presented study has focused on their role within a new context. Thereby, several existing studies have been complemented by considering a current case. The suggested findings represent a basis for future studies that can further research in the field of middle management as well as corporate incubation.

Table 1. The perspectives of middle managers on the successful implementation of a corporate incubator

\begin{tabular}{|c|c|}
\hline \multicolumn{2}{|c|}{$\begin{array}{l}\text { A Middle Manager's Role: } \\
\text { oler-innovator-pacemaker-motivator-project lead }\end{array}$} \\
\hline Key Challenges & Key Success Factors \\
\hline $\begin{array}{l}\text { Individual level } \\
\begin{array}{l}\text { - Willingness to adapt to a new work environment } \\
\text { - Need for security } \\
\text { - Feeling of too-rapid change } \\
\text { - Strong micro-management } \\
\text { - Need for different/novel skills }\end{array}\end{array}$ & $\begin{array}{l}\text { Individual level } \\
\text { - Decision making by operative teams } \\
\text { - Open feedback culture } \\
\text { - Team goals instead of individual goals } \\
\text { - Feeling of responsibility } \\
\text { - Exemplifying cultural change by managers }\end{array}$ \\
\hline 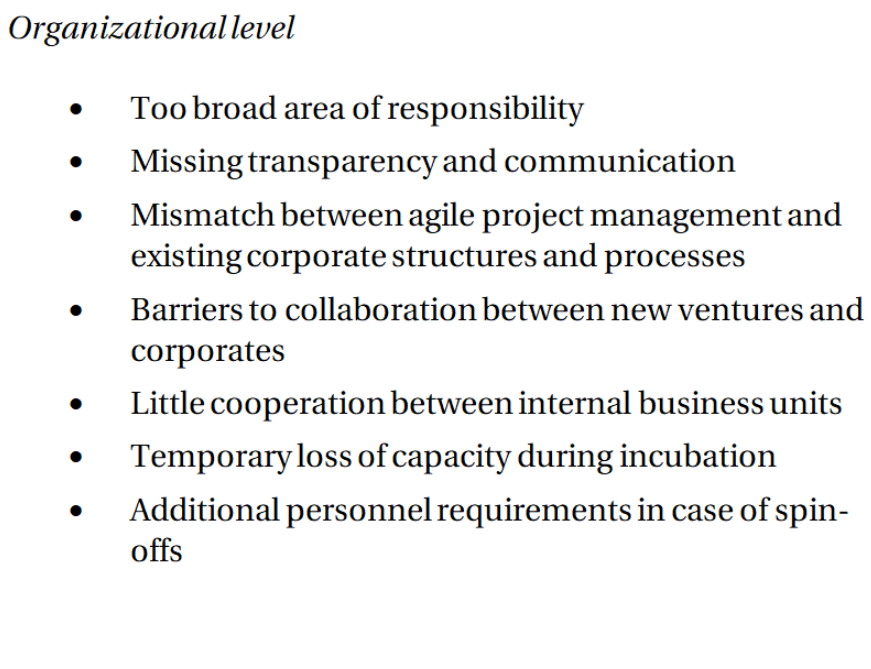 & $\begin{array}{l}\text { Organizationallevel } \\
\text { - } \text { Appointment of board member for transformation } \\
\text { - Reduction of hierarchy levels } \\
\text { - Target-group specific communication } \\
\text { - Reinforced job rotation for increased portfolio of } \\
\text { - Experience } \\
\text { - Ensuring personnel with required skills } \\
\text { - } \text { activities } \\
\text { - Systematic enhancement of employees' motivation } \\
\text { - Strong exchange with external startup world for } \\
\text { knowledge spillovers }\end{array}$ \\
\hline
\end{tabular}




\section{The Role of Middle Managers in the Implementation of a Corporate Incubator: A Case Study in the Automotive Sector Rebecca Hirte}

The findings from this study are particularly relevant for managers of large corporations who are facing the challenge of transforming their organization due to digitalization and unpredictable developments in the market. Corporate incubators are becoming an increasingly popular instrument for many corporations in order to advance their innovation activities. However, managers still struggle regarding their successful implementation, as many lessons learned can only be revealed after several years of running them in practice. Indeed, this study suffers from this same time limitation. A further limitation of this study is the restricted sample of selected experts, who all operate within one organization and the same cultural context. Further studies might enhance this approach by considering different organizations and regions. This study aims to support middle managers, who represent the interface between top management and employees, during the implementation of such an instrument for innovation and change. The findings from this research clearly outline challenges, as well as key measures from the perspective of a middle manager and thereby provide a basis for their decision making before and while they are building up a new entity for incubation.

\section{Acknowledgements}

This article was developed from a paper presented at the ISPIM Innovation Forum in Boston, USA, March 25-28, 2018. ISPIM (ispim-innovation.com) - the International Society for Professional Innovation Management - is a network of researchers, industrialists, consultants, and public bodies who share an interest in innovation management.

\section{About the Author}

Rebecca Hirte is pursuing her doctoral studies at the Karlsruhe Institute of Technology (KIT) in Germany at the Chair of Entrepreneurship and Technology Management (EnTechnon). Her research focuses on corporate innovation systems and their digital transformation. At the same time, she is working for a large German multinational automotive company in the field of business model innovation and corporate incubation. She holds Bachelor's and Master's degrees in International Business, and she has previously worked as a Research Assistant at the Fraunhofer Institute for Systems and Innovation Research (ISI).

\section{References}

Adkins, D. 2002. A Brief History of Business Incubation in the United States. Athens, OH: National Business Incubation Association.

Allen, D. N., \& McCluskey, R. 1991. Structure, Policy, Services and Performance in the Business Incubator Industry. Entrepreneurship: Theory and Practice, 15(2): 61-77. https://doi.org/10.1177/104225879101500207

Balogun, J. 2007. The Practice of Organizational Restructuring: From Design to Reality. European Management Journal, 25(2): 81-91. https://doi.org/10.1016/j.emj.2007.02.001

Balogun, J., \& Hope Hailey, V. 2008. Exploring Strategic Change. London: Prentice Hall.

Barbero, J. L., Casillas, J. C., Ramos, A., \& Guitar, S. 2012. Revisiting Incubation Performance - How Incubator Typology Affects Results. Technological Forecasting \& Social Change, 79(5): 888-902. https://doi.org/10.1016/j.techfore.2011.12.003

Bergek, A., \& Norrman, C. 2008. Incubator Best Practice: A Framework. Technovation, 28(1-2): 20-28. https://doi.org/10.1016/j.technovation.2007.07.008

Bøllingtoft, A., \& Ulhøi, J. P. 2005. The Networked Business Incubator - Leveraging Entrepreneurial Agency. Journal of Business Venturing, 20(2): 265-290.

Bower, J. L. 1970. Managing the Resource Allocation Process. Boston: Harvard Business School.

Brunninge, O., Nordqvist, M., \& Wiklund, J. 2007. Corporate Governance and Strategic Change: The Effects of Ownership, Board Composition and Top Management Teams. Small Business Economics, 29(3): 295-308. https://doi.org/10.1007/s11187-006-9021-2

Burgelman, R. A. 1983. Corporate Entrepreneurship and Strategic Management - Insights from a Process Study. Management Science, 29(12): 1349-1363.

https://doi.org/10.1287/mnsc.29.12.1349 


\section{The Role of Middle Managers in the Implementation of a Corporate Incubator: A Case Study in the Automotive Sector Rebecca Hirte}

Burgess, C. 2013. Factors Influencing Middle Managers' Ability to Contribute to Corporate Entrepreneurship. International Journal of Hospitality Management, 32: 193-201. http://psycnet.apa.org/doi/10.1016/j.ijhm.2012.05.009

Colombo, M. G., \& Delmastro, M. 2002. How Effective are Technologies? - Evidence from Italy. Research Policy, 31(7): 1103-1122.

https://doi.org/10.1016/S0048-7333(01)00178-0

Currie, G., \& Procter, S. 2001. Exploring the Relationship between HR and Middle Managers. Human Resource Management Journal, 11(3): 53-69.

https://doi.org/10.1111/j.1748-8583.2001.tb00045.x

De Cleyn, S. H., Gielen, F., \& Coppens, J. 2013. Incubation Programs from Public Research Organizations as Catalysts for Open Business Ecosystems. Technology Innovation Management Review, 3(4): 29-34.

https://timreview.ca/article/677

Drucker, P. F. 1985. The Discipline of Innovation. Harvard Business Review, 63: 67-72.

Faulbaum, F., Prüfer, P., \& Rexroth, M. 2009. Was ist eine gute Frage? (1st edition). Wiesbaden: VS Verlag für Sozialwissenschaften.

Fenton-O'Creevy, M. 2000. Middle Management Resistance to Strategic Change Initiatives: Saboteurs or Scapegoats. Managing Strategy Implementation. Oxford: Blackwell Publishers.

Floyd, S. W., \& Woolridge, B. 1992. Middle Management Involvement in Strategy and Its Association with Strategic Type: A Research Note. Strategic Management Journal, 13(S1): 153-167. https://doi.org/10.1002/smj.4250131012

Floyd, S. W., \& Woolridge, B. 1994. Dinosaurs or Dynamos? Recognizing Middle Management's Strategic Role. Academy of Management Executive, 8(4): 47-57. https://www.jstor.org/stable/4165222

Ford, S., Garnsey, E., \& Probert, D. 2010. Evolving Corporate Entrepreneurship Strategy: Technology Incubation at Philips. $R \& D$ Management, 40(1): 81-90. https://doi.org/10.1111/j.1467-9310.2009.00580.x

Gao, P., Kaas, H.-W., Mohr, D., \& Wee, D. 2016. Disruptive Trends that Will Transform the Auto Industry. Automotive \& Assembly Report January 2016. New York: McKinsey \& Company,

Gassmann, O., \& Becker, B. 2006a. Towards a Resource-Based View of Corporate Incubators. International Journal of Innovation Management, 10(1): 19-45.

https://doi.org/10.1142/S1363919606001387

Gassmann, O., \& Becker, B. 2006b. Gaining Leverage Effects in Knowledge Modes by Corporate Incubators. R\&D Management, 36(1): 1-16.

https://doi.org/10.1111/j.1467-9310.2005.00411.x

Geisler, E. 1993. Middle Managers as Internal Corporate Entrepreneurs: An Unfolding Agenda. Interfaces, 23(6): 52-63. https://doi.org/10.1287/inte.23.6.52

Gerlach, S., \& Brem, A. 2015. What Determines a Successful Business Incubator? Introduction to an Incubator Guide. International Journal of Entrepreneurial Venturing, 7(3): 286-307. https://doi.org/10.1504/IJEV.2015.071486

Gläser, J., \& Laudel, G. 2010. Experteninterviews und qualitative Inhaltsanalyse. Heidelberg: Springer.
Hackett, S. M., \& Dilts, D. M. 2004. A Real Options-Driven Theory of Business Incubation. The Journal of Technology Transfer, 29(1): 41-54. https://doi.org/10.1023/B:JOTT.0000011180.19370.36

Hansen, M. T., Chesbrough, H. W., Nohria, N., \& Sull, D. N. 2000. Networked Incubators: Hothouse of the New Economy. Harvard Business Review, 78(5): 74-84.

Hornsby, J. S., Kuratko, D. F., \& Zahra, S. A. 2002. Middle Manager's Perception of the Internal Environment for Corporate Entrepreneurship: Assessing a Measurement Scale. Journal of Business Venturing, 17(3): 253-273.

http://doi.org/10.1016/S0883-9026(00)00059-8

Kanter, R. M. 1985. Supporting Innovation and Venture Development in Established Companies. Journal of Business Venturing, 1(1): 47-60.

https://doi.org/10.1016/0883-9026(85)90006-0

Klandt, H., \& Brüning, E. 2002. Das internationale Gründungsklima. Neun Länder im Vergleich ihrer Rahmenbedingungen für Existenzund Unternehmensgründung. Berlin: Duncker \& Humboldt.

Kotter, J. 2012. Leading Change. München: Verlag Franz Wahlen $\mathrm{GmbH}$.

Kuyvenhoven, R., \& Buss, W.C. 2011. A Normative View of the Role of Middle Management in the Implementation of Strategic Change. Journal of Management and Marketing Research, 8(1): 1-14.

Lalkaka, R. 2000. Manual on Technology Business Incubators. Paris: United Nations Educational, Scientific \& Cultural Organization.

Lee, S. S., \& Osteryoung, J. S. 2004. A Comparison of Critical Success Factors for Effective Operations of University Business Incubation on the United States of Korea. Journal of Small Business Management, 42(2): 418-426.

https://doi.org/10.1111/j.1540-627X.2004.00120.x

Lewin, K. 2012. Feldtheorie in den Sozialwissenschaften (2nd edition). Bern: Hans Huber.

Lewis, D. A. 2002. Does Technology Incubation Work? A Critical Review of the Evidence. Research Series / National Business Incubation Association. Athens, OH: National Business Incubation Association.

Mayring, P. 2015. Qualitative Inhaltsanalyse - Grundlagen und Techniken (12th edition). Weinheim, Basel: Beltz Verlag.

Osterman, P. 2009. The Truth About Middle Managers - Who They Are, How They Work, Why They Matter (1st edition). Boston, MA: Harvard Business Press.

Pinchott, G. 1985. Intrapreneurship. New York: Harper \& Row.

Quinn, J. B. 1985. Managing Innovation: Controlled Chaos. Harvard Business Review, 63: 73-84.

Raghu Raman, S. 2009. Middle Managers' Involvement in Strategic Planning: An Examination of Roles and Influencing Factors. Journal of General Management, 34(3): 57-74. https://doi.org/10.1177/030630700903400304

Ratinho, T. F. 2011. Are They Helping? An Examination of Business Incubators' Impact on Tenant Firms. Dissertation. Enschede, Netherlands: University of Twente.

Rezvani, Z. 2017. Who Is a Middle Manager: A Literature Review. International Journal of Family Business and Management, 1(2): $1-9$. 


\section{The Role of Middle Managers in the Implementation of a Corporate Incubator: A Case Study in the Automotive Sector Rebecca Hirte}

Scheepers, M. 2011. Motivating Intrapreneurs: The Relevance of Rewards. Industry \& Higher Education, 25(4): 249-263.

https://doi.org/10.5367/ihe.2011.0051

Schiersmann, C., \& Thiel, H. 2008. Kompetenzen für die Zukunft: Lernen im Betrieb (1st edition). Baltmannsweiler: Schneider Verlag Hohengehren.

Seidel, V. 2001. Frontiers of Entrepreneurship Research. Wellesley, MA: Babson College.

Smilor, R. W. 1987. Managing the Incubator System - Critical Success Factors to Accelerate New Company Development. IEEE Transactions on Engineering Management, 34(3): 146-155. https://doi.org/10.1109/TEM.1987.6498875

Soetanto, D. P. 2004. Research of the Role of the Incubation Policy in Helping the Growth of New Technology Based Firms. Lisbon: Globelics Academy.

Uyterhoeven, H. 1989. General Managers in the Middle. Harvard Business Review, 67: 136-145.

Von Zedtwitz, M. 2003. Classification and Management of Incubators: Aligning Strategic Objectives and Competitive Scope for New Business Facilitation. International Journal of Entrepreneurship and Innovation Management, 3(1/2): 16-196.

http://dx.doi.org/10.1504/IJEIM.2003.002227

Wang, Z. M., \& Schneider, B. 2003. A Longitudinal Study on CrossCultural Leadership Team Development in 40 Chinese Local and Joint Venture Companies. In: Z. M. Wang (Ed.), China HR and OB Research Review. Shanghai: The Shanghai People's Press.

Yin, R. K. 2011. Qualitative Research from Start to Finish. New York: The Guilford Press.

Zahra, S. A. 1991. Predictors and Financial Outcomes of Corporate Entrepreneurship - An Exploratory Study. Journal of Business Venturing, 6(4): 259-286.

https://doi.org/10.1016/0883-9026(91)90019-A

Citation: Hirte, R. 2018. The Role of Middle Managers in the Implementation of a Corporate Incubator: A Case

Study in the Automotive Sector. Technology Innovation

Management Review, 8(7): 31-39.

http://doi.org/10.22215/timreview/1169

Keywords: corporate incubator, middle managers,

innovation management, case study, intrapreneurship 


\title{
A Topic Modelling Analysis of Living Labs Research \\ Mika Westerlund, Seppo Leminen, and Mervi Rajahonka
}

\author{
"If we have data, let's look at data. If all we have") \\ are opinions, let's go with mine.
}

Jim Barksdale

Former Netscape CEO

\begin{abstract}
This study applies topic modelling analysis on a corpus of 86 publications in the Technology Innovation Management Review (TIM Review) to understand how the phenomenon of living labs has been approached in the recent innovation management literature. Although the analysis is performed on a corpus collected from only one journal, the TIM Review has published the largest number of special issues on living labs to date, thus it reflects the advancement of the area in the scholarly literature. According to the analysis, research approaches to living labs can be categorized under seven broad topics: 1) Design, 2) Ecosystem, 3) City, 4) University, 5) Innovation, 6) User, and 7) Living lab. Moreover, each topic includes a set of characteristic subtopics. A trend analysis suggests that the emphasis of research on living labs is moving away from a conceptual focus on what living labs are and who is involved in their ecosystems to practical applications of how to design and manage living labs, their processes, and participants, especially users, as key stakeholders and in novel application areas such as the urban city context.
\end{abstract}

\section{Introduction}

Living labs are one of the most prominent and growing areas within the popular open innovation paradigm. The potential of living labs has been acknowledged globally because they offer a fruitful architecture for deploying open innovation through user involvement and co-creation mechanisms (Nyström et al., 2014). The European Network of Living Labs (ENoLL) has over 150 active living lab members worldwide, but the organization has recognized more than 400 living labs since its inception in 2006. While some members eventually disengage from operations for one reason or another, each call for members brings a new "wave" of applicants from around the world. Simultaneously, there has been a parallel wave of increasing scholarly research on living labs.

Along with seven special issues (2012, 2013a, 2013b, $2015,2016,2017 a, 2017 b)$ and numerous additional articles on living labs in other issues, "living labs" has been a prominent theme in the TIM Review (McPhee et al., 2017a). Those contributions have been of relevance to scholars and practitioners of collaborative innovation, and the journal has played a considerable role in the transformative debate on living labs (Steen \& van Bueren, 2017). That said, after all these years, the literature still remains sparse in terms of guidance on how to establish a living lab and how to run and manage it to create value for its stakeholders. Innovation in living labs builds on exposing participants to real-world problems and "understanding, learning, and sharing among the involved stakeholders" (Ståhlbröst \& Holst, 2017), but those launching and running living labs often have to learn their lessons the hard way, and every new study on living labs is a valuable and helpful source of information.

Despite the remaining gaps, there have been numerous scholars working on the area for over a decade, and research on living labs has become increasingly finegrained (Leminen et al., 2017). At the same time, living labs is a conceptually challenging and multifaceted area. Some fundamental aspects of living labs remain 


\section{A Topic Modelling Analysis of Living Labs Research}

\section{Mika Westerlund, Seppo Leminen, and Mervi Rajahonka}

dispersed, and there is not one commonly accepted definition of "living lab". This issue is highlighted by Steen and van Bueren (2017), who reviewed over 30 articles on living labs published in the TIM Review in order to compare how different authors have defined living labs, and by the fact that the ENoLL website actually provides three definitions for living labs (enoll.org/ about-us/). According to ENoLL's primary definition, living labs are "user-centred, open innovation ecosystems based on systematic user co-creation approach, integrating research and innovation processes in real life communities and settings". The view is in concordance with, for example, Leminen, Westerlund, and Nyström (2012), who define living labs as "physical regions or virtual realities in which stakeholders form public-privatepeople partnerships (4Ps) of firms, public agencies, universities, institutes, and users all collaborating for creation, prototyping, validating, and testing of new technologies, services, products, and systems in reallife contexts."

The increasing number of studies on living labs is beneficial to scholars and practitioners, but it also brings about challenges in terms of understanding the key research streams in the area. The more research that gets published, the more information there is to be read. Fortunately, novel technologies in the era of big data and machine learning provide opportunities to examine large corpora of text in easy and convenient ways. Text mining techniques can be used to extract knowledge from unstructured or semi-structured textual data, and they have widespread applications in analyzing and processing textual documents. Such text analytics enable the discovery of previously unknown information by automatically extracting information from various written resources (Moreno \& Redondo, 2016). Further, combining textual mining techniques with bibliometric analysis helps us discover more unseen patterns in research fields than with simple bibliometric analysis alone (Nie \& Sun, 2017).

One of the most efficient text mining techniques is topic modelling, and it is gaining popularity among scholars in diverse fields (Alghamdi \& Alfalqi, 2015). Here, we use topic modelling to analyze a corpus of 86 publications on living labs published in the TIM Review from 2011 to 2017. The analysis provides us with key topics in living labs research and their trends over the examined period of six years, which is comparable with McLoughlin and colleagues (2018), who utilized other bibliometric analysis techniques and datasets to understand topics and trends in living labs.
The article is structured as follows. First, we discuss the essentials of topic modelling. Then, we explain the method, including the data and tool(s) used for the analysis. Thereafter, we provide the results. The article concludes with a summary and discussion of contributions of our results to research on living labs, as well as limitations of the current study and future research avenues.

\section{Topic Modelling}

In today's era of booming interest in big data analytics by scholars and businesses, topic modelling provides a convenient way to analyze big unclassified text (Alghamdi \& Alfalqi, 2015). Since topic modelling was first proposed, it has received a lot of attention and gained widespread interest among researchers in many research fields (Liu et al., 2016). Put shortly, topic modelling is a text-mining technique for discovering topics in documents (Blei, 2012). A topic contains a cluster of words that frequently occur together, and topic modelling can connect words that have similar meanings and can distinguish between uses of words with multiple meanings (Alghamdi \& Alfalqi, 2015). Given that text documents are composed of words, a topic covered in more than one document can be expressed by a combination of strongly related words, and any given document can be associated with more than one topic (Jeong et al., forthcoming). Thus, topic modelling is a technique that can be used to infer hidden topics in a collection of text documents (Jeong et al., forthcoming). According to McPhee and co-authors (2017a), the two key outputs from generating a topic model on a collection of documents are: 1) a list of topics (i.e., groups of words that frequently occur together) and 2) lists of the documents that are strongly associated with each of the topics. Ideally, each topic should be distinguishable from other topics.

There are multiple techniques and algorithms that can be used when data mining text documents. Among them, Latent Dirichlet Allocation (LDA) has gained popularity, as it is known to have the highest performance among several topic modelling algorithms when dealing with large-scale documents and interpreting identified latent topics (Jeong et al., forthcoming). LDA was introduced by Blei, Ng, and Jordan (2003) as a generative probabilistic model for collections of discrete data such as text corpora; in particular, it was described as a three-level hierarchical Bayesian model. LDA-based topic modelling is a useful and increasingly applied technique for latent topic identification from a 


\section{A Topic Modelling Analysis of Living Labs Research}

\section{Mika Westerlund, Seppo Leminen, and Mervi Rajahonka}

large corpus (Jeong et al., forthcoming). It can be applied to text corpora comprising scholarly papers, and because it uses machine learning and has no critical presumptions on the meanings of the words, it works with texts in any discipline. For example, Nie and Sun (2017) used LDA-based topic modelling to identify research trends in design; Amado and colleagues (2018) applied it to analyze research trends on big data in marketing; and Antons, Kleer, and Salge (2016) used the technique to identify topics published in an innovation management journal over a period of three decades. As a probabilistic method, it works particularly well with large corpora; Sehra and co-authors (2017) analyzed a corpus of 1178 articles to identify research trends in software effort estimation, and Mathew, Agrawal, and Menzies (forthcoming) analyzed over 35,000 papers from software conferences.

\section{Method}

We performed the analysis using the J-Tool application for topic modelling developed by Carleton University. The J-Tool is an in-browser application that allows researchers to quickly and easily perform LDA-based topic modelling analyses on TIM Review articles or other textual corpora. The TIM Review (timreview.ca) is a monthly scholarly publication focused on technology innovation and entrepreneurship, and the publications in each issue typically revolve around a special theme introduced by the editor or guest editor(s). With the JTool, the researcher can analyze textual data using topic modelling, visually explore relationships of these papers, examine topic trends over time, examine author contributions, and export citations in selected formats. The J-Tool is based on open source components and, although still in a development stage, it can help scholars and students of technology innovation management to perform text data mining analyses on topics relevant to the discipline, as well as current and prospective authors of the TIM Review to gain understanding of the published research in the journal.

The first research article focused on living labs in the TIM Review was published in the October 2011 issue of the journal. Thus, we performed the analysis using the following settings:

1. Coverage: TIM Review issues and publications from October 2011 through October 2017

2. Key term(s): "living lab"
3. Document types: all document types, including articles, editorials, TIM Lecture reports, and Q\&A short communication articles

4. Number of topics: provide an output of seven topics (which is the default setting in the J-Tool)

5. Topic threshold: apply a topic threshold of $30 \%$ to maximize the number of publications to be included in the topic modelling analysis

Whereas topic threshold value sets a floor for the given topic's proportions in retrieved documents, setting a lower threshold is considered useful when maximal recall is desired (Talley et al., 2011), such as in our study. That said, we also performed the analysis using $70 \%$ topic threshold, which results in fewer works involved in the analysis. The topics seemed fairly similar to those resulting from using a 30\% threshold, suggesting that a lower topic threshold would not cause significant bias in the results. Finally, we used the J-Tool's default settings for stop words (i.e., common words such as "a" or "the" and domain-specific words such as "issue" or "editorial" that are to be ignored because they do not relate to the subject matter specifically), and we opted for a visualization of the results that explicates bridging articles (articles that connect multiple topics), big topics (topics that are a compound of articles as variables), and variable link lengths (reflecting loadings of articles to topics).

In summary, we included all issues of the TIM Review since the first issue in late 2011 until late 2017, the endpoint reflecting the version of the publication database connected with the J-Tool topic modelling tool that we used. The overall data covering six years of the TIM Review comprised more than 70 journal issues with almost 450 publications. In particular, the data comprised seven special issues devoted to living labs. As a result of using "living lab" as a key term, we obtained a corpus of 86 publications that were analyzed using the J-Tool topic modelling tool. The resulting corpus included 54 research articles; the remaining publications were editorials, public lecture reports, and short communications. We decided to include all types of publications because they may put forward interesting perspectives on the topics that may be otherwise underrepresented in the data. Further, including more publications in the corpus was expected to improve the results due to the probabilistic nature of LDA-based topic modelling. According to the J-Tool development team, the corpus analyzed using the method should include a minimum of 30 publications. 


\section{A Topic Modelling Analysis of Living Labs Research}

\section{Mika Westerlund, Seppo Leminen, and Mervi Rajahonka}

\section{Results}

According to the J-Tool settings we specified, the topic modelling analysis on the corpus of 86 publications provided seven topics that were associated with living labs. The number of topics is a user-specified parameter where larger values will produce finer-grained, more detailed topics whereas smaller values will produce coarser-grained, more general topics. There is no single value that is appropriate in all situations and all datasets (Barua et al., 2012). Thus, researchers need to choose the desired number of topics based on a calculation of the optimal number of topics (cf. Jeong et al., forthcoming) or based on the interpretability of the solution, or both. Interpretability plays a particularly significant role, as topic modelling may also result in "junk topics", which are uninterpretable topics that pick out idiosyncratic word combinations in the corpus (AlSumait et al., 2009). Following the example of Barua, Thomas, and Hassan (2012), we tried the analysis with a various number of topics until we concluded that seven topics provided a solution that is easy to interpret and provides meaningful characterization and results. For example, an eight-topic solution provided similar results, but the additional topic was overlapping with another topic - a situation that Schmiedel, Müller, and vom Brocke (2018) recommend avoiding. Out of the 86 publications, 51 (59\%) were single-topic publications and 35 (41\%) were multi-topic publications; the latter we consider as "bridging articles" because they represent a link between topics. Table 1 shows the seven topics and their associated keywords; these keywords are listed in a decreasing order of relevance to each topic, and the JTool uses the first keywords (i.e., the words that have the highest relevance to each topic) to label each topic.
In Table 1, certain keywords appear under several topics; for example, the keyword "innovation" is listed under the topics of Innovation, Living lab, Ecosystem, and City. Given that the output of the analysis provided by the J-Tool not only provides automatically generated labels for the topics but also details of the relevance of words to topics versus other topics (i.e., relation strength), we ensured that the provided labels are representative of the topics and that there are no overlapping topics that cannot be distinguished from the others.

In the following subsections, we discuss our subjective interpretations of each topic in the light of the articles that fall under that topic. We followed the guidance of Maier and colleagues (2018), who report that researchers often read through a sample of documents associated with a given topic in addition to the interpretation and labelling of the topic based on its top word(s). Hence, we drilled into the publications associated with the topics and, in particular, read the titles and abstracts of publications associated with the topics. Whenever in doubt, we also browsed the substantive contents. Of note, we were familiar with many of the included publications because we served as guest editors in their associated special issues. Thus, we were able to obtain insight of why the topic modelling tool may have associated a given publication with the specific topic, as well as subjectively identify subtopics under the topic. Put differently, drilling into the publications associated with the seven topics allowed us to better understand what each topic is about and how the subtopics comprise the topic when put together. After discussing the seven topics, we briefly report findings related to bridging articles.

Table 1. The seven identified topics and their associated keywords

\begin{tabular}{|c|c|}
\hline Topic & Keywords \\
\hline 1. Design & design, system, user, work, group, technology, study, care, context, phase \\
\hline 2. Ecosystem & ecosystem, university, business, region, local, creation, global, innovation, tourism, research \\
\hline 3. City & city, urban, innovation, citizen, public, smart, collaborative, platform, development, sector \\
\hline 4. University & university, business, technology, innovation, entrepreneur, management, Canada, open, source, global, program \\
\hline 5. Innovation & innovation, process, company, user, knowledge, service, model, business, project, research \\
\hline
\end{tabular}

7. Living lab living lab, innovation, project, user, network, study, case, activity, process, research 


\title{
A Topic Modelling Analysis of Living Labs Research
}

\author{
Mika Westerlund, Seppo Leminen, and Mervi Rajahonka
}

\section{Topic 1: Design}

The first topic focuses on the design approach to living labs with three easily identifiable subtopics: 1) designdriven approaches to living labs (e.g., Brankaert \& Ouden, 2017), 2) design as a driver of innovation (e.g., Gray et al., 2014), and 3) design of living lab methodology and processes (e.g., Mulder, 2012). In general, design is a term defined and understood in different ways by different people. In our data, design-driven approach refers to adding design characteristics such as exploration and dealing with uncertainty in order to help living labs to better deal with complex problems. It also considers who the stakeholders are that should be involved in the living lab. Design as a driver is an approach that argues that design is a key factor in innovation and highlights the importance of users as co-designers. Design of living lab methodology and processes is a view that argues living labs are methodologies that need to be designed in a way that they provide experiences to participants, and thus become living and sustainable.

\section{Topic 2: Ecosystem}

The second topic focuses on the ecosystems approach to living labs, and it has three subtopics: 1) regional innovation ecosystems (e.g., Viitanen, 2016), 2) global innovation ecosystems (e.g., Seppä, 2012), and 3) open innovation ecosystems (e.g., León \& Martinez, 2016). Regional innovation ecosystems view regions as areas whose innovation performance can be improved through collaborative initiatives such as living labs and the related ecosystem. Conversely, global innovation ecosystems discusses a new era of knowledge institutions building globally distributed living lab ecosystems to meet global innovation needs. Finally, the open innovation ecosystem focuses on the challenges and opportunities for the tertiary educational sector to partake in novel open innovation ecosystems such as living labs. Common to all of these subtopics is that the described ecosystems include or build around regional universities.

\section{Topic 3: City}

The third topic clearly focuses on the use of living labs in the urban city context. The topic has three subtopics: 1) cities as collaborative innovation platforms (e.g., Tukiainen et al., 2015), 2) urban living labs (e.g., Juujärvi \& Lund, 2016), and 3) smart city development (e.g., Khomsi, 2016). Cities as collaborative innovation platforms focuses on the role of the city in innovation and the uses of living labs for collaborative innovation. Typically, the idea is to develop the city and improve the lives of its residents, businesses, public sector or- ganizations, and others such as tourists. A very specific goal for a city's development through living labs is that of becoming a smart city.

\section{Topic 4: University}

This topic builds upon a large number of editorials of special issues related to living labs and other collaborative forms of innovation. Moreover, it includes other types of university-driven activities such as public lectures on innovation and entrepreneurship organized by the university. Although some editorials only briefly mention living labs, for example, because of announcing a forthcoming issue on living labs, other editorials discuss them in more detail. Three main subtopics in the corpus are: 1 ) research advances on living labs (e.g., McPhee et al., 2017b), 2) universities as knowledge mobilization platforms for innovation (e.g., McPhee, 2016), and 3) entrepreneurial practice and experiences using collaborative innovation (e.g., McPhee, 2014). In this respect, the topic does not introduce a specific perspective to living labs, but likely reflects the university's key role in knowledge dissemination of research related to living labs and other collaborative innovation to scholarly and practitioner communities. That said, it should be noted that TIM Review editorials commonly introduce authors and their institutions and, hence, the term "university" comes up multiple times in each editorial. While this fact supports the view of universities and their scholars as disseminators of knowledge related to living labs, it also weakens the interpretability and validity of this topic.

\section{Topic 5: Innovation}

The fifth topic addresses the use of living labs by companies and other organizations for innovation. The main subtopics are: 1) the challenges of using living labs (e.g., Westerlund \& Leminen, 2011), 2) the benefits of using living labs (e.g., Niitamo et al., 2012), 3) the perceived experiences of using living labs (e.g., Ståhlbröst, 2013), and 4) the management of living labs (e.g., Katzy \& Bücker, 2015). In essence, these subtopics describe the motivation and expected value of getting involved in innovation through living labs, as well as the management and coordination challenges of conventional development projects versus the open innovation model. Management is discussed in terms of activities and processes ensuring innovation performance and economic sustainability of the living lab.

\section{Topic 6: User}

This topic focuses on the quintessential role of users in living lab experiments. The subtopics within the topic are: 1) managing user involvement in living labs (e.g., 


\title{
A Topic Modelling Analysis of Living Labs Research
}

\author{
Mika Westerlund, Seppo Leminen, and Mervi Rajahonka
}

Schuurman \& De Marez, 2012), 2) understanding user dropouts in living lab experiments (e.g., Georges et al., 2016), and 3) the real-life environment of user as a context for innovation (e.g., Coorevits \& Jacobs, 2017). The first and second subtopics discuss how to increase the likelihood that a user will remain involved in innovation throughout multiple phases of the process. In addition, real-life environment refers to the intense user-system interaction in a real-life context as a key to successful user input during the process.

\section{Topic 7: Living lab}

Finally, the seventh topic examines the living lab itself to understand what living labs and their defining characteristics are. The subtopics are focused on providing taxonomies, typologies, and categorizations: 1) the characteristics of living labs (e.g., Steen \& van Bueren, $2017), 2)$ living labs as a type of user innovation methodology (e.g., Almirall et al., 2012), 3) living labs as open innovation networks (e.g., Leminen et al., 2012), 4) categorization of innovation tools in living labs (e.g., Leminen \& Westerlund, 2017), and 5) classification of the environment in living labs (e.g., Bergvall-Kåreborn et al., 2015). Characteristics of living labs can be used to categorize true living labs from improperly labelled living labs. Living labs, as a type of user innovation methodology, categorize different user innovation methodologies and explain how living labs differ from other methodologies. The network view considers living labs as networks to categorize different living labs based on their driving actors. Categorization of innovation tools suggests a new typology of living labs based on their innovation process characteristics and usage of tools. Finally, classification of the environment views living labs as places and spaces where innovation happens.

\section{Bridging articles}

As mentioned previously, more than $40 \%$ of included publications were multi-topic publications, or "bridging articles". The analysis revealed 11 combinations of topics; most of them were a combination of two topics, and one was a combination of three. It turned out that 7 out of these 11 combinations included Innovation as one of the topics. In fact, Innovation was connected with all the other topics and such combinations covered $77 \%$ of the bridging articles. This is not surprising given that the topic of Innovation was found to discuss fundamentals of using living labs for collaborative innovation. Another non-surprising topic that showed up in various combinations was that of University. Again, this is expected given that the majority of publications falling under this topic were editorials or other non-research article publications emphasizing the role of university in disseminating knowledge. However, we consider the possibility that most of the authors mentioned in the editorials were academics and therefore the word "university" often appeared in the editorials. That said, the role of university is visible even in the basic definition of living labs, which emphasizes them as public-private-people partnerships (cf. Leminen et al., 2012); in fact, universities typically represent a key public sector participant.

Figure 1 visualizes how the seven topics and their associated publications are constructed and interlinked. The large nodes in the illustration are topics and each small node is a publication; those small nodes that are connected to only one topic are single topic publications reflective of that specific topic, whereas those that connect two or more topics are bridging articles. The JTool allows the researcher to easily identify any of the articles by simply hovering the mouse pointer on nodes. Further details are then given in an output table that helps to report the results. The TIM Review is represented by the centre of the illustration because it is what connects the topics. As said previously, we also opted for variable length links to reflect article to topic loadings in the illustration; however, a brief investigation did not reveal anything interesting in terms of those nodes that have short links versus those that have long links. Thus, we decided to leave a more detailed analysis of variable link lengths outside of the scope of this article.

\section{Trend Analysis}

Similar to McPhee and co-authors (2017a), we use the degree of association of documents to a topic over time to reflect overall trends in topics. Figure 2 shows the overall trends of the seven identified living lab topics in the TIM Review from October 2011 through October 2017. Of note, although the vertical axis (i.e., relative strength of association) does not show the count of words or articles, it does reflect the popularity of the topics in the journal issues and publications over the examined six years period of time. Further, although an analysis of statistical significance would add credibility to the trend analysis (cf. Choi et al., 2017), the output did not provide accurate, usable data for such calculations. However, the output enabled us to estimate values to calculate an increase index as suggested by Sun and Yin (2017). Drawing on their idea of increase index formulation, we used estimates of the document-totopic relevance from the first two years (2011-2012) and the last two years (2016-2017) of the examined period 


\section{A Topic Modelling Analysis of Living Labs Research}

\section{Mika Westerlund, Seppo Leminen, and Mervi Rajahonka}

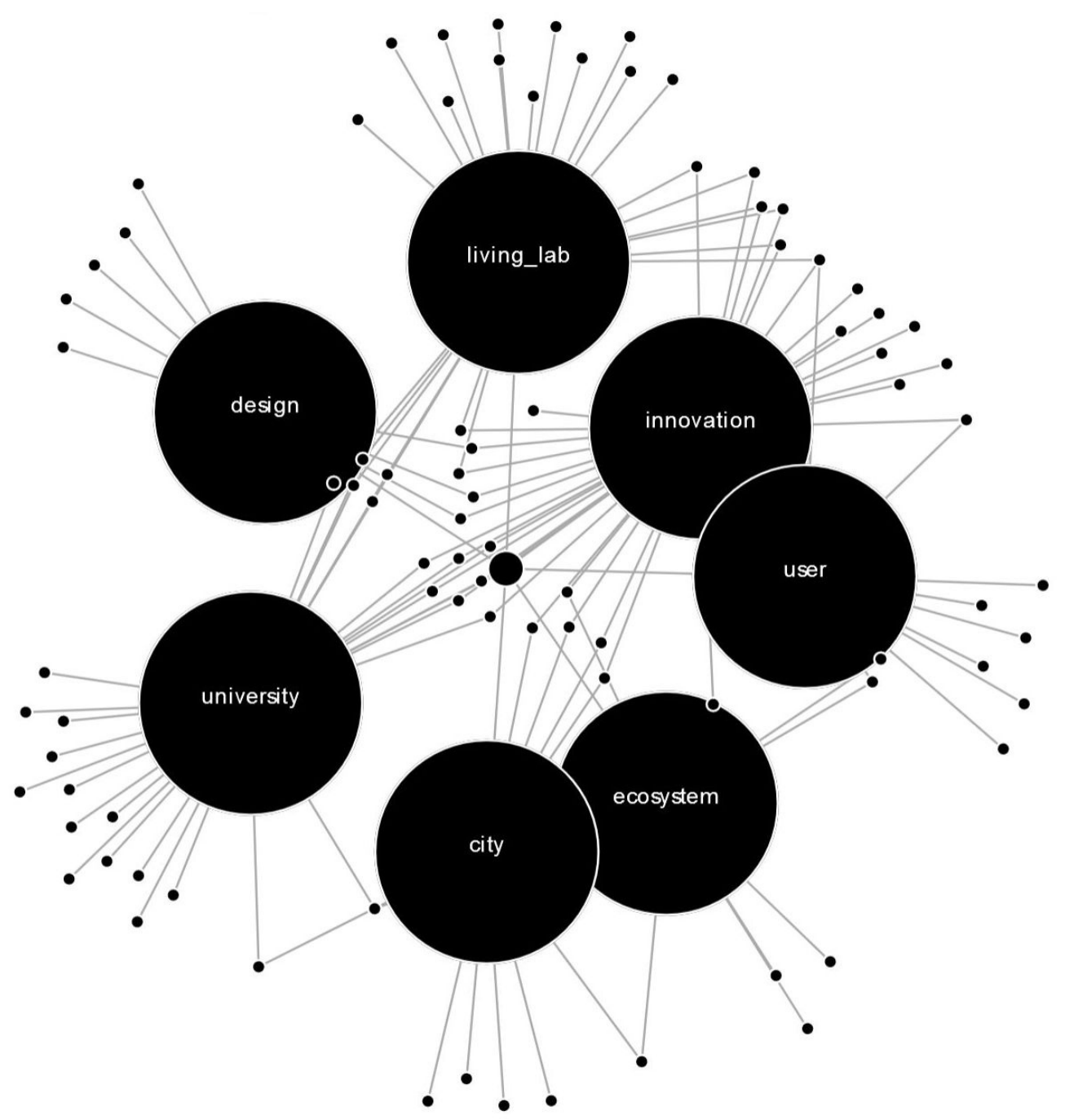

Figure 1. Visualization of topics and their connections

in order to create an index. In short, our increase index $r^{k}$ shows the difference in the document-to-topic relevance for each topic between two time windows, and it provides numerical support for visual interpretation of the trends shown in Figure 2. An index value in excess of 1.00 reflects an upward trend and lower than 1.00 indicates a downward trend. Further, values of $1.00 \pm 0.05$ suggest a stagnant trend; this accepted margin of error is especially due to potential inaccuracies in estimated values.

As shown in Figure 2, there are three kinds of trends related to the identified topics: decreasing, increasing, and constant. We report these trends together with their increase index values $\left(r^{k}\right)$. To start with, University $\left(r^{k}=0.47\right)$ and Innovation $\left(r^{k}=0.73\right)$ are decreasing trends in terms of popularity. In particular, the decreasing trend of University is evident as its relative strength (reflecting popularity) halved in six years. Innovation faced a slightly smaller decrease, losing a third of its relative strength during the years. Then again, User $\left(r^{k}=5.80\right)$, City $\left(r^{k}=2.25\right)$, and Design $\left(r^{k}=1.88\right)$ are increasing trends. Interestingly, the trend reflecting the popularity of User in connection with living labs shows the highest growth. Whereas the relative strength for the topic User was almost non-existent and clearly lowest of the seven in late 2011, it had reached the third-highest rank by late 2017. Both City and Design doubled in terms of relative strength during the period. Finally, Living lab $\left(r^{k}=0.97\right)$ and Ecosystem $\left(r^{k}=1.00\right)$ seem to be constant trends showing little to no changes over the six-year period. That said, the relative strength of the Living lab topic is high throughout the period, which is not surprising given the topic's foundational nature. 


\section{A Topic Modelling Analysis of Living Labs Research}

\section{Mika Westerlund, Seppo Leminen, and Mervi Rajahonka}

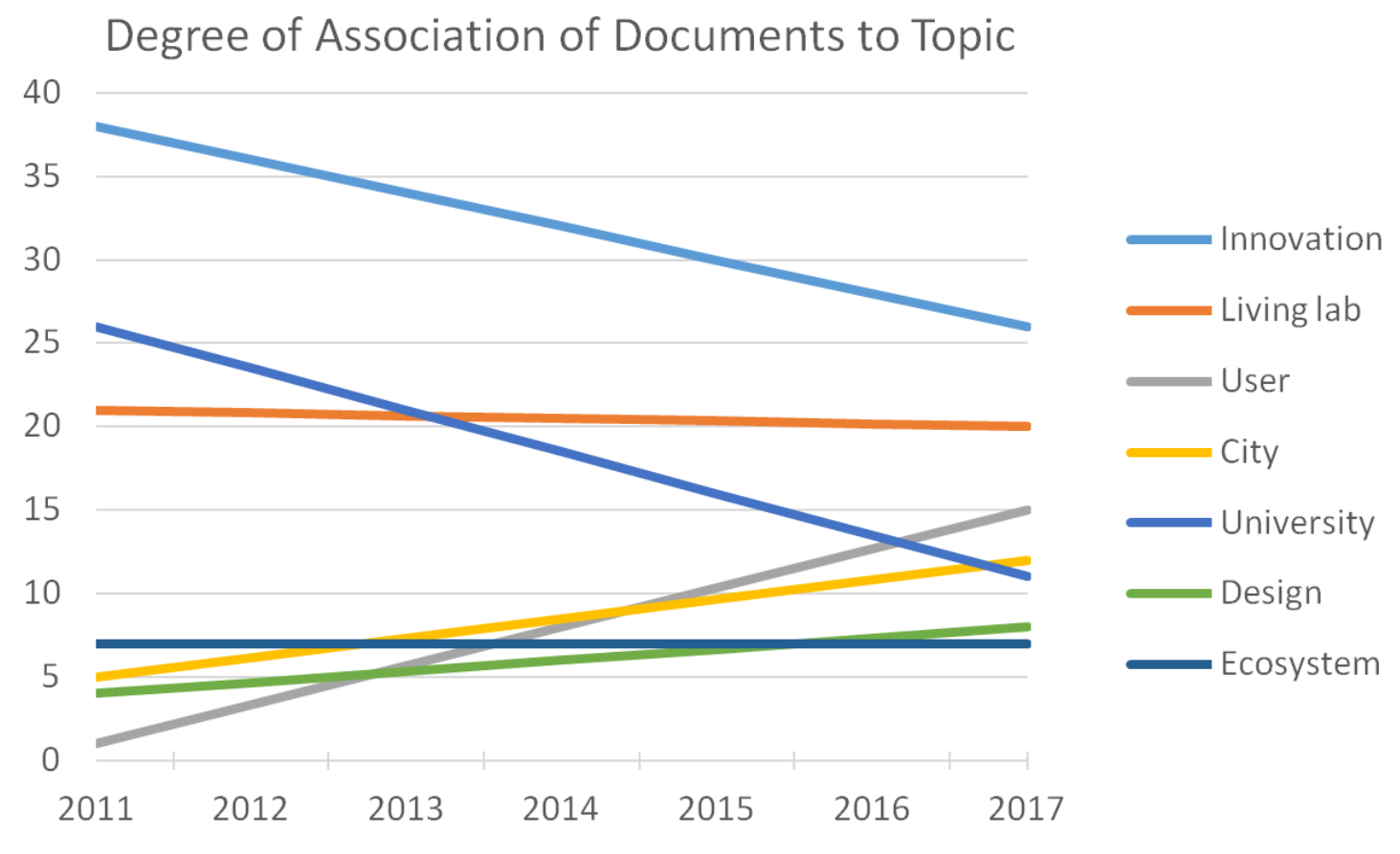

Figure 2. Overall trends of living lab topics in the TIM Review during 2011-2017

\section{Discussion}

This study applied topic modelling analysis on a corpus of publications in the TIM Review published from 2011 to 2017 to examine how authors have approached living labs in the recent innovation management literature. To our knowledge, the TIM Review has published the largest number of special issues focused on living labs to date; thus, we considered that it can reflect the progress of the scholarly research in regard to living labs. Further, we drilled into the topics and examined the titles and contents of the articles that were associated with each topic. In this vein, our study combined textual mining techniques and bibliometric analysis to discover unseen patterns in a specific research field, as suggested by Nie and Sun (2017).

We found that research related to living labs in the TIM Review can be categorized under seven broad topics: 1 ) Design, 2) Ecosystem, 3) City, 4) University, 5) Innovation, 6) User, and 7) Living lab. In addition, each topic includes various subtopics that, when put together, reflect the topic in a comprehensive way. Out of the seven identified topics, Ecosystem, University, Innovation, and Living lab reflect broader, more conceptual approaches to the phenomenon of living labs. These topics are essentially focusing on what living labs are by definition, who are being involved in the operations, and what the benefits of living labs are both in a broad sense and in specific. Conversely, Design, City, and User represent a more applied approach to living labs. In other words, these topics discuss how living labs can be designed and managed to overcome various challenges, how users as key participants should be handled, and how living labs can be applied to urban contexts in order to create value to stakeholders. Of note, our results are in concordance with those of McLoughlin and co-authors (2018), who performed various bibliometric analyses on datasets comprising publications with a conceptual or methodological focus on living labs. Although their study included articles from various disciplines and outlets (mostly computer and information science as well as engineering publications), their analysis revealed fairly similar topics, with "smart city" emerging among the most prevalent topics in terms of popularity and maturity. Our analysis using a different method and dataset also put the urban/smart city context among the top topics. In this vein, our results gain support from recent research applying bibliometric approaches in order to understand the scholarly field of living labs.

Interestingly, the trend analysis we performed on the topics suggested that the research emphasis in living 


\section{A Topic Modelling Analysis of Living Labs Research}

\section{Mika Westerlund, Seppo Leminen, and Mervi Rajahonka}

labs seems to be moving away from conceptual understanding of what living labs are, what types of living labs there are, and who are being involved in living lab ecosystems to practical applications of how to design and manage living labs and their participants, especially users as key stakeholders, in novel application areas such as the urban city context. We believe that, despite the yet emerging literature on living labs, there is nowadays a sufficient number of conceptually oriented studies on the fundamentals of living labs in order for scholars to move on to a deeper, more practically oriented level of research. In addition, there may be more empirical data for practice-oriented research available as the phenomenon of living labs matures. An aspect supporting the view that the fundamentals of living labs are quite well discussed in the literature is our finding of a large number of bridging articles that connect two or more topics. Almost all of the bridging articles combined either Innovation or University with another topic; the two being fundamental topics when we think of what living labs are and how they are defined. Our results add another dimension to the findings by McLoughlin and co-authors (2018), who investigated trends in living lab research, including a number of pre-2011 publications, and found that there has been a shift from a technology focus to a social focus in the application and context of living labs.

Furthermore, we believe that another reason driving the shift from conceptually oriented studies to more practically oriented studies on living labs is that there is a growing demand for practically oriented studies that can help newcomers in the field, namely inexperienced innovation and living lab managers seeking to build new living labs that are arguably a complex form of collaborative innovation. There are few practical guidelines on how to create and grow a living lab or how to manage its crucial processes. Newcomers to the field need advice, best practices, and lessons learned from others about what to do in order to maximize the success of their initiative and speed up innovation. That said, there is an increasing pool of knowledge and expertise accumulating, and this knowledge can be turned into research outputs. In particular, interesting research opportunities are arising as some living labs that have been operating for a long time are ending their operations, merging into new forms of collaborative innovation (cf. Claudel, 2018; Leminen et al., 2017; Steen \& van Bueren, 2017), or establishing financial mechanisms to support their operations after the initial funding dries out.

\section{Limitations and Future Research}

Every research project has limitations. In this study, there are several limitations that may affect the generalizability of the results. First, the articles used in the analysis may represent a specific perspective to living labs. We only analyzed works published in one journal, namely the TIM Review. Although the journal has earned a strong reputation as a scholarly peer-reviewed journal that has published the largest number of special issues focused on living labs as of 2018, its focus on innovation management and the fact that many of the special issues were developed from papers published in innovation management conferences may have affected the approaches and views taken by the authors of the studied publications. It is possible that certain scholars of livings labs who represent another academic discipline beyond innovation management, such as sociology, may have produced interesting insights on the topic that are not represented in the TIM Review.

Second, the examined timeframe does not include foundational studies from the early period of living lab research, because the first article on living labs was only published in the TIM Review in late 2011. Until late 2011, the journal operated under another name and focused on the business aspects of open source software. However, a number of foundational articles were published on living labs prior to 2011 in other scholarly outlets, and including them in the study would enrich the results. In comparison, the bibliometric analysis of living lab literature by McLoughlin and co-authors (2018) comprised numerous pre-2011 publications, including some foundational papers. However, due to the utilized filtering criteria, they ended up with a narrowed-down dataset comprising mainly studies in computer and information science as well as engineering.

Third, the examined data included a relatively small number of papers. LDA-based topic modelling is considered an effective method for analyzing textual corpora. However, due to the probabilistic nature of the method, results from the analysis are likely to be better and more reflective of the data when applied to larger corpora. Hence, previous research providing bibliometric analyses on given disciplines has applied topic modelling to textual corpora consisting of publications in the range of a thousand to tens of thousands. Our data only included 86 papers. Reviewing and analyzing 86 papers is a major effort for a human researcher, and certainly exceeds the minimum requirement for the topic modelling tool; nonetheless, it is still a small number in 


\section{A Topic Modelling Analysis of Living Labs Research Mika Westerlund, Seppo Leminen, and Mervi Rajahonka}

machine learning based data analytics that was essentially designed for big data.

Fourth, there are various limitations related to the topic modelling tool that we used. For instance, topic models are likely to vary based on the random seed that is required for the analysis. In the J-Tool, the seed is hardcoded in order for it to remain the same over multiple runs, thus allowing for replication of the analysis with similar results. In this vein, it can be considered a strength, because we could run multiple experiments without the fear of facing varied results due to the changes in the seed. On the other hand, if the seed were set differently in the first place, the results might be somewhat different. Moreover, the early version of the tool that we used did not provide the outputs that would add further credibility and accuracy to the analysis. For example, we were unable to calculate statistical significance for the identified trends.

Future research should apply topic modelling over a larger corpus of studies on living labs, potentially including the early (pre-2011) notions of the concept and reaching out to the most recent publications on the phenomenon. Although the early version of the J-Tool that we used was limited to the TIM Review publication database, the version under development can handle almost any article and many other types of data entry inputted into the analysis. In addition, the added features of the newer version provide the researchers with additional output and reporting tools, such as data required for statistical significance calculations, as well as word clouds and various illustrations showing document counts that may illuminate the contents and development of the identified topics in a richer and more accurate manner, and allow for a more descriptive discussion.

\section{Acknowledgements}

Funding from FedDev Ontario, through the Innovation Centre at Bayview Yards in Ottawa, Canada, enabled the development of the J-Tool used to perform the topic modelling analysis presented in this article.

\section{About the Authors}

Mika Westerlund, DSc (Econ), is an Associate Professor at Carleton University in Ottawa, Canada. He previously held positions as a Postdoctoral Scholar in the Haas School of Business at the University of California Berkeley and in the School of Economics at Aalto University in Helsinki, Finland. Mika earned his doctoral degree in Marketing from the Helsinki School of Economics in Finland. His research interests include open and user innovation, the Internet of Things, business strategy, and management models in high-tech and service-intensive industries.

Seppo Leminen is an Adjunct Professor of Business Development at Aalto University in Helsinki, Finland, and an Adjunct Research Professor at Carleton University in Ottawa, Canada. He holds a doctoral degree in Marketing from the Hanken School of Economics in Finland and a doctoral degree in Industrial Engineering and Management from the School of Science at Aalto University. His research and consulting interests include living labs, open innovation, innovation ecosystems, robotics, the Internet of Things (IoT), as well as management models in high-tech and service-intensive industries. He is serving as an associate editor in the BRQ Business Research Quarterly, on the editorial board of the Journal of Small Business Management, as a member of the Review Board for the Technology Innovation Management Review, and on the Scientific Panel of the International Society for Professional Innovation Management (ISPIM). Prior to his appointment at Aalto University, he worked in the ICT and pulp and paper industries.

Mervi Rajahonka, DSc (Econ), works as an RDI Advisor at the Small Business Center (SBC), currently a part of the South-Eastern Finland University of Applied Sciences XAMK, Finland, and she is an Adjunct Research Professor at Carleton University in Ottawa, Canada. She has been working at the SBC for about 10 years. She earned her doctoral degree in Logistics from the Department of Information and Service Economy at Aalto University School of Business in Helsinki, Finland. She also holds a Master's degree in Technology from the Helsinki University of Technology and a Master's degree in Law from the University of Helsinki. Her research interests include sustainable logistics and supply chain management, business models, service modularity, and service innovations. Her research has been published in a number of journals in the areas of logistics, services, and operations management. 


\section{A Topic Modelling Analysis of Living Labs Research \\ Mika Westerlund, Seppo Leminen, and Mervi Rajahonka}

\section{References}

Alghamdi, R., \& Alfalqi, K. 2015. A Survey of Topic Modeling in Text Mining. International Journal of Advanced Computer Science and Applications, 6(1): 147-153. https://doi.org/10.14569/IJACSA.2015.060121

Almirall, E., Lee, M., \& Wareham, J. 2012. Mapping Living Labs in the Landscape of Innovation Methodologies. Technology Innovation Management Review, 2(9): 12-18.

http://doi.org/10.22215/timreview/603

AlSumait, L., Barbará, D., Gentle, J., \& Domeniconi, C. 2009. Topic Significance Ranking of LDA Generative Models. In Proceedings of the European Conference on Machine Learning and Knowledge Discovery in Databases (ECML/PKDD): 67-82.

https://doi.org/10.1007/978-3-642-04180-8_22

Amado, A., Cortez, P., Rita, P., \& Moro, S. 2018. Research Trends on Big Data in Marketing: A Text Mining and Topic Modeling Based Literature Analysis. European Research on Management and Business Economics, 24(1): 1-7.

https://doi.org/10.1016/j.iedeen.2017.06.002

Antons, D., Kleer, R., \& Salge, T. O. 2016. Mapping the Topic Landscape of JPIM, 1984-2013: In Search of Hidden Structures and Development Trajectories. Journal of Product Innovation Management, 33(6): 726-749.

https://doi.org/10.1111/jpim.12300

Barua, A., Thomas, S. W., \& Hassan, A. E. 2012. What Are Developers Talking About? An Analysis of Topics and Trends in Stack Overflow. Empirical Software Engineering, 19(3): 619-654.

https://doi.org/10.1007/s10664-012-9231-y

Bergvall-Kåreborn, B., Ihlström Eriksson, C., \& Ståhlbröst, A. 2015. Places and Spaces within Living Labs. Technology Innovation Management Review, 5(12): 37-47.

http://doi.org/10.22215/timreview/951

Blei, D. M., Ng, A. Y., \& Jordan, M. I. 2003. Latent Dirichlet Allocation. Journal of Machine Learning Research, 3: 993-1022.

Blei, D. M. 2012. Probabilistic Topic Models. Communications of the ACM, 55(4): 77-84. http://dx.doi.org/10.1145/2133806.2133826

Brankaert, R., \& Ouden, E. 2017. The Design-Driven Living Lab: A New Approach to Exploring Solutions to Complex Societal Challenges. Technology Innovation Management Review, 7(1): 44-51.

http://doi.org/10.22215/timreview/1049

Choi, H. S., Lee, W. S., \& Sohn, S. Y. 2017. Analyzing Research Trends in Personal Information Privacy Using Topic Modeling. Computers \& Security, 67: 244-253. https://doi.org/10.1016/j.cose.2017.03.007

Claudel, M. 2018. From Organizations to Organizational Fields: The Evolution of Civic Innovation Ecosystems. Technology Innovation Management Review, 8(6): 34-47. http://doi.org/10.22215/timreview/1163

Coorevits, L., \& Jacobs, A. 2017. Taking Real-Life Seriously: An Approach to Decomposing Context Beyond "Environment" in Living Labs. Technology Innovation Management Review, 7(1): 26-36.

http://doi.org/10.22215/timreview/1047
Georges, A., Schuurman, D., \& Vervoort, K. 2016. Factors Affecting the Attrition of Test Users During Living Lab Field Trials. Technology Innovation Management Review, 6(1): 35-44. http://doi.org/10.22215/timreview/959

Gray, M., Mangyoku, M., Serra, A., Sánchez, L., \& Aragall, F. 2014. Integrating Design for All in Living Labs. Technology Innovation Management Review, 4(5): 50-59. http://doi.org/10.22215/timreview/793

Jeong, B., Yoon, J., \& Lee, J.-M. Forthcoming. Social Media Mining for Product Planning: A Product Opportunity Mining Approach Based on Topic Modeling and Sentiment Analysis. International Journal of Information Management. https://doi.org/10.1016/j.ijinfomgt.2017.09.009

Juujärvi, S., \& Lund, V. 2016. Enhancing Early Innovation in an Urban Living Lab: Lessons from Espoo, Finland. Technology Innovation Management Review, 6(1): 17-26. http://doi.org/10.22215/timreview/957

Katzy, B. R., \& Bücker, C. 2015. The Organization of Living Labs: Coordinating Activities for Regional Innovation. Technology Innovation Management Review, 5(9): 23-28. http://doi.org/10.22215/timreview/927

Khomsi, M. 2016. The Smart City Ecosystem as an Innovation Model: Lessons from Montreal. Technology Innovation Management Review, 6(11): 26-31. http://doi.org/10.22215/timreview/1032

Leminen, S., Westerlund, M., \& Nyström, A. - G. 2012. Living Labs as Open-Innovation Networks. Technology Innovation Management Review, 2(9): 6-11. http://doi.org/10.22215/timreview/602

Leminen, S., \& Westerlund, M. 2017. Categorization of Innovation Tools in Living Labs. Technology Innovation Management Review, 7(1): 15-25. http://doi.org/10.22215/timreview/1046

Leminen, S., Rajahonka, M., \& Westerlund, M. 2017. Towards ThirdGeneration Living Lab Networks in Cities. Technology Innovation Management Review, 7(11): 21-35.

http://doi.org/10.22215/timreview/1118

León, G., \& Martínez, R. 2016. Q\&A. How Can a University Drive an Open Innovation Ecosystem? Technology Innovation Management Review, 6(7): 48-51. http://doi.org/10.22215/timreview/1004

Liu, L., Tang, L., Dong, W., Yao, S., \& Zhou, W. 2016. An Overview of Topic Modeling and Its Current Applications in Bioinformatics. SpringerPlus, 5(1): 1608. http://doi.org/10.1186/s40064-016-3252-8

Maier, D., Waldherr, A., Miltner, P., Wiedemann, G., Niekler, A., Keinert, A., Pfetsch, B., Heyer, G., Reber, U., Häussler, T., SchmidPetri, H., \& Adam, A. 2018. Applying LDA Topic Modeling in Communication Research: Toward a Valid and Reliable Methodology. Communication Methods and Measures, 12(2-3): 93-118.

https://doi.org/10.1080/19312458.2018.1430754

Mathew, G., Agrawal, A., \& Menzies, T. Forthcoming. A Method for Finding Trends in Software Research. IEEE Transactions in Software Engineering. https://arxiv.org/pdf/1608.08100 


\section{A Topic Modelling Analysis of Living Labs Research Mika Westerlund, Seppo Leminen, and Mervi Rajahonka}

McLoughlin, S., Maccani, G., Prendergast, D., \& Donnellan, B. 2018. Living Labs: A Bibliometric Analysis. Paper presented at the 51st Hawaii International Conference on System Sciences (HICSS), January 2-6, 2018, Hawaii, USA.

McPhee, C. 2014. Editorial: Innovation and Entrepreneurship. Technology Innovation Management Review, 4(12): 3-5. http://doi.org/10.22215/timreview/852

McPhee, C. 2016. Editorial: Knowledge Mobilization. Technology Innovation Management Review, 6(9): 3-3. http://doi.org/10.22215/timreview/1013

McPhee, C., Santonen, T., Shah, A., \& Nazari, A. 2017. Reflecting on 10 Years of the TIM Review. Technology Innovation Management Review, 7(7): 5-20.

http://doi.org/10.22215/timreview/1087

McPhee, C., Schuurman, D., Ballon, P., Leminen, S., \& Westerlund, M. 2017b. Editorial: Innovation in Living Labs. Technology Innovation Management Review, 7(1): 3-6. http://doi.org/10.22215/timreview/1044

Moreno, A., \& Redondo, T. 2016. Text Analytics: The Convergence of Big Data and Artificial Intelligence. International Journal of Interactive Multimedia and Artificial Intelligence, 3(6): 57-64. https://doi.org/10.9781/ijimai.2016.369

Mulder, I. 2012. Living Labbing the Rotterdam Way: Co-Creation as an Enabler for Urban Innovation. Technology Innovation Management Review, 2(9): 39-43. http://doi.org/10.22215/timreview/607

Nie, B., \& Sun, S. 2017. Using Text Mining Techniques to Identify Research Trends: A Case Study of Design Research. Applied Sciences, 7(4): 401. https://doi.org/10.3390/app7040401

Niitamo, V.-P., Westerlund, M., \& Leminen, S. 2012. A Small-Firm Perspective on the Benefits of Living Labs. Technology Innovation Management Review, 2(9): 44-49. http://doi.org/10.22215/timreview/608

Nyström, A.-G., Leminen, S., Westerlund, M., \& Kortelainen, M. 2014. Actor Roles and Role Patterns Influencing Innovation in Living Labs. Industrial Marketing Management, 43(3): 483-495. https://doi.org/10.1016/j.indmarman.2013.12.016

Schmiedel, T., Müller, O., \& vom Brocke, J. Forthcoming. Topic Modeling as a Strategy of Inquiry in Organizational Research: A Tutorial With an Application Example on Organizational Culture. Organizational Research Methods. https://doi.org/10.1177/1094428118773858

Schuurman, D., \& De Marez, L. 2012. Structuring User Involvement in Panel-Based Living Labs. Technology Innovation Management Review, 2(9): 31-38. http://doi.org/10.22215/timreview/606

Sehra, S.K., Brar, Y.S., Kaur, N., \& Sehra, S.S. 2017. Research Patterns and Trends in Software Effort Estimation. Information and Software Technology, 91: 1-21. https://doi.org/10.1016/j.infsof.2017.06.002
Seppä, M. 2012. From Business Administration to Business Creation: The Case of the Kalevala Global Business Creation School. Technology Innovation Management Review, 2(6): 6-11. http://doi.org/10.22215/timreview/562

Steen, K., \& van Bueren, E. 2017. The Defining Characteristics of Urban Living Labs. Technology Innovation Management Review, 7(7): 21-33. http://doi.org/10.22215/timreview/1088

Ståhlbröst, A. 2013. A Living Lab as a Service: Creating Value for Micro-enterprises through Collaboration and Innovation. Technology Innovation Management Review, 3(11): 37-42. http://doi.org/10.22215/timreview/744

Ståhlbröst, A., \& Holst, M. 2017. Reflecting on Actions in Living Lab Research. Technology Innovation Management Review, 7(2): 27-34. http://doi.org/10.22215/timreview/1055

Sun, L., \& Yin, Y. 2017. Discovering Themes and Trends in Transportation Research Using Topic Modeling. Transportation Research Part C, 77: 49-66. https://doi.org/10.1016/j.trc.2017.01.013

Talley, E. M., Newman, D., Mimno, D., Herr, B. W., Wallach, H. M., Burns, G. A. P. C., Leenders, A. G. M., \& McCallum, A. 2011. Database of NIH Grants Using Machine-Learned Categories and Graphical Clustering. Supplementary Data. Nature Methods, 8(6): 443-444. http://doi.org/10.1038/nmeth.1619

Tukiainen, T., Leminen, S., \& Westerlund, M. 2015. Cities as Collaborative Innovation Platforms. Technology Innovation Management Review, 5(10): 16-23. http://doi.org/10.22215/timreview/933

Viitanen, J. 2016. Profiling Regional Innovation Ecosystems as Functional Collaborative Systems: The Case of Cambridge. Technology Innovation Management Review, 6(12): 6-25. http://doi.org/10.22215/timreview/1038

Westerlund, M., \& Leminen, S. 2011. Managing the Challenges of Becoming an Open Innovation Company: Experiences from Living Labs. Technology Innovation Management Review, 1(1): 19-25. http://doi.org/10.22215/timreview/489

Citation: Westerlund, M., Leminen, S., \& Rajahonka, M. 2018. A Topic Modelling Analysis of Living Labs Research. Technology Innovation Management Review, 8(7): 40-51. http://doi.org/10.22215/timreview/1170

Keywords: living lab, living laboratory, innovation, topic modeling, topic modelling, big data, text analytics, data mining, research trends 


\section{Q\&A \\ Paavo Ritala and Robin Gustafsson}

\section{Q. Innovation and Entrepreneurial Ecosystem Research: Where Are We Now and How Do We Move Forward?}

\begin{abstract}
A. attract significant attention from both scholars and practitioners. These concepts have gained prominence due to the exponential growth of data, information, and knowledge, related collaboration and coordination needs of diverse organizations and individuals, as well as the adoption of technologies that can facilitate the connectivity of multi-actor ecosystems. While the field has progressed considerably particularly in recent years, researchers are still discussing and debating the suitability of the proposed conceptual and empirical approaches. Therefore, it is useful to take a moment to reflect on the current progression and the future outlook of this fascinating field. Indeed, as "innovation ecosystems" and "entrepreneurial ecosystems" are increasingly studied across the management, marketing, and policy realms (Aarikka-Stenroos \& Ritala, 2017; Adner, 2007; Ansari et al., 2016; Autio et al., 2018; Clarysse et al., 2014; Dattée et al., 2018; Scaringella \& Radziwon, 2017; Spiegel, 2017; Tsujimoto et al., 2017), the research field is rather scattered and involves diverse views and approaches to the topic. To this end, we chaired a professional development workshop titled "Fostering Rigor in Innovation and Entrepreneurial Ecosystem Research: Concepts, Methods and Theory" at the 2017 Academy of Management Annual Conference. In addition to our own presentations, we also invited four prominent ecosystem scholars to present and discuss their views on the theme: Erkko Autio (Imperial College, UK), Satish Nambisan (Case Western Reserve University, USA), Mark Phillips (University of Cambridge, UK), and Mats Magnusson (KTH, Sweden). The aim of the workshop was to facilitate the following:
\end{abstract}

1. A shared interpretation of concepts and phenomena.

2. An appreciation and understanding of differences in research methods and approaches.

3. The advancement of a joint view and discussion by the research community on directions for the progress of innovation and entrepreneurial ecosystem research.
The workshop ended with an onsite, real-time survey that was conducted among all participants, including a moderated discussion around the survey results. In addition to the chairs and presenters, the workshop included around 60 junior and senior academics from around the world, of which 55 completed our onsite survey using their personal devices. The survey was conducted using the Kahoot platform (kahoot.com), and for each question, the participants had 45 seconds to vote among pre-set alternatives.

The survey focused on five multiple-choice questions:

1. How do you perceive the concept of "ecosystem"?

2. What is the biggest challenge in conducting ecosystem research?

3. What are the most promising theoretical foundations of ecosystems?

4. To empirically study an "ecosystem," you need to...

5. What should be done next in ecosystem research?

In the sections that follow, we report the distribution of the participants' responses to each of the five questions. In discussing these themes, we build on the insights of the presentations that took place in the workshop, as well as the overall discussion among the participants and the presenters. Finally, we end each section with our own conclusions regarding the state and promising directions for progress in the research field of innovation and entrepreneurial ecosystems.

\section{How do you perceive the concept of "ecosystem"?}

-A useful analogy or metaphor that describes novel phenomena: $62 \%$

- A promising new scholarly field of its own: $30 \%$

- A buzzword without much added value: $8 \%$ 


\section{Q\&A. Innovation and Entrepreneurial Ecosystem Research: Where Are We Now and How Do We Move Forward? Paavo Ritala and Robin Gustafsson}

The question of what "ecosystem" means is typically the first reaction that innovation and entrepreneurship researchers encounter when using the term for scholarly purposes. In this regard, an increasing number of studies discussing the applicability and boundary conditions of the ecosystem concept have been conducted (Oh et al., 2016; Ritala \& Almpanopoulou, 2017; Stam, 2015; Tsujimoto et al., 2017). However, the conceptualization of ecosystems in innovation and entrepreneurship research remains a debated issue. At the same time, the concept was valued by most of the workshop participants: a strong majority viewed it as a useful analogy or metaphor for novel phenomena. Both analogies and metaphors are important tools in theory building, with each playing a different role in the process (Ketokivi et al., 2017). The term "ecosystem" has certainly worked as both an inspiration (i.e., metaphor) to understand the networked nature of innovation and entrepreneurship, as well as an analogy to explain such phenomena by utilizing concepts from biological ecosystems. Nearly a third of participants viewed it as $a$ promising scholarly field of its own. This can perhaps be attributed to the increasing prominence of ecosystems in the management research lexicon. However, before becoming anything near to a "field", theoretical and methodological distinctiveness should be pursued, and currently, the literature is lacking such foundations (for new openings to this direction, see Adner, 2017 and Jacobides et al., 2018). Finally, some participants labelled ecosystem as a buzzword due to its traction among practitioners and academics, while overlapping with other concepts such as innovation systems (see Oh et al., 2016, for a related discussion).

Overall, an "ecosystem" was perceived as a useful concept, or even a scholarly field in its own right, within the areas of innovation and entrepreneurship. This finding certainly reflects the audience's involvement and interest in ecosystem research, some having already published on it, some doing research drawing on the concept, some evaluating whether to engage with the concept or not, and all having decided to attend a workshop on this topic. However, to unlock the concept's potential, ecosystem researchers need to address several challenges from conceptual, empirical, and theoretical standpoints. We discuss these in the remaining sections.

\section{What is the biggest challenge in conducting ecosystem research?}

- Conceptual ambiguity: 39\%
- Methodological challenges: $35 \%$

- Lack of a rigorous theoretical foundation: $24 \%$

- Difficulties in publishing: $2 \%$

Conceptual ambiguity is a major challenge for innovation and entrepreneurial ecosystems research, given its close resemblance to other network or system-level concepts such as interorganizational networks, clusters, geographical regions, systems, or platforms (see, e.g., Adner, 2017). This ambiguity crops up across the research field in heterogeneous formulations of the concept, and it is causing difficulties in establishing a coherent research program. This is experienced, for example, in review processes, where reviewers, editors, and authors commonly challenge the use of the concept and its applicability, as well as in doctoral courses, where discussions arise on the meaning and application of the ecosystem concept. Relatedly, methodological challenges arise: how do we study interconnected systems that include actors such as business organizations, universities, individuals, regulatory actors, competitors, and complementors? Such a systemlevel inquiry is very difficult to obtain using any established research methods due to the excessive amount of data gathering needed and the multiple influences all of these components have on one another, creating challenges for both qualitative and quantitative researchers alike. Also, reporting of system-level phenomena with an excessive amount of data can be a challenge given the current journal requirements for reporting format and page limits. Furthermore, an important challenge for the research community is to find solutions to the lack of rigour in the theoretical foundations. The ecosystem concept has been analogously derived from ecological studies (Moore, 1993). Given that the concept is contested even in its original domain (e.g., O’Neill, 2001), it becomes difficult to theorize based on a mere analogy. Perhaps, for this reason, many authors have used ecosystem metaphorically to describe the interconnected nature of innovation and entrepreneurship, while drawing from other theoretical foundations for explanations of the phenomena.

We argue that such a conceptual ambiguity is a root cause of other problems (methodological and theoretical) in ecosystems research. Given its multi-purpose heuristic use to study such subjects as Deutsche Telecom's "open innovation ecosystem" (Rohrbeck et al., 2009), the "Silicon Valley ecosystem" (Engel, 2015), and the "US Television ecosystem" (Ansari et al., 2016), we 


\section{Q\&A. Innovation and Entrepreneurial Ecosystem Research: Where Are We Now and How Do We Move Forward? Paavo Ritala and Robin Gustafsson}

can see that both boundaries, as well as levels of analysis of ecosystem phenomena, vary considerably. This is perhaps not a problem if the concept is scalable, but it shows that we need to better understand its fundamental features.

\section{What are the most promising theoretical foundations of ecosystems?}

- Systems theory, complex adaptive systems: $44 \%$

- Network theory, social networks: $32 \%$

- Institutional theory and institutional mechanisms: $16 \%$

- Something else/new: $8 \%$

As the concept ecosystem implies, the role of "system" is integral to understanding the phenomenon in focus. Almost half of the workshop participants found the most promising theoretical foundation to be grounded in systems theory or complex adaptive systems. The use of some system-level theoretical concepts such as emergence, interdependence, and dynamics is rather frequent in current scholarly work (see, e.g., Adner \& Kapoor, 2010; Ansari et al., 2016; Stam, 2015). However, a more overarching emphasis on system-level theoretical principles and concepts is much rarer (for exceptions and discussion, see, e.g., Peltoniemi, 2006; Ritala \& Almpanopoulou, 2017; Roundy et al., 2018; Scaringella \& Radziwon, 2017). Second, network theory and social networks were seen as another promising theoretical foundation. Indeed, much of the ecosystem literature draws from network literature, including ecosystem definitions involving the concept of "network" (Adner \& Kapoor, 2010), as well as utilizing social network analysis to examine innovation ecosystem structures (Clarysse et al., 2014; Still et al., 2014). A critical challenge for this approach is to distinguish ecosystem studies from network studies: if there is no difference, do we need a new concept? Finally, institutional theory and institutional mechanisms are seen as a possible theoretical foundation. Some authors have already picked up on this by suggesting that institutional theory concepts such as "organizational field" be infused into an ecosystem analysis (Claudel, 2018; Thomas \& Autio, 2014).

We see that there is certainly potential to examine ecosystems through multiple lenses. This is similar to innovation and entrepreneurial networks, which have been studied not just from a network-theoretical perspective, but also from institutional and contextual per- spectives (Autio et al., 2014), for instance. However, there is a risk in relabelling networks as ecosystems, just because the latter might resonate better with some of the ongoing discussions, thereby helping to argue for novelty via reconceptualization. To harness the distinctive nature of the analogy, we need to understand the ecological component when it comes to explaining interdependencies and coevolution, as well as the systems component when it comes to studying not only network linkages, but also other actors in the broader system (see also Ritala \& Almpanopoulou, 2017). Also, innovation and entrepreneurial ecosystems could be viewed as cultural or value systems (Fisher et al., 2017; Glynn \& Lounsbury, 2005). We believe that efforts to develop theory both from complex adaptive systems (e.g., Peltoniemi, 2006) and institutional theory (e.g., Vargo et al., 2015) show particular promise for creating bases for theorizing on innovation and entrepreneurial ecosystems. Finally, some studies have recently examined ecosystems through organizational lenses, viewing them as meta-organizations (e.g., Järvi et al., 2018). These and other types of theoretical approaches related to the organization of innovation and entrepreneurial ecosystems could be useful to understand the "microfoundations" of ecosystem governance.

\section{To empirically study an "ecosystem", you need to... \\ - Examine the ecosystem in its contextual and institutional environment: $64 \%$ \\ - Examine the complete set/all ecosystem actors: $19 \%$ \\ - Study a specified set of actors: $17 \%$}

The strong majority of the participants in the professional development workshop opted for examination of the ecosystem in its overall contextual and institutional environment. This is important given the regulative and normative relevance of context for any actor, organization, and collective (Suddaby et al., 2010; Zietsma et al., 2017). For instance, several scholars have suggested that any analysis of innovation and entrepreneurship in an ecosystem context should include the understanding of institutions and institutionalization (AarikkaStenroos \& Ritala, 2017; Autio et al., 2018; Vargo et al., 2015). Other, less popular options included the two alternative approaches to studying ecosystems: examination of the complete set of actors or studying a specified set of actors. Although the former is ideal for understanding the overall system and its interdependencies, researchers often tend to focus on a focal actor and its 


\section{Q\&A. Innovation and Entrepreneurial Ecosystem Research: Where Are We Now and How Do We Move Forward? Paavo Ritala and Robin Gustafsson}

ecosystem. This approach resembles the distinction between network studies of whole networks and egocentric networks (Provan et al., 2007).

We see substantial challenges in conducting rigorous empirical studies of innovation and entrepreneurial ecosystems, particularly in the understanding of contextual interactions taking place within them (Autio et al., 2014). Studies need to account for both the institutional complexities arising from contexts with multiple institutional logics (Greenwood et al., 2011) and the contested and fragmented nature of institutional environments (Pache \& Santos, 2010, 2013). Furthermore, as the number of actors, technologies, and institutions grows, the challenges of accessing such data become difficult. Advances in empirical approaches and research methodologies to account for the complex and fragmented nature of environments, as well as the multitude of interactions between actors, are needed to move the innovation and entrepreneurial ecosystem field forward.

\section{What should be done next in ecosystem research?}

- Move on and find empirical evidence: $38 \%$

- Integrate ecosystem research into existing streams: $32 \%$

- Keep clarifying the conceptual underpinnings: $17 \%$

- Create new, solid, and unique foundations: 13\%

Where should we go next? A majority of the workshop participants were inclined to suggest moving on and collecting empirical evidence. The ecosystem literature tends to revolve around conceptual papers and discussions, and it would be useful to start collecting empiric- al evidence that would utilize the perspective. Many authors have certainly done this, but the problem remains that an ecosystem is typically defined quite differently, leading to major differences in empirical research designs. The other suggestions include perhaps some remedies to this problem. First, a sufficiently popular option was to integrate ecosystem research into existing streams. This would help not only in empirical research design but also in grounding ecosystems in established research traditions and programs. Second, clarifying the conceptual underpinnings is still a valid future direction given the lack of consensus on what an ecosystem is and how it can be studied. Third, creating a new and unique foundation for ecosystem research is a lucrative option, already pursued by authors in strategy research (see, e.g., Adner, 2017). For innovation and entrepreneurial ecosystem scholars, the same challenge and opportunity remain in sight, with many scholars discussing the concept and its uniqueness in these fields (Autio \& Thomas, 2014; Stam, 2015; Tsujimoto et al., 2017).

\section{Conclusion}

Innovation and entrepreneurial ecosystems remain important topics in the ever-connecting and expanding digital economy. Given the practical relevance and rapidly increasing utilization of the ecosystem concept by managers, entrepreneurs, and policy actors, it is no surprise that researchers from different backgrounds and disciplines are flocking to these topics. Increasing diversity of conceptual and empirical applications creates both a challenge and opportunity for ecosystem scholars. Whether the analogy will be retained within the long-lasting scholarly lexicon remains to be seen and this will be strongly affected not only by the relevance of the ecosystem concept, but also the rigour that researchers are able to bring to its application. 


\section{Q\&A. Innovation and Entrepreneurial Ecosystem Research: Where Are We Now and How Do We Move Forward? Paavo Ritala and Robin Gustafsson}

\section{About the Authors}

Paavo Ritala, D.Sc. (Econ. \& Bus. Adm.) is a Professor of Strategy and Innovation at the School of Business and Management at Lappeenranta University of Technology (LUT), Finland. He is interested in questions and themes around organizing heterogeneous systems and networks, where different actors and institutions co-evolve, collaborate, and compete. In particular, his research has focused on the topics of value creation and appropriation, innovation, networks and ecosystems, coopetition, business models, and sustainable value creation. His research has been published in journals such as $R e$ search Policy, Journal of Product Innovation Management, Industrial and Corporate Change, and Technological Forecasting \& Social Change. He is also closely involved with business practice over these topics through company-funded research projects, executive and professional education programs, and in speaker and advisory roles. Prof. Ritala currently serves as an Associate Editor of $R \& D$ Management.

Robin Gustafsson is Department Vice-Head for Research and Associate Professor of Strategic Management at Department of Industrial Engineering and Management, Aalto University, Finland. His research focuses on strategy and organization in industry and market disruptions (especially technology-induced disruptions). His research and teaching are increasingly focused on how digital is disrupting existing industries and markets, successful digital platform strategies, new sources of competitive advantage arising from digitalization, open digital platforms, and multi-sided platforms, and corporate digital strategies. His research has been published in journals such as Academy of Management Journal, Research Policy, and Technological Forecasting \& Social Change.

\section{References}

Aarikka-Stenroos, L., \& Ritala, P. 2017. Network Management in the Era of Ecosystems: Systematic Review and Management Framework. Industrial Marketing Management, 67: 23-36. https://doi.org/10.1016/j.indmarman.2017.08.010

Adner, R. 2017. Ecosystem as Structure: An Actionable Construct for Strategy. Journal of Management, 43(1): 39-58. https://doi.org/10.1177/0149206316678451

Ansari, S. S., Garud, R., \& Kumaraswamy, A. 2016. The Disruptor's Dilemma: TiVo and the US Television Ecosystem. Strategic Management Journal, 37(9): 1829-1853.

https://doi.org/10.1002/smj.2442

Autio, E., Kenney, M., Mustar, P., Siegel, D., \& Wright, M. 2014. Entrepreneurial Innovation: The Importance of Context. Research Policy, 43(7): 1097-1108. https://doi.org/10.1016/j.respol.2014.01.015

Autio, E., \& Thomas, L. D. W. 2014. Innovation Ecosystems: Implications for Innovation Management? In M. Dodgson, D. M. Gann, \& N. Phillips (Eds.), The Oxford Handbook of Innovation Management: 204-288. Oxford: Oxford University Press. http://doi.org/10.1093/oxfordhb/9780199694945.013.012

Autio, E., Nambisan, S., Thomas, L. D., \& Wright, M. 2018. Digital Affordances, Spatial Affordances, and the Genesis of Entrepreneurial Ecosystems. Strategic Entrepreneurship Journal, 12(1): 72-95. https://doi.org/10.1002/sej.1266

Clarysse, B., Wright, M., Bruneel, J., \& Mahajan, A. 2014. Creating Value in Ecosystems: Crossing the Chasm between Knowledge and Business Ecosystems. Research Policy, 43(7): 1164-1176. https://doi.org/10.1016/j.respol.2014.04.014

Claudel, M. 2018. From Organizations to Organizational Fields: The Evolution of Civic Innovation Ecosystems. Technology Innovation Management Review, 8(6): 34-47. http://doi.org/10.22215/timreview/1163

Dattée, B., Alexy, O., \& Autio, E. 2018. Maneuvering in Poor Visibility: How Firms Play the Ecosystem Game when Uncertainty Is High. Academy of Management Journal, 61(2): 466-498. https://doi.org/10.5465/amj.2015.0869

Engel, J. S. 2015. Global Clusters of Innovation: Lessons from Silicon Valley. California Management Review, 57(2): 36-65. https://doi.org/10.1525/cmr.2015.57.2.36

Fisher, G., Kuratko, D. F., Bloodgood, J. M., \& Hornsby, J. S. 2017. Legitimate to Whom? The Challenge of Audience Diversity and New Venture Legitimacy. Journal of Business Venturing, 32(1): 52-71.

https://doi.org/10.1016/j.jbusvent.2016.10.005

Glynn, M. A. \& Lounsbury, M. (2005). From the Critics' Corner: Logic Blending, Discursive Change and Authenticity in a Cultural Production System. Journal of Management Studies, 42(5): 1031-1055.

https://doi.org/10.1111/j.1467-6486.2005.00531.x

Greenwood, R., Raynard, M., Kodeih, F., Micelotta, E. R., \& Lounsbury, M. (2011). Institutional Complexity and Organizational Responses. Academy of Management Annals, 5(1): 317-371. https://doi.org/10.5465/19416520.2011.590299 


\section{Q\&A. Innovation and Entrepreneurial Ecosystem Research: Where Are We Now and How Do We Move Forward? Paavo Ritala and Robin Gustafsson}

Jacobides, M. G., Cennamo, C., \& Gawer, A. 2018. Towards a Theory of Ecosystems. Strategic Management Journal. https://doi.org/10.1002/smj.2904

Järvi, K., Almpanopoulou, A., \& Ritala, P. 2018. Organization of Knowledge Ecosystems: Prefigurative and Partial forms. Research Policy, 47(8): 1523-1537. https://doi.org/10.1016/j.respol.2018.05.007

Ketokivi, M., Mantere, S., \& Cornelissen, J. 2017. Reasoning by Analogy and the Progress of Theory. Academy of Management Review, 42(4): 637-658. https://doi.org/10.5465/amr.2015.0322

Moore, J. F. 1993. Predators and Prey: A New Ecology of Competition. Harvard Business Review, 71(3): 75-83.

Oh, D. S., Phillips, F., Park, S., \& Lee, E. 2016. Innovation Ecosystems: A Critical Examination. Technovation, 54: 1-6. https://doi.org/10.1016/j.technovation.2016.02.004

Pache, A. C., \& Santos, F. 2010. When Worlds Collide: The Internal Dynamics of Organizational Responses to Conflicting Institutional Demands. Academy of Management Review, 35(3): 455-476. https://www.jstor.org/stable/25682424

Pache, A. C., \& Santos, F. 2013. Inside the Hybrid Organization: Selective Coupling as a Response to Competing Institutional Logics. Academy of Management Journal, 56(4): 972-1001. https://doi.org/10.5465/amj.2011.0405

Peltoniemi, M. 2006. Preliminary Theoretical Framework for the Study of Business Ecosystems. Emergence: Complexity and Organization, 8(1): 10-19.

Provan, K. G., Fish, A., \& Sydow, J. 2007. Interorganizational Networks at the Network Level: A Review of the Empirical Literature on Whole Networks. Journal of Management, 33(3): 479-516. https://doi.org/10.1177/0149206307302554

Ritala, P., \& Almpanopoulou, A. 2017. In Defense of 'Eco' in Innovation Ecosystem. Technovation, 60-61: 39-42. http://doi.org/10.1016/j.technovation.2017.01.004

Rohrbeck, R., Hölzle, K., \& Gemünden, H. G. 2009. Opening Up for Competitive Advantage - How Deutsche Telekom Creates an Open Innovation Ecosystem. R\&D Management, 39(4): 420-430. https://doi.org/10.1111/j.1467-9310.2009.00568.x

Roundy, P. T., Bradshaw, M., \& Brockman, B. K. 2018. The Emergence of Entrepreneurial Ecosystems: A Complex Adaptive Systems Approach. Journal of Business Research, 86: 1-10. https://doi.org/10.1016/j.jbusres.2018.01.032

Scaringella, L., \& Radziwon, A. 2017. Innovation, Entrepreneurial, Knowledge, and Business Ecosystems: Old Wine in New Bottles? Technological Forecasting and Social Change. https://doi.org/10.1016/j.techfore.2017.09.023
Spigel, B. 2017. The Relational Organization of Entrepreneurial Ecosystems. Entrepreneurship Theory and Practice, 41(1): 49-72. https://doi.org/10.1111/etap.12167

Stam, E. 2015. Entrepreneurial Ecosystems and Regional Policy: A Sympathetic Critique. European Planning Studies, 23(9): 1759-1769. https://doi.org/10.1080/09654313.2015.1061484

Still, K., Huhtamäki, J., Russell, M. G., \& Rubens, N. 2014. Insights for Orchestrating Innovation Ecosystems: The Case of EIT ICT Labs and Data-Driven Network Visualisations. International Journal of Technology Management, 66(2-3): 243-265. https://doi.org/10.1504/IJTM.2014.064606

Suddaby, R., Elsbach, K. D., Greenwood, R., Meyer, J. W., \& Zilber, T. B. 2010. Organizations and Their Institutional Environments Bringing Meaning, Values, and Culture Back In: Introduction to the Special Research Forum. Academy of Management Journal, 53(6): 1234-1240.

https://doi.org/10.5465/amj.2010.57317486

Thomas, L. D. W, \& Autio, E. 2014. The Fifth Facet: The Ecosystem as an Organizational Field. Academy of Management Proceedings, 2014(1): 10306.

http://doi.org/10.5465/AMBPP.2014.10306abstract

Tsujimoto, M., Kajikawa, Y., Tomita, J., \& Matsumoto, Y. 2017. A Review of the Ecosystem Concept-Towards Coherent Ecosystem Design. Technological Forecasting and Social Change. http://doi.org/10.1016/j.techfore.2017.06.032

Vargo, S. L., Wieland, H., \& Akaka, M. A. 2015. Innovation through Institutionalization: A Service Ecosystems Perspective. Industrial Marketing Management, 44: 63-72.

https://doi.org/10.1016/j.indmarman.2014.10.008

Zietsma, C., Groenewegen, P., Logue, D. M., \& Hinings, C. R. (Bob). 2017. Field or Fields? Building the Scaffolding for Cumulation of Research on Institutional Fields. Academy of Management Annals, 11(1): 391-450. https://doi.org/10.5465/annals.2014.0052

Citation: Ritala, P., \& Gustafsson, R. 2018. Q\&A. Innovation and Entrepreneurial Ecosystem Research: (cc) BY Where Are We Now and How Do We Move Forward? Technology Innovation Management Review, 8(7): 52-57. http://doi.org/10.22215/timreview/1171

Keywords: innovation ecosystem, entrepreneurial ecosystem, business ecosystem, research, methods, approaches, theoretical foundations 


\section{Author Guidelines}

These guidelines should assist in the process of translating your expertise into a focused article that adds to the knowledge resources available through the Technology Innovation Management Review. Prior to writing an article, we recommend that you contact the Editor to discuss your article topic, the author guidelines, upcoming editorial themes, and the submission process: timreview.ca/contact

\section{Topic}

Start by asking yourself:

- Does my research or experience provide any new insights or perspectives?

- Do I often find myself having to explain this topic when I meet people as they are unaware of its relevance?

- Do I believe that I could have saved myself time, money, and frustration if someone had explained to me the issues surrounding this topic?

- Am I constantly correcting misconceptions regarding this topic?

- Am I considered to be an expert in this field? For example, do I present my research or experience at conferences?

If your answer is "yes" to any of these questions, your topic is likely of interest to readers of the TIM Review.

When writing your article, keep the following points in mind:

- Emphasize the practical application of your insights or research.

- Thoroughly examine the topic; don't leave the reader wishing for more.

- Know your central theme and stick to it.

- Demonstrate your depth of understanding for the topic, and that you have considered its benefits, possible outcomes, and applicability.

- Write in a formal, analytical style. Third-person voice is recommended; first-person voice may also be acceptable depending on the perspective of your article.

\section{Format}

1. Use an article template: .doc .odt

2. Indicate if your submission has been previously published elsewhere. This is to ensure that we don't infringe upon another publisher's copyright policy.

3. Do not send articles shorter than 2000 words or longer than 5000 words.

4. Begin with a thought-provoking quotation that matches the spirit of the article. Research the source of your quotation in order to provide proper attribution.

5. Include a 2-3 paragraph abstract that provides the key messages you will be presenting in the article.

6. Provide a 2-3 paragraph conclusion that summarizes the article's main points and leaves the reader with the most important messages.

7. Include a 75-150 word biography.

8. List the references at the end of the article.

9. If there are any texts that would be of particular interest to readers, include their full title and URL in a "Recommended Reading" section.

10. Include 5 keywords for the article's metadata to assist search engines in finding your article.

11. Include any figures at the appropriate locations in the article, but also send separate graphic files at maximum resolution available for each figure. 


\section{Issue Sponsor}

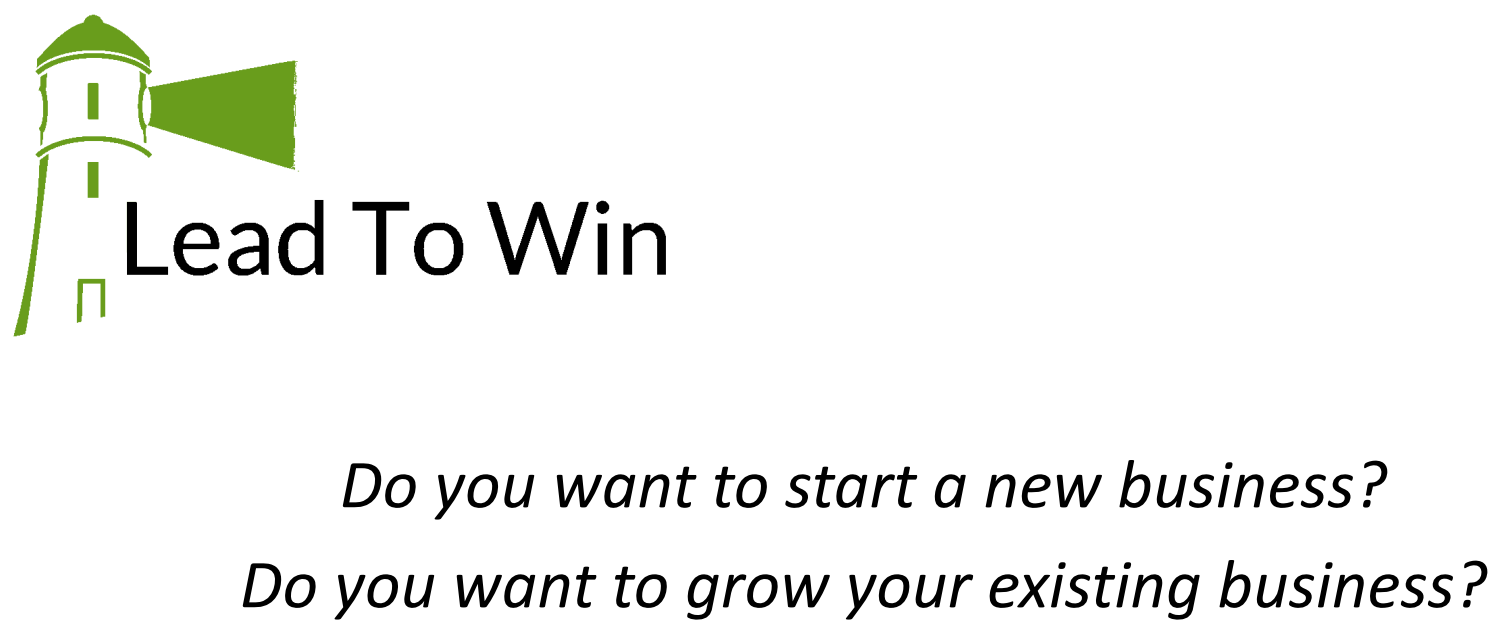

Lead To Win is a free business-development program to help establish and grow businesses in Canada's Capital Region.

Benefits to company founders:

- Knowledge to establish and grow a successful businesses

- Confidence, encouragement, and motivation to succeed

- Stronger business opportunity quickly

- Foundation to sell to first customers, raise funds, and attract talent

- Access to large and diverse business network

\section{Apply Now}

* Twitter

f Facebook

in Linkedin

E Eventbrite

9 Slideshare

- YouTube

- Flickr 


\section{Academic Affiliations and Funding Acknowledgements}

Canadà
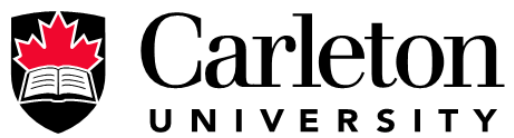

U N I V E R S I T Y

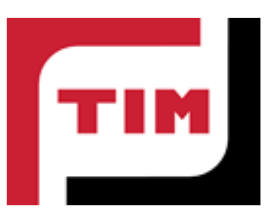

The Federal Economic Development Agency for Southern Ontario (FedDev Ontario; feddevontario.gc.ca) is part of the Innovation, Science and Economic Development portfolio and one of six regional development agencies, each of which helps to address key economic challenges by providing regionallytailored programs, services, knowledge and expertise.

- The TIM Review receives partial funding from FedDev Ontario's Investing in Regional Diversification initiative.

Technology Innovation Management (TIM; timprogram.ca) is an international master's level program at Carleton University in Ottawa, Canada. It leads to a Master of Applied Science (M.A.Sc.) degree, a Master of Engineering (M.Eng.) degree, or a Master of Entrepreneurship (M.Ent.) degree. The objective of this program is to train aspiring entrepreneurs on creating wealth at the early stages of company or opportunity lifecycles.

- The TIM Review is published in association with and receives partial funding from the TIM program. 